Aus der Abteilung Nephrologie und Rheumatologie

(Prof. Dr. med. G. A. Müller)

im Zentrum Innere Medizin

der Medizinischen Fakultät der Universität Göttingen

\title{
Erkennung diagnostischer Frühmarker der \\ Nierenfibrose beim Tiermodell des Alport-Syndroms mittels proteomischer Methoden
}

\author{
INAUGURAL-DISSERTATION \\ zur Erlangung des Doktorgrades \\ der Medizinschen Fakultät \\ der Georg-August-Universität zu Göttingen
}

vorgelegt von

Imke Schmidt-Eylers

aus Bremerhaven

Göttingen 2012 
Dekan: Prof. Dr. med. M. P. Schön

Berichterstatter: Prof. Dr. med. O. Gross

Berichterstatter/in: i.V. Prof. Dr. phil. nat. Burckhardt

Berichterstatter/in: Prof. Dr. rer. nat. Virsik-Köpp

Tag der mündlichen Prüfung: 22. April 2013 


\section{Inhaltsverzeichnis}

\begin{tabular}{ll}
\hline Abbildungsverzeichnis & 1
\end{tabular}

\begin{tabular}{ll}
\hline Tabellenverzeichnis & 4
\end{tabular}

\begin{tabular}{|ll}
\hline Abkürzungsverzeichnis & 5
\end{tabular}

\begin{tabular}{lll}
\hline $\mathbf{1}$ & Einleitung & $\mathbf{7}$
\end{tabular}

1.1 Funktion und Aufbau der Nieren . . . . . . . . . . . . . . . . . . . . . . . 7

1.2 Molekulare Perspektive ． . . . . . . . . . . . . . . . . . . . . . . . . 10

1.2 .1 Mutation im Typ-IV-Kollagen . . . . . . . . . . . . . . . . . . 10

1.2 .2 Detektion des Typ-IV-Kollagen-Defektes über Rezeptoren . . . . . . . . 13

1.2 .3 Glomerulosklerose und tubulointerstitielle Fibrose . . . . . . . . . . . . . 16

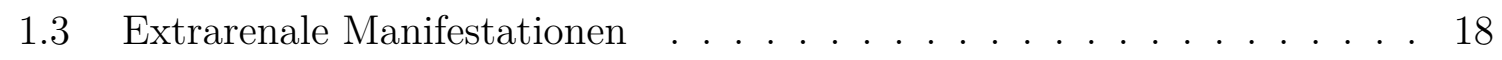

1.4 Vererbung und Häufigkeit . . . . . . . . . . . . . . . . . . . . . . . . . . . . . . . . . . . . .

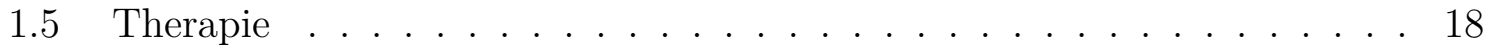

1.6 Biomarker . . . . . . . . . . . . . . . . . . . . . . . . . 20

1.6 .1 Biomarkerdefinition . . . . . . . . . . . . . . . . . . . . . . 20

1.6 .2 Biomarkerdetektion mithilfe von Proteomics . . . . . . . . . . . . . . . . 21

1.7 Zielsetzung . . . . . . . . . . . . . . . . . . . . . . . . . . . . . . . 22

2 Material und Methoden 23

2.1 Materialien . . . . . . . . . . . . . . . . . . . . . . . . 23

2.1 .1 Urin $\ldots \ldots \ldots \ldots \ldots \ldots$

2.1 .2 Chemikalien . . . . . . . . . . . . . . . . . . . . . . . . 24

2.1 .3 Verbrauchsmaterialien . . . . . . . . . . . . . . . . . 26

2.1 .4 Geräte . . . . . . . . . . . . . . . . . . . . 26

2.1 .5 Software . . . . . . . . . . . . . . . . . . . . . . 27

$2.2 \quad$ Proteinbiochemische Methoden zur Vorbereitung der Gelelektrophorese . 28

2.2 .1 Proteinfällung $\ldots \ldots \ldots \ldots$

2.2 .2 Proteinbestimmung nach Bradford . . . . . . . . . . . . . . . . . 29

$2.3 \quad$ Zweidimensionale Elektrophorese in der Proteomforschung . . . . . . . . 30

2.3 .1 Allgemeine Grundlagen der zweidimensionalen Elektrophorese . . . . . . 30

2.3 .2 Die erste Dimension: Isoelektrische Fokussierung (IEF) . . . . . . . . . . 31 
2.3 .3 Equilibrierung $\ldots \ldots \ldots \ldots \ldots$

2.3.4 Die zweite Dimension: SDS-Polyacrylamid-Gelelektrophorese (SDS-PAGE) 32

2.4 Färbungsmethoden für 2D-Gele $\ldots \ldots \ldots \ldots \ldots \ldots \ldots$

2.4 .1 Flamingofärbung $\ldots \ldots \ldots \ldots \ldots \ldots$

2.4 .2 Coomassiefärbung . . . . . . . . . . . . . . . . . . . 33

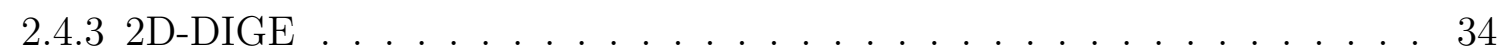

2.5 Trypsin-Verdau von Proteinen $\ldots \ldots \ldots \ldots \ldots$

2.6 Massenspektrometrische Methoden . . . . . . . . . . . . . . 36

2.6 .1 MALDI-TOF-MS $\ldots \ldots \ldots \ldots \ldots \ldots$

2.6 .2 Targetvorbereitung . . . . . . . . . . . . . . . . . . . . . . . . 38

2.6 .3 Spektrenerfassung und Proteinidentifikation . . . . . . . . . . 38

$2.7 \quad$ Western Blot $\ldots \ldots \ldots \ldots \ldots \ldots$

$\begin{array}{lll}3 & \text { Ergebnis } & 41\end{array}$

$3.1 \quad$ Darstellung der histologischen und elektronenmikroskopischen Präparate 41

3.2 Darstellung der 2D-Gele . . . . . . . . . . . . . . . . . . . . . 45

3.2 .1 Identifizierung der Urinproteine mit MALDI-TOF-MS $\ldots \ldots \ldots . .48$

3.2 .2 Quantitative Auswertung der 2D-DIGE-Gele mit Delta 2D . . . . . . . 55

$3.3 \quad$ Ergebnisdarstellung der 1D-Western Blots . . . . . . . . . . . . . . 59

3.3.1 Auswertung der Bandenintensitäten zum Zeitpunkt von 4,5 Wochen . . 59

3.3.2 Auswertung der Bandenintensitäten zum Zeitpunkt von 6 Wochen . . . 63

3.3 .3 Zusammenfassung der Ergebnisse im 1D-Western Blot . . . . . . . . . 67

\begin{tabular}{lll}
\hline & Diskussion & 69
\end{tabular}

$4.1 \quad$ Biomarkersuche bei der diabetischen Nephropathie . . . . . . . . . . . 69

4.2 Der Podozyt im Fokus der Erkrankung. . . . . . . . . . . . . . . . . . 69

4.3 Die potentiellen Biomarker $\ldots \ldots \ldots \ldots \ldots$

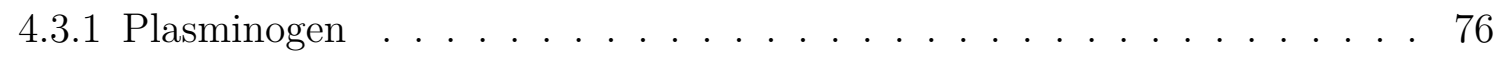

4.3 .2 Antithrombin III $\ldots \ldots \ldots \ldots \ldots . \ldots \ldots$

4.3 .3 Serine protease inhibitor $\mathrm{A} 3 \mathrm{~K} . \ldots \ldots \ldots \ldots \ldots \ldots$

4.3 .4 Serum amyloid P-component . . . . . . . . . . . . . . . . . . 82

$4.4 \quad$ Frühzeitige Biomarker im Urin $\ldots \ldots \ldots \ldots$

\begin{tabular}{lll}
\hline 5 & Zusammenfassung & 86
\end{tabular}

$\begin{array}{lll}6 & \text { Anhang: Messwerttabellen 6.1-6.3 } & 88\end{array}$

\begin{tabular}{lll}
\hline 7 & Literaturverzeichnis & 90
\end{tabular} 


\section{Abbildungsverzeichnis}

1.1 Architektur der Nieren . . . . . . . . . . . . . . . . . . . . . 8

1.2 Schematische Darstellung eines Glomerulums . . . . . . . . . . . . 9

1.3 Blut-Harn-Schranke . . . . . . . . . . . . . . . . . 10

1.4 Struktur des Typ-IV-Kollagens . . . . . . . . . . . . . . . . 11

1.5 Der Entstehungsmechanismus der Nierenfibrose beim Alport-Syndrom im Überblick . . . . . . . . . . . . . . . . . . . . . . . . 13

1.6 Verlust des Podozyten-Schlitzdiaphragmas . . . . . . . . . . . 15

1.7 Der Weg vom Genom zum Proteom - oder: Von der Raupe zum Falter 21

2.1 Schematische Darstellung der 2D-Gelelektrophorese . . . . . . . . . 33

2.2 Trypsin-Verdau von Proteinen als erster Schritt zur Proteinidentifikation mit dem Massenspektrometer . . . . . . . . . . . . . . 36

2.3 Funktionselemente eines Massenspektrometers . . . . . . . . . . 36

2.4 Die MALDI-Ionisierungsmethode . . . . . . . . . . . . . . . . . 37

2.5 Schematische Darstellung der Immundetektion . . . . . . . . . . 40

$3.1 \quad$ Histologische Nierenschnitte von Wildtyp- und COL4A3-KnockoutMäusen zum Zeitpunkt von 4,5 Wochen . . . . . . . . . . . . 42

3.2 Histologische Nierenschnitte von Wildtyp- und COL4A3-KnockoutMäusen zum Zeitpunkt von 6 Wochen. . . . . . . . . . . . . . . . . 43

3.3 Histologische Nierenschnitte von Wildtyp- und COL4A3-KnockoutMäusen zum Zeitpunkt von 4,5 und 6 Wochen . . . . . . . . . . . . 44

$3.4 \quad$ Elektronenmikroskopische Nierenschnitte von Wildtyp- und COL4A3Knockout-Mäusen zum Zeitpunkt von 4,5 Wochen . . . . . . . . . . 45

$3.5 \quad$ Urinproteomprofil der Wildtyp- und COL4A3-Knockout-Mäuse im Stadium von 4,5 Wochen . . . . . . . . . . . . . . . . . . . 46

3.6 Urinproteomprofil der Wildtyp- und COL4A3-Knockout-Mäuse im Stadium von 6 Wochen im Vergleich $\ldots \ldots \ldots$. . . . . . 47

3.7 Vergleichende Darstellung der Urinproteomprofile von COL4A3-KnockoutMäusen in den Stadien 4,5 und 6 Wochen. . . . . . . . . . . . . . 48

3.8 Proteinidentifikation des Wildtyp-Urinproteoms zum Zeitpunkt von 4,5 Wochen $\ldots \ldots \ldots \ldots \ldots \ldots$. . . . . . . . 49 
3.9 Proteinidentifikation des COL4A3-Knockout-Urinproteoms im Stadium von 4,5 Wochen . . . . . . . . . . . . . . . . . . . 50 50

3.10 Proteinidentifikation des COL4A3-Knockout-Urinproteoms im Stadi-

un von 6 Wochen . . . . . . . . . . . . . . . . . . . . . 51

3.11 Proteinidentifikation des Wildtyp-Urinproteoms zum Zeitpunkt von 6 Wochen . . . . . . . . . . . . . . . . . . . 52

3.12 Analyse des Urin-Proteoms von COL4A3-Knockout-Mäusen zum Zeitpunkt von 4,5 Wochen . . . . . . . . . . . . . . . . . . . 55

3.13 Analyse des Urinproteoms von COL4A3-Knockout-Mäusen zum Zeitpunkt von 6 Wochen . . . . . . . . . . . . . . . 56

3.14 Quantitative Auswertung der normierten Spotvolumen . . . . . . . . 57

3.15 Statistische Auswertung der Bandenintensitäten von Plasminogen zum

Zeitpunkt von 4,5 Wochen . . . . . . . . . . . . . . . 60

3.16 Statistische Auswertung der Bandenintensitäten von Serum amyloid

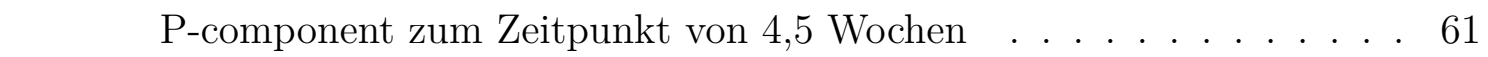

3.17 Statistische Auswertung der Bandenintensitäten von Antithrombin

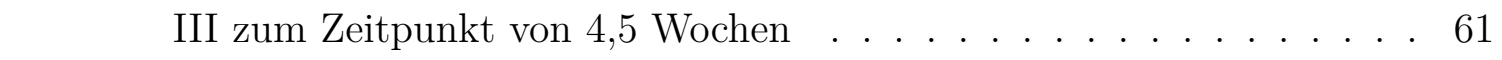

3.18 Statistische Auswertung der Bandenintensitäten von Serine protease

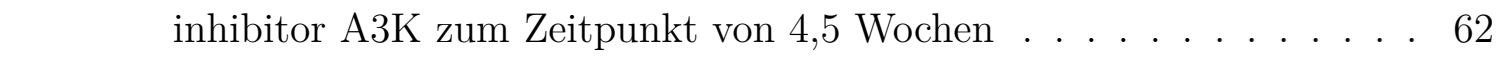

3.19 Statistische Auswertung der Bandenintensitäten von Haptoglobin zum

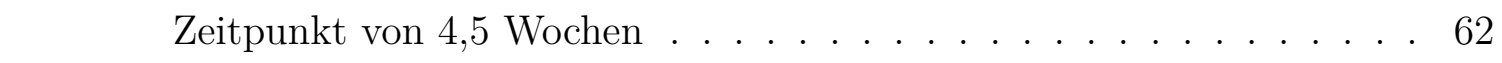

3.20 Statistische Auswertung der Bandenintensitäten von Parvalbumin zum

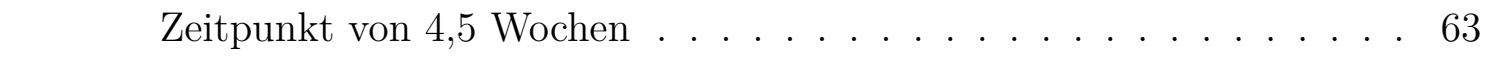

3.21 Statistische Auswertung der Bandenintensitäten von Plasminogen zum

Zeitpunkt von 6 Wochen . . . . . . . . . . . . . . . 64

3.22 Statistische Auswertung der Bandenintensitäten von Serum amyloid

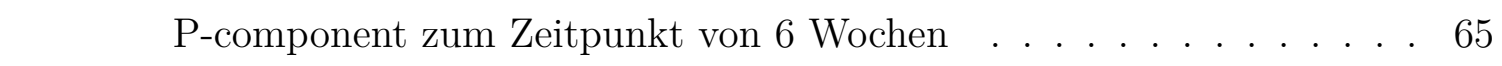

3.23 Statistische Auswertung der Bandenintensitäten von Antithrombin

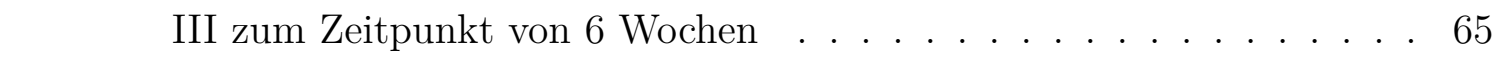

3.24 Statistische Auswertung der Bandenintensitäten von Serine protease inhibitor A3K zum Zeitpunkt von 6 Wochen . . . . . . . . . . . . . . 66

3.25 Statistische Auswertung der Bandenintensitäten von Haptoglobin zum

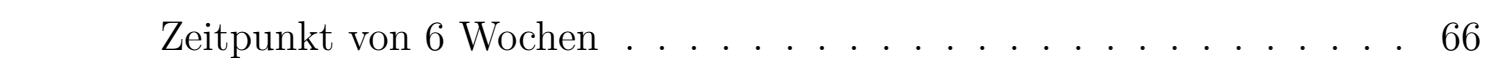

3.26 Statistische Auswertung der Bandenintensitäten von Parvalbumin zum Zeitpunkt von 6 Wochen . . . . . . . . . . . . . . . 67

4.1 Schematische Darstellung der Pathogenese beim Alport-Syndrom . . 75

4.2 Schematische Darstellung der Plasminogen-Struktur . . . . . . . . . . 76

4.3 Modulierung der Serpin-Konformation . . . . . . . . . . . . . . . 79

4.4 Schematische Darstellung der Antithrombin-III-Struktur . . . . . . . 79 
4.5 Schematische Darstellung der Struktur von Serine protease inhibitor

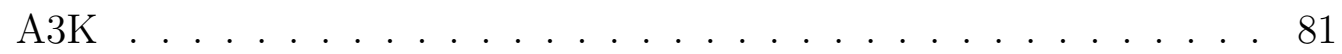

4.6 Schematische Darstellung einer Untereinheit von Serum amyloid Pcomponent . . . . . . . . . . . . . . . . . . . . . . . . . 83

4.7 Histologische Nierenschnitte von Wildtyp- und COL4A3-KnockoutMäusen zum Zeitpunkt von 4,5 Wochen . . . . . . . . . . . . . . . . . 85 


\section{Tabellenverzeichnis}

2.1 Chemikalien . . . . . . . . . . . . . . . . . . . . 24

2.2 Primär- und Sekundärantikörper. . . . . . . . . . . . . . . . . 25

2.3 Verbrauchsmaterialien . . . . . . . . . . . . . . . . . 26

2.4 Geräte . . . . . . . . . . . . . . . . . . . . . . . . 26

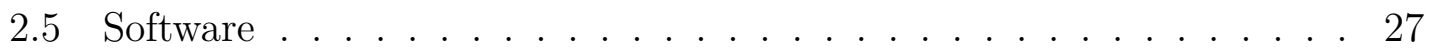

2.6 Bradford-Pipettierschema $\ldots \ldots \ldots \ldots$

$2.7 \quad$ Fokussierprogramm für die erste Dimension $\ldots \ldots \ldots \ldots$

3.1 Identifizierung der Proteinspots $\ldots \ldots \ldots \ldots \ldots \ldots$

6.1 Messwerte der 2D-DIGE-Auswertung . . . . . . . . . . . . . 88

$6.2 \quad$ Ergebnisse des unverbundenen t-Tests bei WT- und COL4A3-KnockoutMäusen zum Zeitpunkt von 4,5 Wochen. . . . . . . . . . . . . . . . 89

$6.3 \quad$ Ergebnisse des unverbundenen t-Tests bei WT- und COL4A3-KnockoutMäusen zum Zeitpunkt von 6 Wochen. . . . . . . . . . . . . . . . . 89 


\section{Abkürzungsverzeichnis}

\begin{tabular}{|c|c|c|c|}
\hline $\mathrm{ACE}$ & $\begin{array}{l}\text { Angiotensin- } \\
\text { Converting-Enzym }\end{array}$ & $\mathrm{HE}$ & Hämatoxylin-Eosin \\
\hline $\mathrm{ACN}$ & Acetonitril & IAA & Iodacetamid \\
\hline Ambic & Ammoniumbikarbonat & IEF & $\begin{array}{l}\text { Isoelektrische } \\
\text { Fokussierung }\end{array}$ \\
\hline APS & Ammoniumpersulfat & IPG & $\begin{array}{l}\text { Immobilisierter pH- } \\
\text { Gradient }\end{array}$ \\
\hline $\mathrm{AT}$ & Angiotensin & $\mathrm{KBP}$ & $\begin{array}{l}\text { Kallikrein-bindendes } \\
\text { Protein }\end{array}$ \\
\hline BSA & Bovines Serum-Albumin & $\mathrm{kDa}$ & Kilodalton \\
\hline Chaps & $\begin{array}{l}\text { 3-[(3-Cholamidopropyl })- \\
\text { dimethylammonio]- } \\
\text { propan-sulfonat }\end{array}$ & $\begin{array}{l}\text { MALDI- } \\
\text { TOF-MS }\end{array}$ & $\begin{array}{l}\text { Matrix assisted laser } \\
\text { desorption ionization } \\
\text { time-of-flight mass } \\
\text { spectrometry }\end{array}$ \\
\hline CR1 & Komplement-Rezeptor 1 & MCP & $\begin{array}{l}\text { Membran-Kofaktor- } \\
\text { Protein }\end{array}$ \\
\hline CTGF & $\begin{array}{l}\text { Connective tissue } \\
\text { growth factor }\end{array}$ & MMP & Matrixmetalloproteinase \\
\hline DDR & $\begin{array}{l}\text { Discoidin-Domain- } \\
\text { Rezeptor }\end{array}$ & MOPS & $\begin{array}{l}\text { 3-Morpholinopropan-1- } \\
\text { sulfonsäure }\end{array}$ \\
\hline DHB & $\begin{array}{l}\text { 2,5-Dihydroxy- } \\
\text { benzoesäure }\end{array}$ & PA & Plasminogen-Aktivator \\
\hline DIGE & $\begin{array}{l}\text { Differentielle In-Gel- } \\
\text { Elektrophorese }\end{array}$ & PAGE & Polyacrylamidgelelektrophorese \\
\hline $\mathrm{DMF}$ & N,N-Dimethylformamid & PAI-1 & $\begin{array}{l}\text { Plasminogen-Aktivator- } \\
\text { Inhibitor-1 }\end{array}$ \\
\hline DTT & 1,4-Dithiothreitol & PAS & $\begin{array}{l}\text { Perjodsäure-Schiffsches- } \\
\text { Reagenz }\end{array}$ \\
\hline EZM & Extrazelluläre Matrix & RAAS & $\begin{array}{l}\text { Renin-Angiotensin- } \\
\text { Aldosteron-System }\end{array}$ \\
\hline GBM & $\begin{array}{l}\text { Glomeruläre Basal- } \\
\text { membran }\end{array}$ & RCL & Reactive center loop \\
\hline
\end{tabular}




\begin{tabular}{ll|ll} 
SDS & Sodiumdodecylsulfat & T-PA & $\begin{array}{l}\text { Gewebe-Plasminogen- } \\
\text { Aktivator }\end{array}$ \\
TEMED & N,N,N',N'- & U-PA & $\begin{array}{l}\text { Urokinase-Plasminogen- } \\
\text { Aktivator }\end{array}$ \\
& $\begin{array}{l}\text { Tetramethylethylen- } \\
\text { diamin }\end{array}$ & & \\
TFA & Trifluoressigsäure & Vh & Voltstunde \\
TGF- $\beta$ & Transforming growth & $\mathrm{w} / \mathrm{v}$ & Gewicht pro Volumen \\
& factor- $\beta$ & & \\
TIMP & Tissue inhibitor of ma- & $\mathrm{z}$ & Ladung \\
& trixmetalloproteinases & & \\
TNF- $\alpha$ & Tumornekrosefaktor- $\alpha$ & & Es wurden die gebräuch- \\
& & & lichen SI-Einheiten ver- \\
& & & wendet
\end{tabular}




\section{Einleitung}

Das Alport-Syndrom ist eine hereditäre, progredient verlaufende Nierenerkrankung, die durch Mutation der $\alpha 3$-/ $\alpha 4$ - oder $\alpha 5$-Ketten des Typ-IV-Kollagens hervorgerufen wird. Infolge von charakteristischen Veränderungen der glomerulären Basalmembran manifestiert sich eine Proteinurie und Hämaturie. Die Erkrankung kann außerdem mit Innenohrschwerhörigkeit und typischen Augenveränderungen einhergehen, da auch hier die $\alpha 3-/ \alpha 4$ - und $\alpha 5(\mathrm{IV})$-Ketten lokalisiert sind. Im Verlauf der Erkrankung kommt es sowohl zur Glomerulosklerose als auch tubulointerstitiellen Fibrose, was schließlich zum terminalen Nierenversagen und zu einer eingeschränkten Lebenserwartung des Patienten führt (Alport 1927; Gross und Weber 2005).

Die Therapie der ersten Wahl stellt derzeit der Angiotensin-Converting-EnzymeHemmer (ACE-Hemmer) Ramipril dar. Zwar kann Ramipril den strukturellen Schaden der glomerulären Basalmembran nicht beheben, dafür aber den Krankheitsprogress verlangsamen und die Dialyse-Pflichtigkeit hinauszögern. Insbesondere bei frühzeitigem Therapieeinsatz mindert Ramipril die Proteinurie und wirkt nephroprotektiv und antifibrotisch (Gross et al. 2003).

Es ist daher wichtig, das Alport-Syndrom so früh wie möglich zu diagnostizieren. Bislang sind bis auf das Verfahren der Nierenbiopsie und direkter Sequenzierung keine Marker für das Alport-Syndrom bekannt. Unter Verwendung der COL4A3Knockout-Maus als Tiermodell des Alport-Syndroms soll in dieser Arbeit nach Biomarkern gesucht werden, die für ein frühes Stadium des Alport-Syndroms charakteristisch sind. Diese bei den COL4A3-Knockout-Mäusen im Vergleich zu WildtypMäusen hochregulierten Proteine könnten in der Pathogenese des Alport-Syndroms eine wichtige Rolle spielen.

\subsection{Funktion und Aufbau der Nieren}

$\mathrm{Zu}$ Beginn wird die Funktion der Nieren und ihr mikroskopischer und makroskopischer Aufbau erläutert, bevor näher auf die Veränderungen der glomerulären Basalmembran (GBM) eingegangen wird.

Die Nieren sind paarig im Retroperitonealraum angelegte Organe, welche für die Regulation des Wasser-, Säure-Basen- und Salzhaushalts sowie der Ausscheidung harnpflichtiger Stoffwechselprodukte zuständig sind. Bei der Produktion des Harns 
entsteht zunächst durch Filtration des Blutes in den Kapillarschlingen der sogenannte Primärharn. Dieser wird dann in einem System aus hintereinander geschaltete Kanälchen - als Tubulussystem der Niere bezeichnet - durch Wasserentzug und Sekretions-und Resorptionsvorgänge so konzentriert und in seiner Zusammensetzung verändert, dass er als sogenannter Endharn ausgeschieden werden kann Aumüller et al. 2007).

Des Weiteren spielen die Nieren eine Rolle bei der Produktion des Hormons Erythropoetin, welches für die Bildung der Erythrozyten von Bedeutung ist. Durch Beteiligung am Vitamin D-Stoffwechsel regulieren sie den Kalziumhaushalt. Darüber hinaus sind die Nieren durch renale Autoregulation in der Lage, auf den systemischen Blutdruck einzuwirken (Aumüller et al. 2007).

Die Nieren sind sowohl von einer bindegewebigen Kapsel als auch einer Fettkapsel umgeben. Makroskopisch lassen sich die Nieren in Rinde und Mark unterteilen. Das Mark besitzt eine pyramidenförmige Form, dessen Spitze (Papilla renalis) in einen Kelch des Nierenbeckens ragt, an welchem der konzentrierte Endharn mündet. Die Rinde schließt sich nach außen hin dem Mark an und setzt sich als Columnae renales auch zwischen den Markpyramiden fort, von denen aus Markstrahlen in die Rinde ragen. Die Mark-freien Areale werden insgesamt als Rindenlabyrinth bezeichnet (LüllmannRauch 2009).

Die mikroskopisch wichtigen Bauelemente sind die Nierenkörperchen (Corpusculus renalis), die

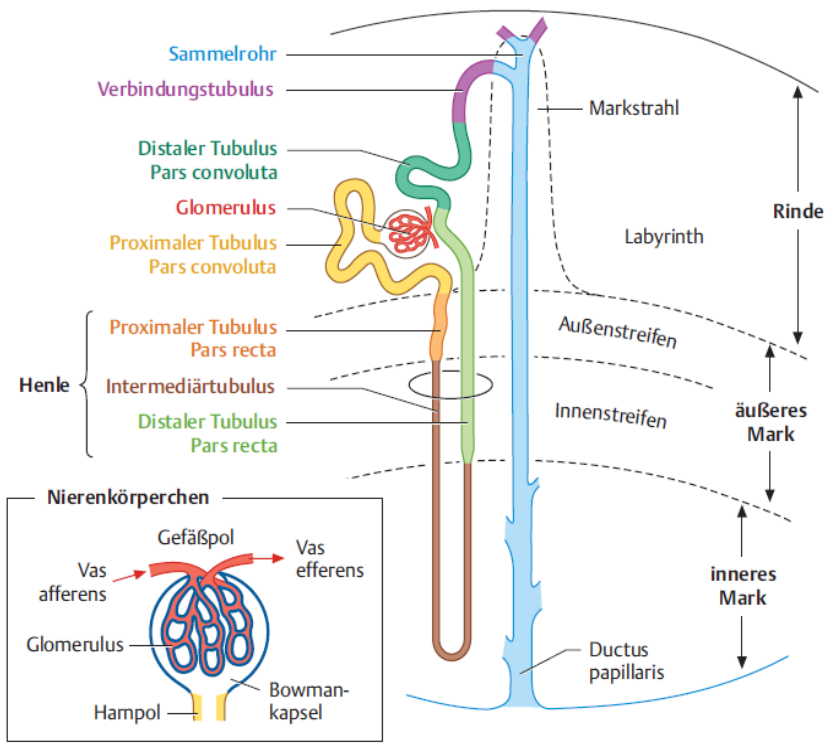

Abbildung 1.1: Tubulussystem der Niere. Das Tubulussystem durchzieht Mark- und Rindenbereiche der Niere, sodass der Urin in das Nierenbecken münden und mit den ableitenden Harnwegen ausgeschieden werden kann (Lüllman-Rauch 2009, S. 446).

Nierenkanälchen (Tubulus renalis) und die Blutgefäße im Interstitium, welche die wesentlichen Strukturen des Nierenparenchyms darstellen (Lüllmann-Rauch 2009). Das im Rindenlabyrinth befindliche Nierenkörperchen fungiert als Verbindungsstück zwischen den Gefäßen und dem Tubulussystem. Es besteht aus einer zentral mehrfach gewundenen Gefäßschlinge, dem Glomerulum, und einer sie umgebenden doppelwandigen Kapsel, dem parietalen Blatt der Bowman-Kapsel (Schünke et al. 2005). Zum Glomerulum werden in der anatomischen Terminologie neben der Gefäßschlinge noch weitere Strukturen gezählt: GBM, Podozyten und Mesangium. Die Podozyten 
bestehen aus spezialisierten Epithelzellen und entsprechen dem viszeralen Blatt der Bowman-Kapsel. Das Mesangium ist kontraktil und dient insbesondere der Stabilisierung der Gefäßschlinge. Zum glomerulären Filter werden das Kapillarendothel, die

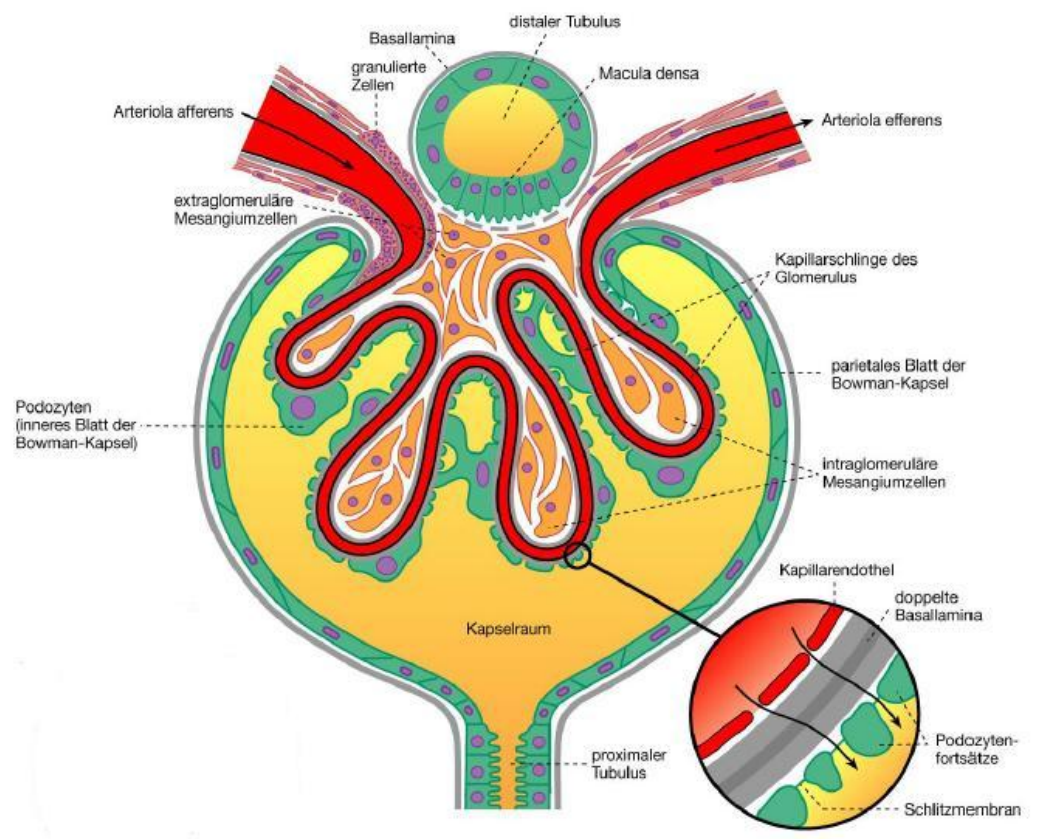

Abbildung 1.2: Schematische Darstellung eines Glomerulums.

Zum Glomerulum werden in der anatomischen Terminologie Gefäßschlinge, glomeruläre Basalmembran, Podozyten und Mesangium gezählt (Welsch 2003, S. 454).

GBM und die Podozytenfüße gezählt, welche zusammen die Blut-Harn-Schranke bilden (Lüllmann-Rauch 2009). Dabei besitzt das Endothel Fenster mit einem Durchmesser von 50 - $100 \mathrm{~nm}$ ohne Diaphragma. Die zum Lumen gerichtete Plasmamembran trägt eine negativ geladene Glykokalyx, welche etwa $400-500 \mathrm{~nm}$ dick ist und die Fensteröffnungen bedeckt. Der Zellleib der Podozyten befindet sich im Harnraum seitlich der GBM. Von dem Zellleib gehen Primärfortsätze ab, von welchen sich die Sekundärfortsätze, die sogenannten Podozytenfüße, abzweigen. Mit diesen haftet er an der GBM. Die Gesamtheit der Podozytenfüße bildet eine fast vollständige Abdeckung der GBM, es verbleiben lediglich schmale etwa $40 \mathrm{~nm}$ breite Filtrationsschlitze, die von einem Schlitzdiaphragma überbrückt sind. Neben anderen Proteinen kommt dem Transmembranprotein Nephrin ein besondere Rolle zu. Die langen Nephrinmoleküle benachbarter Podozytenfortsätze durchspannen den Filtrationsschlitz so, dass sie sich nach Art eines Reißverschlusses in der Mitte des Schlitzes verzahnen. Beidseits der Mitte lassen sie jedoch Filtrationsporen frei (Lüllmann-Rauch 2009).

Wie bereits beschrieben liegt zwischen dem Kapillarendothel bzw. Mesangium und den Podozyten die GBM. Ihr Grundgerüst wird von der Lamina densa gebildet, welche aus einem molekularen Netz aus u.a. Typ-IV-Kollagen, Laminin 11 und Proteoglykanen besteht. Beidseits wird die Lamina densa von den Laminae rarae umgeben; so wird die Lamina densa auf der Endothelseite von der Lamina rara interna und 
auf Seite der Podozyten von der Lamina rara externa umschlossen. In die Laminae rarae ragen Zelladhäsionsproteine wie zum Beispiel Integrine, die der Verankerung der Endothelzellen und Podozyten dienen. Weiterhin befestigen negativ-geladene Heparansulfat-Proteoglykane die Lamina densa mit den Laminae rarae, sodass die GBM stark negativ geladen ist. Für die Neusynthese der GBM sind in erster Linie die Podozyten, in zweiter Linie die Mesangiumzellen verantwortlich. Die $\alpha 3-/ \alpha 4-$ und $\alpha 5$-Ketten des Typ-IV-Kollagens werden hingegen ausschließlich von den Podozyten gebildet, während für den Abbau beide gleichermaßen zuständig sind (LüllmannRauch 2009; Abrahamson et al. 2009).

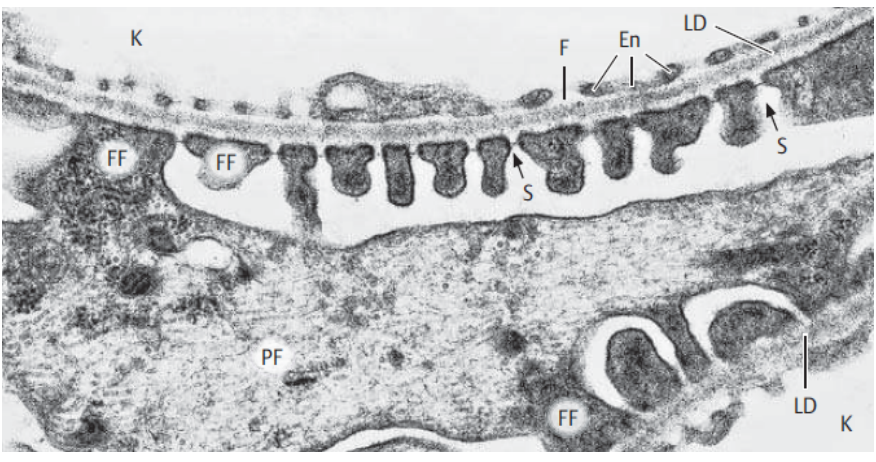

(a) Blut-Harn-Schranke

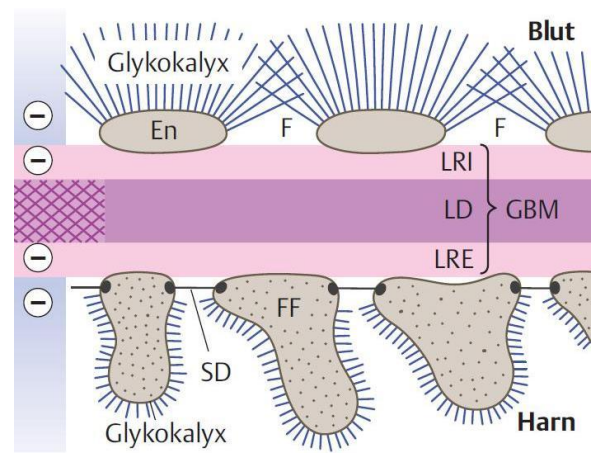

(b) Negativ geladene Glykokalyx

Abbildung 1.3: Blut-Harn-Schranke.

In (a) ist ein elektronenmikroskopisches Bild bei 25000-facher Vergrößerung, in (b) eine schematische Darstellung der Blut-Harn-Schranke mit seiner negativ geladenen Glykokalyx gezeigt. En, Endothel, F, Fenster, K, Kapillare, LD, Lamina densa, PF, Primärfortsatz eines Podozyten. Die Filtrationsschlitze (FS) zwischen den Fußfortsätzen (FF) sind durch ein Schlitzdiaphragma (SD) überbrückt (Lüllman-Rauch 2009, S. 453 u. 455).

Der glomeruläre Filter besitzt die Aufgabe, Makromoleküle zu selektieren. Entscheidende Kriterien für die Filtrierbarkeit eines großen Moleküls sind seine Größe und elektrische Ladung. Die Sortierung nach Größe erfolgt hauptsächlich durch die Lamina densa und die Poren im Schlitzdiaphragma. Für die Ladungsselektion werden die anionischen Bestandteile des Filters und zwar insbesondere die Glykokalyx des Kapillarendothels verantwortlich gemacht. So sind anionische Moleküle wie beispielsweise das Albumin sehr viel schlechter filtrierbar als neutral geladene Moleküle gleicher Größe, da negativ geladene Moleküle von der ebenfalls negativ geladenen Glykokalyx abgestoßen werden (Lüllmann-Rauch 2009).

\subsection{Molekulare Perspektive}

\subsubsection{Mutation im Typ-IV-Kollagen}

Zunächst wird der Aufbau des Typ-IV-Kollagens beschrieben, bevor seine Relevanz im Zusammenhang mit dem Alport-Syndrom dargestellt wird. 
Die extrazelluläre Matrix besteht aus vielen verschiedenen Proteinen und Kohlenhydraten. Als wichtigstes Protein ist das Kollagen zu nennen, welches zu der Gruppe der Glykoproteine gehört. Glykoproteine sind Proteine mit einem Kohlenhydratanteil, der aber kleiner ist als sein Proteinanteil. Zudem sind Kollagene Strukturproteine des Binde- und Stützgewebes sowie der Basallamina. Alle Kollagene besitzen die gleiche Grundstruktur, bestehend aus einer rechtsgängigen Tripelhelix. Die Bildung erfolgt durch Zusammenlagerung von drei linksgängigen Kollagen- $\alpha$-Ketten. Es sind derzeit etwa 25 verschiedene Kollagen- $\alpha$-Ketten bekannt, die jeweils von einem eigenen Gen kodiert werden. Es besteht die Möglichkeit, aus diesen Kollagen- $\alpha$-Ketten ca. 10000 verschiedene Kombinationen zu bilden; dennoch findet man nur 20 mit römischen Ziffern durchnummerierte Kollagen-Typen (Rassow et al. 2008).

Das Typ-IV-Kollagen ist als nicht-fibrilläres Kollagen Hauptbestandteil aller Gefäßbasalmembranen. Es besteht aus einem sehr langen Kollagenschwanz und einer

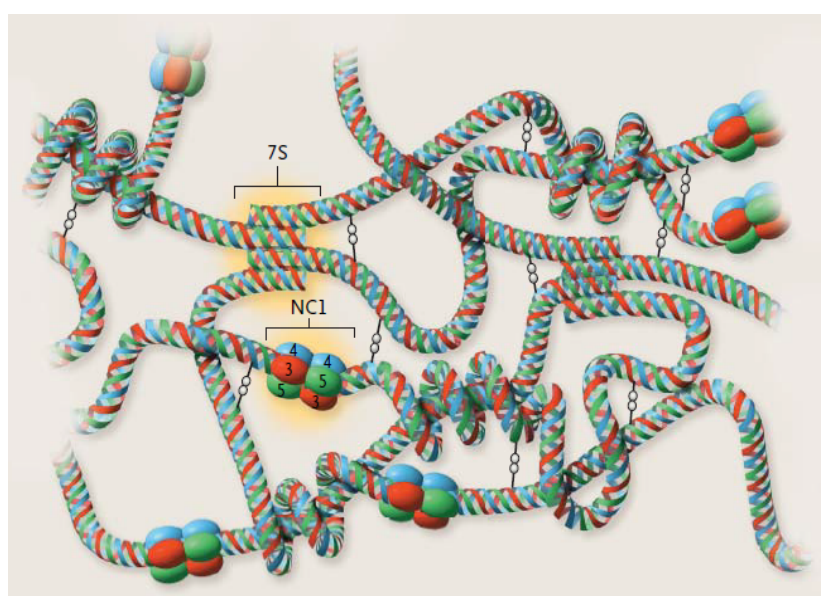

Abbildung 1.4: Struktur des Typ-IV-Kollagens. Es sind die $\alpha 3-/ \alpha 4-/ \alpha 5$-Ketten des TypIV-Kollagens schematisch gezeigt, die beim Alport-Syndrom mutiert sind (Hudson et al. 2003, S. 2545). evolutionär hochkonservierten nichtkollagenen Domäne, der sog. NC1Domäne. Diese befindet sich am C-terminalen Ende des Kollagenschwanzes. Außerdem existiert eine 7S-Domäne, die am N-terminalen Abschnitt befindlich ist und zu dem außergewöhnlichen flächigen Netzwerk des Typ-IV-Kollagens beiträgt. Der Kollagenschwanz besteht aus jeweils drei der beim Typ-IVKollagen möglichen sechs $\alpha$-Ketten, die sich $\mathrm{zu}$ einer Tripelhelix zusammenlagern, wobei die $\alpha 1_{(2)^{-} / \alpha 2-}$ Ketten in allen Basalmembranen vorkommen, hingegen die $\alpha 3-/ \alpha 4-/ \alpha 5$-Netzwerke vorwiegend im Glomerulum, im Innenohr und im Auge vorzufinden sind (Hudson et al. 1993; Löffler und Petrides 2003).

Die Zusammensetzung und Sequenz der Aminosäuren im Typ-IV-Kollagen und generell im Kollagen sind von Besonderheit: Der Anteil der Aminosäure Glycin beträgt fast ein Drittel in allen Kollagenmolekülen, was für ein Protein außerordentlich hoch ist. Dies lässt sich folgendermaßen erklären: Da im Inneren der Tripelhelix wenig Platz ist, passt nur Glycin als kleinste Aminosäure sehr gut in die inneren Windungen. Weil eine Windung drei Aminosäuren umfasst, ist es verständlich, dass Glycin in regelmäßigen Abständen an dem Aufbau der Kollagenkette beteiligt ist. Darüber hinaus ermöglicht Glycin die Annäherung verschiedener Polypeptidstränge. Die drei 
Stränge werden durch Wasserstoffbrücken zusammengehalten, wobei die peptidische NH-Gruppe von Glycin Wasserstoffdonor ist. Der Wasserstoffakzeptor ist das carboxyterminale Ende einer anderen Aminosäure der anderen beiden Ketten (Stryer 1991; Hudson et al. 1993).

Die charakteristische Aminosäuresequenz besteht aus der sich wiederholenden Einheit Glycin-X-Y, wobei an Position X oft Prolin steht und an Position Y meist Hydroxyprolin befindlich ist (Rassow et al. 2008). Prolin unterscheidet sich insofern von anderen Aminosäuren, dass seine Seitenkette sowohl mit dem Stickstoffatom als auch mit dem $\alpha$-Kohlenstoffatom verbunden ist und damit eine Ringstruktur ausbildet. Diese erleichtert dem Kollagen die Ausbildung der Tripelhelix, indem es sich nach außen in den Knick der Kollagenkette platzieren kann. Die Hydroxyproline sind durch ihre Hydroxygruppen in der Lage, Wasserstoffbrücken zwischen benachbarten Polypeptidketten zu bauen, um so dem Kollagen bei physiologischen Temperaturen Stabilität zu verleihen. Das Typ-IV-Kollagen zeichnet sich durch den Besitz einer weiteren Aminosäure aus: 5-Hydroxylysin. Diese ist in der Lage, kovalente Verbindungen mit Disacchariden wie beispielsweise Glucose und Galactose einzugehen. Je nach Gewebe variiert die Anzahl der Kohlenhydrateinheiten. Darüber hinaus wird speziell das $\alpha 3-/ \alpha 4-/ \alpha 5$-Netzwerk der GBM durch intramolekulare Disulfidbrücken zusätzlich stabilisiert (Stryer 1991; Löffler und Petrides 2003; Rassow et al. 2008). Wie bereits erwähnt, sind im Typ-IV-Kollagen die $\alpha 1-6$-Ketten identifiziert worden, deren Gene paarweise auf den Chromosomen X, 2 und 13 lokalisiert sind (Gross et al. 2002). Zum Zeitpunkt der Geburt besteht die GBM aus embryonalen $\alpha 1_{(2)^{-}}$ $/ \alpha 2$-Ketten. Ab dem vierten Tag nach der Geburt werden die Gene für die $\alpha 3-/ \alpha 4$ / $\alpha 5$-Ketten aktiviert und die reife Basalmembran bildet sich aus (Miner und Sanes 1994). Das Alport-Syndrom wird durch Mutationen dieser $\alpha 3$ - $/ \alpha 4$ - oder $\alpha 5$-Ketten des Typ-IV-Kollagens verursacht, welche ausschließlich von den Podozyten gebildet werden (Abrahamson et al. 2009). So kommt es durch Glycinmutationen mit nachfolgendem Abknicken der Tripelhelixstruktur oder durch Verkürzung des Genprodukts im Rahmen von größeren Deletionen oder Nonsense-Mutatonen zum defekten extrazellulären Aufbau der Basalmembran. Dies hat Aufsplitterungen und Lamellierungen der GBM zur Folge (Hudson et al. 1993; Gross und Weber 2005). In diesem Zusammenhang sei erwähnt, dass die Faltbarkeit der Tripelhelix des Typ-IV-Kollagens die Schwere des Phänotyps beim Alport-Syndrom bestimmt. So ist der Phänotyp abhängig von der Entfernung der Mutation zur NC1-Domäne, da hier die Faltung der Tripelhelix reißverschlussartig beginnt, was wiederum einen großen Einfluss auf die Faltbarkeit hat (Gross et al. 2010). Die Mutation der $\alpha 3$-/ $\alpha 4$ - oder $\alpha 5$-Ketten führt dazu, dass für sie die embryonalen $\alpha 1_{(2)^{-}} / \alpha 2$-Ketten eingebaut werden. Diese besitzen jedoch weniger Disulfidbrücken und haben somit nicht die ausreichende Stärke, die für den Filtrationsprozess notwenig ist (Gross et al. 2010). Zudem sind sie weni- 
ger vor Matrixmetalloproteinasen geschützt, auf die später näher eingegangen wird (Gunwar et al. 1998).

Aufgrund der Aufsplitterungen der GBM können Proteine in den Bauman-Raum gelangen, die physiologisch nicht in diesen filtriert werden können. Daher gelangen Proteine in das Tubulussystem der Niere und werden letztlich mit dem Urin ausgeschieden.

\subsubsection{Detektion des Typ-IV-Kollagen-Defektes über Rezeptoren}

Die ortsständigen Zellen wie Podozyten, Mesangiumzellen und Endothelzellen stehen durch ihre Rezeptoren in Kontakt mit dem mutierten Typ-IV-Kollagen. Bei den Rezeptoren handelt es sich unter anderem um Discoidin-Domain-Rezeptoren wie DDR1 und um Integrin-Rezeptoren wie die $\alpha 1 \beta 1-, \alpha 2 \beta 1$-, $\alpha 3 \beta 1$ - und $\alpha 5 \beta 1$-Integrine. Über ihre Rezeptoren nehmen die ortsständigen Zellen den Kollagendefekt wahr. Das veränderte Rezeptorsignal führt zu einer Hochregulierung von profibrotischen Faktoren wie beispielsweise TGF- $\beta$ und CTGF sowie verschiedenen Matrixmetalloproteinasen (Gross et al. 2004a; Gross und Weber 2005). Die Discoidin-Domain-Rezeptoren dienen dabei als Initiatoren der fibrotischen Veränderungen, wogegen die Integrine vorwiegend bei der Progression der Erkrankung mitwirken (Fogo 1999).

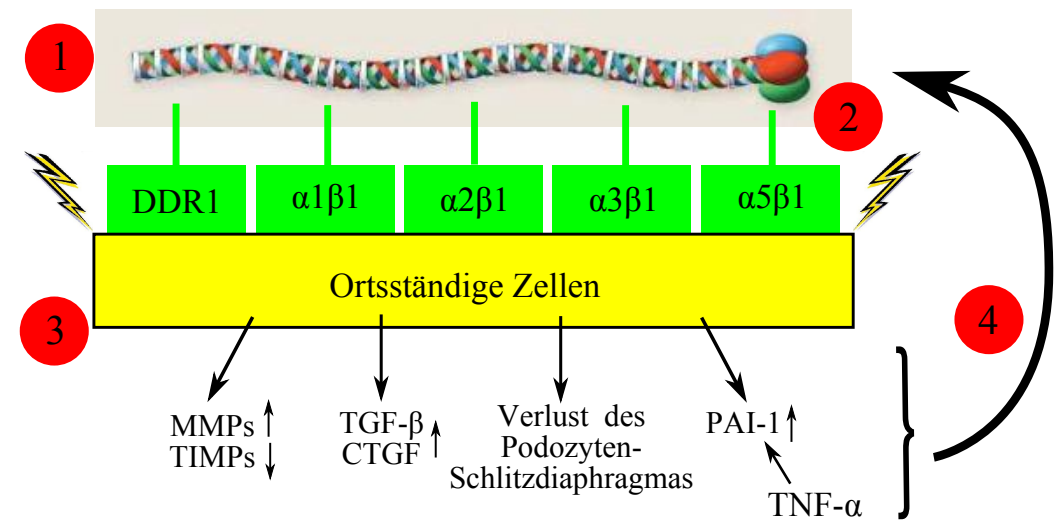

Abbildung 1.5: Der Entstehungsmechanismus der Nierenfibrose beim Alport-Syndrom im Überblick.

1. Mutationen in den $\alpha 3$-/ $\alpha 4$ - oder $\alpha 5$-Ketten des Typ-IV-Kollagens sind ursächlich für das Alport-Syndrom. 2. Ortsständige Zellen wie Podozyten, Mesangiumzellen und Endothelzellen nehmen den Kollagendefekt über Rezeptoren wahr. 3. Das veränderte Rezeptorsignal resultiert in eine Hochregulierung von profibrotischen Faktoren und in weitere Veränderungen. 4. Diese Faktoren führen sekundär zur Glomerulosklerose und tubulointerstitiellen Fibrose. Die Abbildung wurde modifiziert übernommen (Gross und Weber 2005, S. 830).

\section{Discoidin-Domain-Rezeptoren}

Discoidin-Domain-Rezeptoren wie DDR1 sind Transmembran-Rezeptoren, die zur Untergruppe der Rezeptor-Tyrosin-Kinasen gehören und vom Kollagen IV aktiviert werden (Vogel et al. 2000; Abdulhussein et al. 2008). DDRs dienen der Regulation 
von Zelladhäsion, Zellproliferation und dem Umbau der extrazellulären Matrix (Vogel et al. 2006).

DDR1 ist auf verschiedenen Zelltypen zu finden. Innerhalb der Nieren ist er auf der Basalseite der Podozytenfußfortsätze zwischen GBM und Schlitzdiaphragma anzutreffen (Gross et al. 2010). Zur Aktivierung von DDR1 sind ein TransmembranLeucin-Zipper für die Dimerisierung (Noordeen et al. 2006) sowie vier benachbarte, auf der Oberfläche exponierte Kollagenschleifen notwendig (Abdulhussein et al. 2008). Durch Glycinmutationen kommt es zu Veränderungen in den Typ-IVKollagenschleifen, was ein verändertes Rezeptorsignal zur Folge hat. Dies führt zur Hochregulierung von profibrotischen Faktoren wie TGF- $\beta$ und CTGF.

Den Podozyten kommt eine zentrale Rolle beim Alport-Syndrom zu. Einerseits bilden sie die für die GBM wichtigen und reifen $\alpha 3-/ \alpha 4-/ \alpha 5(\mathrm{IV})$-Ketten, die beim Alport-Syndrom mutiert sind. Andererseits reagieren die Podozyten bei Strukturveränderungen der GBM mit Hochregulierung von profibrotischen Faktoren (Gross et al. 2010).

In jüngerer Zeit konnte gezeigt werden, dass TGF- $\beta$ für die vermehrte Ablagerung der EZM wie Fibronektin (Nakamura et al. 1992; Sayers et al. 1999) und Laminin-1 (Cosgrove et al. 1996) verantwortlich ist. Diese Ablagerungen haben eine Verdickung und Aufsplitterung der GBM zur Folge (Gross et al. 2003). Im Verlauf der Erkrankung kommt es durch weitere Akkumulation der EZM zur tubulointerstitiellen Fibrose (Sayers et al. 1999). TGF- $\beta$ führt nicht nur zu einer Überproduktion der EZM in Podozyten, sondern auch zu einem Ungleichgewicht im PlasminogenAktivator/Plasminogen-Aktivator-Inhibitor-1-System. Der PA aktiviert Plasminogen zu Plasmin. Die Protease Plasmin spielt eine wichtige Rolle bei der Gewebereparatur, weil diese durch Aktivierung der Matrixmetalloproteinase-2 entscheidend am Kollagenumbau beteiligt ist (Tomooka et al. 1992, Baricos et al. 1999, Matsumoto et al. 2003). Das Gleichgewicht zwischen Kollagenaufbau und -abbau muss präzise reguliert sein, da dies anderenfalls zur proteolytischen Destruktion der GBM führt. Durch Signalveränderung des DDR1 kommt es zu pleotropen Effekten von Matrixmetalloproteinasen (MMPs) und ihren Inhibitoren, auf die im späteren Abschnitt näher eingegangen wird (Hou et al. 2002; Girgert et al. 2010). Die veränderte Signalwahrnehmung des DDR1 führt außerdem zum partiellen Verlust der Podozyten-Schlitzmembranen. Ein korrektes Signal ist für die Aufrechterhaltung der Transkription von Nephrin oder Nephrin-assoziierten Proteinen wie Synaptopodin unabdingbar, da sie für eine intakte Schlitzmembran verantwortlich sind. Durch den Verlust der Podozyten-Schlitzdiaphragmen können hochmolekulare Proteine die Filtrationsbarriere überwinden und somit in den Urin gelangen (Gross et al. 2004b). 


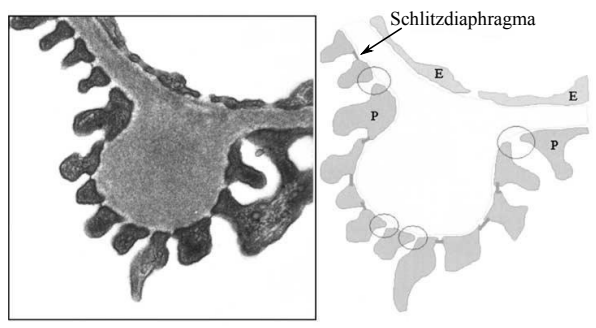

Abbildung 1.6: Verlust des Podozyten-Schlitzdiaphragmas.

P, Podozytenfußfortsatz, E, Endothelzelle (Gross et al. 2004b, S. 109).

Des Weiteren kann TGF- $\beta$ über weitere Signalkaskaden die Apoptose von Podozyten induzieren, was zu einem kompletten Funktionsverlust der Podozyten führt (Schiffer et al. 2002$)$.

\section{Integrine}

Integrine sind heterodimere Oberflächenrezeptoren, bestehend aus einer $\alpha$ - und einer $\beta$-Untereinheit. Innerhalb der Integrin-Familie kann die $\beta$-Untereinheit mit verschiedenen $\alpha$-Untereinheiten einen heterodimeren Rezeptor bilden. Integrine vermitteln mittels Signalen zwischen Komponenten der EZM und Zellen. Sie kontrollieren damit das Zellverhalten wie Zellmigration, -adhäsion und Hochregulierung von Zytokinen (Kreidberg et al. 1996).

$\alpha 1 \beta 1$-Integrine befinden sich zu hohen Konzentrationen auf Mesangiumzellen, $\alpha 2 \beta 1$ Integrine insbesondere auf Epithelzellen des Glomerulums und auf Podozyten, $\alpha 3 \beta 1$ Integrine primär auf den Podozyten und $\alpha 5 \beta 1$-Integrine auf Mesangiumzellen (Korhonen et al. 1990; Cosgrove et al. 2000; Matsumoto et al. 2003). Durch Strukturänderung der glomerulären Basalmembran kommt es zu einem Verlust der direkten Interaktion zwischen $\alpha 1 \beta 1$-Integrin und seinem Liganden Kollagen IV, welches wiederum zur Mesangiumzellexpansion führt (Kashtan 1999). Durch die Signalveränderung des $\alpha 1 \beta 1$-Integrins kommt es zu pleotropen Effekten im Bezug auf die Expression von MMPs und Gewebeinhibitoren der MMPs (TIMPs, von engl. tissue inhibitors of metalloproteinases) in den durch das Alport-Syndrom veränderten Glomeruli. Zum einen werden die MMPs 2, 9 und 14 hochreguliert, während ihre Inhibitoren TIMP-1 und TIMP-3 supprimiert werden (Cosgrove et al. 2008). TIMP-1 ist ein endogener Inhibitor von MMP-9 (Murphy et al. 1994; Roeb et al. 2000). Dennoch hat weder die An- noch die Abwesenheit von MMP-9 Einfluss auf die Progression des AlportSyndroms (Andrews et al. 2000). TIMP-3 ist in der Lage, unter anderem MMP-2 und MMP-14 zu hemmen (Wei et al. 2005). MMPs sind physiologisch an der Degradierung von Matrix- und Nicht-Matrix-Proteinen im Rahmen von Wundheilung, Gewebereparaturen und Umbau beteiligt (Nagase et al. 2006). Dabei findet eine präzise regulierte Degradierung der EZM statt. Kommt die MMP-Regulation wie beim Alport-Syndrom jedoch ins Ungleichgewicht, führt dies zu einem verstärkten 
Abbau und damit zur Progression der Erkrankung (Zeisberg et al. 2006, Murphy und Nagase 2008). Durch fortschreitende proteolytische Destruktion kommt es zur Verdickung, Aufsplitterung und Lamellierung der GBM (Rao et al. 2006).

Einen weiteren wichtigen Aspekt stellt die Tatsache dar, dass die $\alpha 1_{(2)^{-}} / \alpha 2$-Ketten vor MMPs wenig geschützt sind (Kalluri et al. 1997). Vergleicht man die $\alpha$-Ketten des Typ-IV-Kollagens miteinander, so besitzen die $\alpha 1_{(2)^{-}} / \alpha 2$-Ketten weniger Disulfidbrücken innerhalb ihrer Tripelhelix als die $\alpha 3-/ \alpha 4-/ \alpha 5$-Netzwerke, was sie anfälliger für Proteolysen seitens der MMPs macht. Die $\alpha 3-/ \alpha 4-/ \alpha 5$ (IV)-Ketten sind daher gegen die endoproteolytische Spaltung durch MMPs resistenter Gunwar et al. 1998, Cosgrove 2012). Neben den $\alpha 1 \beta 1$-Integrinen befinden sich auch $\alpha 5 \beta 1$-Integrine auf den Mesenchymzellen. Die veränderte Signalwahrnehmung des $\alpha 5 \beta 1$-Rezeptors durch das mutierte Typ-IV-Kollagen führt zur Hochregulierung von TGF- $\beta$ und Plasminogen-Aktivator-Inhibitor-1 (PAI-1). TGF- $\beta$ stimuliert die Produktion der EZM, was zu einer weiteren Verdickung der GBM und schließlich zum Fortschreiten der Erkrankung führt. PAI-1 hemmt PA, der seinerseits dazu in der Lage ist, Plasminogen in Plasmin umzuwandeln. Plasmin ist am Kollagenumbau beteiligt. Da die Aktivierung des Plasmins durch PAI-1 verhindert wird, kann es seine Funktion nicht ausüben (Baricos et al. 1999; Matsumoto et al. 2003).

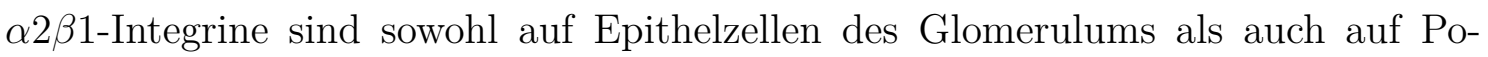
dozyten lokalisiert (Cosgrove et al. 2000; Girgert et al. 2010). Ist aufgrund von Veränderungen des Typ-IV-Kollagens das Signal gestört, kommt es zu einer Hochregulierung von TGF- $\beta$ und CTGF. Dies wiederum stimuliert die Produktion der EZM in Podozyten, was zu einer zusätzlichen Verdickung der GBM und schließlich zum Fortschreiten der Erkrankung führt (Cosgrove et al. 2000).

$\alpha 3 \beta 1$-Integrine befinden sich innerhalb der Niere bevorzugt auf den Podozyten. Der Podozyt ist vielseitig an der Pathogenese des Alport-Syndroms beteiligt: Produktion der mutierten $\alpha 3-/ \alpha 4-/ \alpha 5$ (IV)-Ketten, Hochregulierung von TGF- $\beta$, pleotrope Effekte auf MMPs und TIMPs und Verlust seines Schlitzdiaphragmas. Kommt es aufgrund der Mutation zu einem veränderten Rezeptorsignal des $\alpha 3 \beta 1$-Integrins, so führt dies zum Verlust der Podozytenfußfortsätze und somit zum partiellen Verlust der Podozytenschlitzmembran. Diese stellt in der gesunden Niere eine wichtige Filterbarriere dar, die große Proteine zurückhält (Kreidberg et al. 1996).

\subsubsection{Glomerulosklerose und tubulointerstitielle Fibrose}

Im Verlauf des Alport-Syndroms versucht der Organismus zunächst durch Hochregulierung von profibrotischen Faktoren und MMPs, das Gewebe zu reparieren (Border und Ruoslahti 1992). Die Reparationsversuche sind frustran und scheitern, da die Bildung einer intakten GBM durch die Alport-Mutation nicht möglich ist (Gross und Weber 2005). Stattdessen kommt es zu einer überhöhten Bildung der 
EZM. Des Weiteren führen Signalveränderungen einiger Rezeptoren zum Verlust des Podozyten-Schlitzdiaphragmas. Auch der Tumor-Nekrose-Faktor- $\alpha$ (TNF- $\alpha$ ) trägt hierzu bei. Dieser wird kontinuierlich bei Progression des Alport-Syndroms in glomerulären Zellen wie Podozyten exprimiert. Es konnte gezeigt werden, dass die Progression im Zusammenhang mit dem Nephrin-Verlust von Podozyten steht (Ryu et al. 2012). TNF- $\alpha$ supprimiert die Nephrin-Expression und verhindert somit die Interaktion der Podozyten mit dem Schlitzdiaphragma. Dies führt zur Apoptose des Podozyten und daher zum Zugrundegehen der finalen Filtrationsbarriere (Doublier et al. 2001; Saito et al. 2010; Ryu et al. 2012). Proteine, die aufgrund ihrer Molekülgröße und negativen Ladung von einer intakten GBM zurückgehalten werden, können nun die Filterbarriere überwinden und gelangen in den Urin (Gross et al. 2004b).

Zudem ist auf noch ungeklärte Weise die Aktivierung des Komplementsystems an der Proteinurie beteiligt. Der Komplement-Rezeptor-1 (CR1) ist auf Podozyten des gesunden Glomerulums exprimiert (Pavenstädt et al. 2003). Dieser ist dafür zuständig, zusammen mit seinen Kofaktoren Faktor I und Membran-Kofaktor-Protein (MCP) die aktivierten Komplementkomponenten C3b und C4b zu hemmen. Geht der Podozyt zugrunde, so verliert CR1 seine Funktion und kann C3b und C4b nicht mehr hemmen. Die dadurch vermehrt vorhandenen Komplementkomponenten C3b und C4b führen schließlich zur Proteinurie (Nangaku 1998).

Neben der Proteinurie manifestiert sich auch eine Hämaturie, da Erythrozyten die aufgesplitterte GBM passieren können (Alport 1927). In diesem Zusammenhang und durch weitere noch nicht geklärte Signale wird die Gerinnungskaskade aktiviert, infolgedessen es zu Fibrinablagerungen kommt (Deguchi et al. 1989; Ono et al. 1991). Die Gerinnungskaskade beinhaltet unter anderem die Serinproteasen Kallikrein und Thrombin (Stryer 1991). Thrombin wird durch den glomerulären Schaden generiert und als Progressor der Glomerulosklerose beschrieben (Tsunoda et al. 2001). Thrombin bewirkt einerseits eine beschleunigte TGF- $\beta$-Produktion und -Sekretion und andererseits eine erhöhte Sekretion von PAI-1 und PA aus Podozyten und Mesangiumzellen (Iwamoto et al. 1990; Villamediana et al. 1990). Auch TNF- $\alpha$ stimuliert die PA- und PAI-1-Sekretion aus Podozyten (Le und Vilcek 1987; Iwamoto et al. 1990). PAI-1 steht im Sinne einer Progression der Nierenfibrose, indem er dem Fibrinabbau und somit der Wundheilung entgegenwirkt (Chatziantoniou und Dussaule 2005). Durch unzureichende Plasminbildung kann es sich weder aktiv an der Fibrinolyse noch am Umbau des Kollagens beteiligen (Saksela 1985; Villamediana et al. 1990).

Wie auch bei anderen glomerulären Nierenerkrankungen bildet sich ein glomerulärer Halbmond mit Fibrinablagerungen, Makrophagen und Akkumulation der EZM (Tsunoda et al. 2001). Dies führt sekundär zur Glomerulosklerose und tubulointers- 
titiellen Fibrose, dem gemeinsamen Endpunkt fast aller chronischen Nierenerkrankungen, sowie im weiteren Verlauf schließlich zum terminalen Nierenversagen (Gross et al. 2003).

\subsection{Extrarenale Manifestationen}

Die $\alpha 3-/ \alpha 4-/ \alpha 5(\mathrm{IV})-$ Ketten sind nicht nur in reifen Basalmembranen der Glomeruli vertreten, sondern auch in den Basalmembranen von Innenohr und Augen Kashtan und Michael 1996, Hudson et al. 2003). Durch Mutation dieser Ketten kommt es im Rahmen des Alport-Syndroms häufig zur progredienten Innenohrschwerhörigkeit (Johnsson und Arenberg 1981; Alport 1927). Zudem kann es zu typischen Augenveränderungen wie Lentikonus und Fundus albipunctatus führen (Thompson et al. 1987). Deletionen in der $\alpha 5$-Kette des Typ-IV-Kollagens, die bis in die $\alpha 6$-Kette hineinreichen, führen zum Alport-Syndrom und zusätzlich zur diffusen Leiomyomatose des Ösophagus (Oohashi et al. 2011).

\subsection{Vererbung und Häufigkeit}

Beim Alport-Syndrom gibt es verschiedene Erbgänge. Zu 85 \% wird es X-chromosomal rezessiv vererbt, wobei das COL4A5-Gen betroffen ist (Van Der Loop et al. 1999). Die Mutationshäufigkeit beträgt etwa 1:5000 (Tryggvason et al. 1993). Besonders betroffen sind Männer, da diese nur ein X-Chromosom haben. Jedoch können Väter dieses Gen nicht auf ihre Söhne weitergeben. Zu etwa $14 \%$ wird es autosomal-rezessiv vererbt, dabei kann entweder das COL4A3- oder COL4A4-Gen betroffen sein Gubler et al. 1995: Van Der Loop et al. 2000). Bei der autosomal-rezessiven Vererbung sind beide Elternteile meist Genträger, jedoch sind sie selbst meist phänotypisch unauffällig. Zu etwa $1 \%$ findet ein autosomal-dominanter Erbgang statt, wobei auch dort entweder das COL4A3- oder COL4A4-Gen betroffen ist Van Der Loop et al. 2000). Die Mutationshäufigkeit der beiden letztgenannten Erbgänge beträgt etwa 1:50000 (Flinter et al. 1988).

\subsection{Therapie}

Der ACE-Hemmer Ramipril ist bis dato Therapie der ersten Wahl beim AlportSyndrom (Kashtan et al. 2012). Es gehört zur Gruppe der Antihypertensiva und ist für die Therapie der arteriellen Hypertonie, Herzinsuffizienz, diabetischen Nephropathie mit Mikroalbuminurie und zur Prävention der kardiovaskulären Morbidität und Mortalität beim Erwachsenen zugelassen (Kasper et al. 2005). Bisher gibt es aber 
keine kausale Therapie für das Alport-Syndrom. ACE-Hemmer wirken symptomatisch und sind Inhibitoren des sogenannten Renin-Angiotensin-Aldosteron-Systems (RAAS). In diesem Zusammenhang wird kurz auf das Blutdruck regulierende RAAS eingegangen (Schmidt et al. 2005; Kasper et al. 2005). Das aus der Leber stammende Polypeptid Angiotensinogen wird durch Renin proteolytisch in das Dekapeptid Angiotensin I gespalten. Im juxtaglomerulären Apparat wird sowohl der Blutdruck im Vas afferens als auch der Salzgehalt im Harnkanälchen erfasst. Renin wird freigesetzt, wenn ein Blutdruckabfall oder ein verminderter Kochsalzgehalt und damit Abfall des Blutvolumens gemessen wird. Angiotensin I wird seinerseits durch ACE in das Oktapeptid Angiotensin II umgewandelt. ACE ist insbesondere in Endothelien der Nierengefäße und auf der Oberfläche von Endothelzellen der Lungen lokalisiert. Wird die Bildung von Angiotensin II durch den ACE-Hemmer Ramipril gehemmt, so kann es seine Wirkung nicht mehr entfalten. Einerseits wirkt Angiotensin II mittels seiner AT1- und AT2-Rezeptoren vasokonstriktorisch, was in einem Anstieg des Blutdrucks und einer vermehrten Durchblutung sämtlicher Organe und insbesondere der Nieren resultiert. Andererseits bewirkt ACE eine gesteigerte Aldosteronfreisetzung aus der Nebennierenrinde. Aldosteron ist in der Lage, eine erhöhte Rückresorption von Natrium- und Chloridionen und eine vermehrte Ausscheidung von Kaliumionen in das Tubuluslumen zu bewirken. Dies hat aus osmotischen Gründen eine erhöhte Wasserrückresorption zur Folge, was zu einem erhöhten Blutvolumen und damit zu einem erhöhten Blutdruck führt. Des Weiteren bewirkt Angiotensin II eine vermehrte Ausschüttung des antidiuretischen Hormons (ADH) aus dem Hypophysenhinterlappen. Dies trägt durch vermehrte Rückresorption von Wasser und Vasokonstriktion ebenfalls zur Steigerung des Blutdrucks bei. Bisher ist jedoch der genaue Wirkmechanismus der ACE-Hemmer in Bezug auf die Pathogenese des Alport-Syndroms nicht geklärt.

Dennoch konnte gezeigt werden, dass der ACE-Hemmer Ramipril einen nephroprotektiven und antifibrotischen Effekt bewirkt (Gross et al. 2003). Unbehandelte COL4A3-Knockout-Mäuse erlitten eine massive Proteinurie, Glomerulosklerose und tubulointerstitielle Fibrose mit komplettem Verlust der glomerulären Funktion. Sie verstarben im Alter von zehn bis elf Wochen am terminalen Nierenversagen. Im Alter von vier Wochen therapierte Alport-Mäuse wiesen eine deutlich reduzierte Proteinurie und eine über 100 \% verlängerte Überlebenszeit auf. Zum Zeitpunkt von sieben Wochen behandelte COL4A3-Knockout-Mäuse zeigten ebenfalls einen Abfall der Proteinurie, die Überlebensspanne hat sich jedoch nicht signifikant verlängert. In einer anderen Studie konnte gezeigt werden, dass Ramipril TGF- $\beta$ um mehr als $200 \%$ und CTGF um mehr als $400 \%$ herunterreguliert (Gross et al. 2004a). Zwar kann Ramipril nicht den strukturellen Schaden der GBM verbessern, aber dafür bei frühem Therapieeinsatz durch verminderte Proteinurie nephroprotektiv und antifi- 
brotisch wirken (Gross et al. 2003).

In den Alport-Registern von Nordamerika und Europa sind derzeit keine lebensbedrohlichen Nebenwirkungen der ACE-Hemmer beschrieben Gross und Kashtan 2009). Das Spektrum möglicher Nebenwirkungen ist im Allgemeinen gut bekannt: Trockener Husten, symptomatische Hypotonie, Schwächegefühl, Geschmacksstörungen bedingt durch orale Aphthen, Nierenfunktionsstörung im Sinne eines akuten Nierenversagens, Hyperkaliämie oder Exantheme und angioneurotisches Ödem Kasper et al. 2005).

ACE-Hemmer werden im Laufe der Behandlung aufdosiert, um einen bestmöglichen antiproteinurischen Effekt erreichen zu können. Beim Menschen wird die maximale Blutdrucksenkung bei $5 \mathrm{mg}$, die maximale nephroprotektive Wirkung unter $10 \mathrm{mg}$ erreicht. ACE-Hemmer werden oft als Ester hergestellt, in der Leber zum aktiven Metaboliten umgewandelt und schließlich über die Nieren ausgeschieden (Kasper et al. 2005).

\subsection{Biomarker}

\subsubsection{Biomarkerdefinition}

Ein Biomarker, der im klinischen Bereich Anwendung finden soll, muss einfach, risikoarm und nicht-invasiv vom Patienten zu gewinnen sein. Zur Diagnostik des Alport-Syndroms wurden bisher Nierenbiopsien und Mutationsnachweise durchgeführt (Kashtan et al. 2012). Die Biopsieentnahme ist mit hohem Aufwand und Schmerzen beim Patienten behaftet und birgt das Risiko von Nachblutungen und möglichen Infektionen. Eine leichtere und sicherere Entnahmetechnik ist die Gewinnung von Körperflüssigkeiten wie Blut, Urin oder Speichel. Biomarker in wenig invasiven und leicht gewinnbaren Proben wie Urin wären beim Alport-Syndrom wünschenswert. Aufgrund des Pathomechanismus gelangen Proteine in den Urin, die die Erkrankung möglicherweise frühzeitig anzeigen können. Es könnten Proteine sein, die zeitlich früher als die Vernarbung der Niere einsetzen. Dadurch könnte eine frühere Diagnosestellung ermöglicht werden, die wiederum eine frühe Therapie erlaubt. Bis heute sind jedoch keine Biomarker des Alport-Syndroms bekannt. Ein Ansatz zur Biomarkerfindung in Blutseren wird von einer Arbeitsgruppe aus Jena versucht (Baum et al. 2008). In den letzten Jahren konnten sich die leistungsfähigen massenspektrometrischen Verfahren zur Proteinanalyse immer stärker durchsetzen (Schrattenholz 2001). Durch ihre rasante Entwicklung ist die Biomarkerdetektion eine der Hauptaufgaben in der Proteomforschung geworden. Die Detektion von Biomarkern in leicht zugänglichen Medien wie Urin stellt dabei einen der aussichtsreichsten Ansätze dar (Aebersold und Mann 2003). 


\subsubsection{Biomarkerdetektion mithilfe von Proteomics}

Der Begriff Proteom setzt sich aus den Wörtern Protein und Genom (von engl. protein complement expressed by the genome) zusammen und beschreibt die Gesamtheit aller Proteine in einer Zelle oder einem Medium zu einem bestimmten Zeitpunkt (Wilkins et al. 1996). Im Gegensatz zum statischen Genom ist das Proteom als ein dynamisches Proteinmuster anzusehen, welches seinerseits auf dem Genom basiert. Proteine reagieren auf veränderte Umweltbedingungen von Zellmilieu, Temperatur, Stress oder Gewebestruktur und -eigenschaften. Das alte Paradima Ein Gen - ein Protein ist nicht länger gültig, da ein Gen für die Kodierung verschiedener Proteine verantwortlich sein kann (Müller et al. 2007).

Im Nachfolgenden wird kurz der Weg von einer DNA-Sequenz zum Protein beschrie-

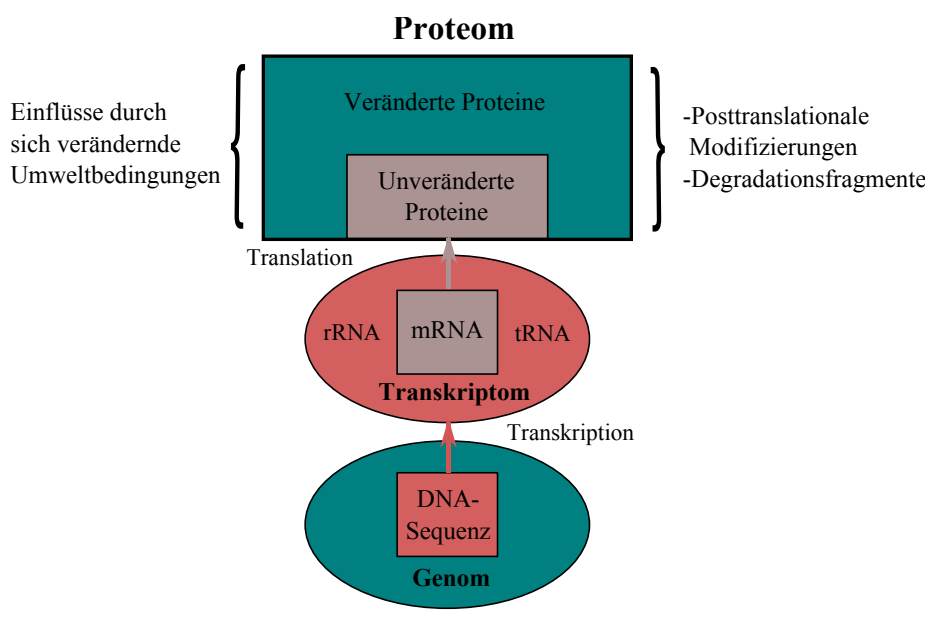

(a) Vom Genom zum Proteom

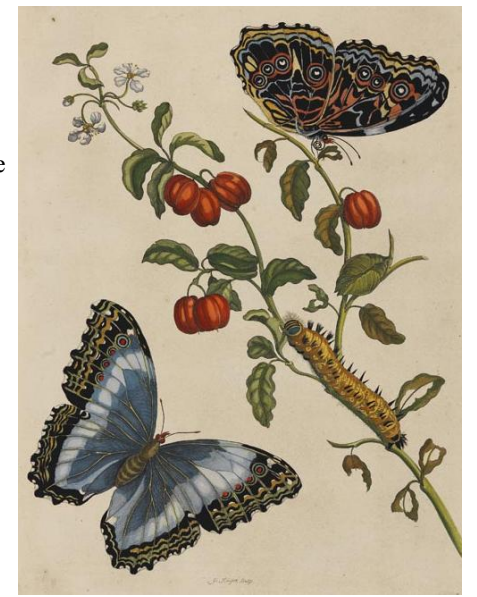

(b) Metamorphose von der Raupe zum Falter

Abbildung 1.7: Der Weg vom Genom zum Proteom - oder: Von der Raupe zum Falter.

In (a) ist der Weg vom Genom über das Transkriptom zum Proteom schematisch dargestellt. Diese Abbildung wurde modifiziert übernommen (Tilleman et al. 2005, S. 1218). Abbildung (b) zeigt Raupe und Falter als vereinfachtes Beispiel für das Wort Proteom. Das Genom dieser beiden ist identitisch, die Proteine können dennoch vielfältig sein. Dieses Bild wurde von Maria Sybilla Merian angefertigt (1647-1717). Bildquelle: http://www.radierung.de/popup_image.php?pID=1053\&imgID=0, abgerufen am 04.07.2012

ben. Durch Transkription wird aus der DNA die mRNA, die ihrerseits durch alternatives Splicen zu verschiedenen RNA-Molekülen verwandelt werden kann. Mittels Translation entstehen letztlich Proteine, die beispielsweise durch Glykosylierungen, Acetylierungen, Phosphorylierungen oder Hydroxylierungen posttranslational modifiziert werden und in Interaktion mit anderen Proteinen treten. Hierdurch und durch äußere Einflüsse auf die Proteine können sich verschiedene Proteinisoformen und modifizierte Proteine bilden. Das anfängliche Genom wird über das Transkriptom schließlich zum dynamischen Proteom (Tilleman et al. 2005). Als vereinfachtes Beispiel lässt sich die Bedeutung des Proteoms in Abbildung 1.7b durch die Metamorphose von der Raupe zum Falter auf den Punkt bringen. 
Veränderungen, die den Proteinen durch Umwelteinflüsse und Modifizierungen widerfahren, lassen sich nur durch quantitative Proteomanalysen erfassen. In diesem Projekt sollen durch etablierte proteomische Verfahren Urinproteine identifiziert werden, die im Alport-Urin klinisch relevant hochreguliert sind und im Rahmen dieser Erkrankung als Biomarker fungieren könnten. Die Kopplung von zweidimensionaler Elektrophorese mit einem hochaufösenden Massenspektrometer bildet dabei die Grundlage. Mithilfe von Proteomics soll die Analyse von einem Körpermedium wie Urin die krankheitsbedingten Proteinveränderungen des Alport-Syndroms widerspiegeln.

\subsection{Zielsetzung}

Beim Alport-Syndrom geht die natürliche Filterbarriere der Niere zugrunde. Es gelangen Proteine in den Urin, die möglicherweise zeitlich früher in den Urin treten als die Vernarbung der Nieren einsetzt. Diese Biomarker könnten die Erkrankung damit frühzeitig anzeigen.

In dieser Arbeit soll der Urin von Wildtyp- und COL4A3-Knockout-Mäusen zum frühen Krankheitszeitpunkt von 4,5 und 6 Wochen untersucht werden. Das Ziel der vorliegenden Untersuchung besteht darin, Proteinmarker zu finden, die im Urin von COL4A3-Knockout-Mäusen klinisch relevant hochreguliert und spezifisch für das Alport-Syndrom sind.

Zur Erreichung dieses Ziels wird nach folgender Methode vorgegangen:

Im ersten Abschnitt werden histologische und elektronenmikroskopische Nierenschnitte von Wildtyp- und COL4A3-Knockout-Mäusen angefertigt, um zu verdeutlichen, dass zum frühen Krankheitszeitpunkt des Alport-Syndroms kaum histologische oder elektronenmikroskopische Veränderungen zu sehen sind.

Im zweiten Abschnitt werden Proteomprofile des Wildtyp- und Alport-Urins zum Zeitpunkt von 4,5 und 6 Wochen erstellt. Dazu werden die Proteine mittels 2D-SDSPAGE (2D-Sodiumdodecylsulfat-Polyacrylamidgelelektrophorese) und 2D-DIGE (2Ddifference in gel electrophoresis) nach Ladung und Masse aufgetrennt. Im Anschluss folgen die massenspektrometrische Analyse und die Auswertung der Regulationsunterschiede der identifizierten Proteine.

Im dritten Teil werden ausgewählte klinisch relevant hochregulierte Proteine mittels Western Blot geprüft.

Abschließend werden die im Western Blot als klinisch relevant hochreguliert verifizierten Proteine biochemisch diskutiert, indem im Idealfall ein Zusammenhang zur Pathogenese des Alport-Syndroms hergestellt wird. 


\section{Material und Methoden}

\subsection{Materialien}

Alle Materialien wurden als Einwegartikel verwendet, um Sterilität und Reinheit dieser sicherzustellen. Sofern nicht anders vorgegeben, wurden alle anderen Verbrauchsmaterialien mit einem Wasserdampfdruck von 2 Bar bei $121^{\circ} \mathrm{C}$ für 20 Minuten im Autoklaven sterilisiert.

\subsubsection{Urin}

Im Lauf dieser Laborarbeit wurden Urinproben von Wildtyp -und COL4A3-Knockout-Mäusen zum Zeitpunkt von 4,5 und 6 Wochen analysiert. Die COL4A3-KnockoutMaus stellt ein etabliertes Tiermodell für das humane Alport Syndrom dar. So entwickelt diese das Vollbild des Alport-Syndroms, einschließlich Proteinurie, Hämaturie und Versterben an Nierenversagen. Es kommt wie beim Menschen zum ersatzweisen Einbau von $\alpha 1_{(2)^{-}}$und $\alpha 2$-Ketten aufgrund des fehlenden Einbaus der regulären $\alpha$-Ketten. Diverse Studien am Tiermodell deuten an, dass der Schaden in der GBM ursächlich für sekundäre Schäden ist, welche dann zur interstitiellen Fibrose und zum Nierenversagen führen (Gross und Weber 2005).

Die Mäuse für dieses Projekt wurden von einer großen Studie bezogen, in welcher der Hauptteil der COL4A3-Knockout-Mäuse mit ACE-Hemmern behandelt wurde. Das Niedersächsische Landesamt für Verbraucherschutz und Lebensmittelsicherheit hat der Studie zugestimmt. Die Prüfungsnummer lautet G 10/163. Im Rahmen dieses Projektes ist das Analysieren des Mäuseurins ethisch tragbar, da anhand des Tiermodells wichtige Rückschlüsse über die Erkrankung bei Menschen und ihre Präventionsmöglichkeiten gezogen werden können.

Der Urin wurde mittels optimierter Urinabnahmetechnik auf einer sterilen Unterfläche abgenommen und für dieses Projekt zur Verfügung gestellt. Alle Proben wurden bis zu ihrer Verwendung bei $-20{ }^{\circ} \mathrm{C}$ eingefroren. Für diese Arbeit stand der Urin von insgesamt 33 Wildtyp-Mäusen zur Verfügung, darunter befanden sich 16 Weibchen und 17 Männchen. Von den COL4A3-Knockout-Mäusen gab es insgesamt 29, von denen 11 weiblich und 18 männlich waren. 


\subsubsection{Chemikalien}

Die im Folgenden aufgeführten Chemikalien, Antikörper, Verbrauchsmaterialien, Geräte und wissenschaftliche Software kamen während dieser Arbeit zum Einsatz. Sie wurden von verschiedenen Firmen bezogen, die im Einzelnen in den nachfolgenden Tabellen aufgelistet sind.

Tabelle 2.1: Chemikalien

\begin{tabular}{|c|c|}
\hline Chemikalien & Hersteller \\
\hline 1,4-Dithiothreitol & Roth, Karlsruhe \\
\hline 2-Mercaptoethanol minimum $98 \%$ & Sigma-Aldrich, Steinheim \\
\hline 2,5-Dihydroxybenzoesäure & Sigma-Aldrich, Steinheim \\
\hline Acetonitril 99,5\% & Sigma-Aldrich, Steinheim \\
\hline Ammoniumbikarbonat & Sigma-Aldrich, Steinheim \\
\hline Ammoniumpersulfat & Sigma-Aldrich, Steinheim \\
\hline Bio-Lyte 3/10 Ampholyte & Bio-Rad, München \\
\hline Bromphenolblau & Sigma-Aldrich, Steinheim \\
\hline BSA-Standard & Sigma-Aldrich, Steinheim \\
\hline Butanol & Merck, Darmstadt \\
\hline Calciumchlorid-Dihydrat & Merck, Darmstadt \\
\hline Chaps & Merck, Darmstadt \\
\hline Chloroform $99 \%$ & Roth, Karlsruhe \\
\hline Coomassie Brilliant Blue G-250 & Bio-Rad, München \\
\hline $\begin{array}{l}\text { Criterion XT MOPS Running Buffer } \\
20 \mathrm{x}\end{array}$ & Bio-Rad, München \\
\hline Cy3 DY-547-NHS-Ester & Dyomics, Jena \\
\hline Cy5 DY 647-NHS-Ester & Dyomics, Jena \\
\hline Destilliertes Wasser & Laboreigene Herstellung \\
\hline Essigsäure 99-100 \% & Roth, Karlsruhe \\
\hline Ethanol & Merck, Darmstadt \\
\hline Flamingo Fluorescent Gel Stain $10 \mathrm{x}$ & Bio-Rad, München \\
\hline Glycerin $87 \%$ & Merck, Darmstadt \\
\hline Glycin $99 \%$ & Roth, Karlsruhe \\
\hline Jodacetamid & Sigma-Aldrich, Steinheim \\
\hline L-Lysin Monohydrochlorid & Sigma-Aldrich, Steinheim \\
\hline Methanol $99 \%$ & Roth, Karlsruhe \\
\hline Mineralöl & Bio-Rad, München \\
\hline Natriumchlorid & Merck, Darmstadt \\
\hline N,N-Dimethylformamid minimum $99 \%$ & Sigma-Aldrich, Steinheim \\
\hline
\end{tabular}




\begin{tabular}{|l|l|}
\hline $\begin{array}{l}\text { N,N,N',N'-Tetramethylethylendiamin } \\
99 \%\end{array}$ & Sigma-Aldrich, Steinheim \\
\hline Ponceau S solution for electrophoresis & $\begin{array}{l}\text { Serva Electrophoresis GmbH, } \\
\text { Heidelberg }\end{array}$ \\
\hline $\begin{array}{l}\text { Precision Plus Protein Standards Mar- } \\
\text { kerprotein }\end{array}$ & Bio-Rad, München \\
\hline Protein Assay & Bio-Rad, München \\
\hline Roti-Blue 5x-Konzentrat & Roth, Karlsruhe \\
\hline Rotiphorese Gel 30 & Roth, Karlsruhe \\
\hline Salzsäure rauchend Rotipuran 37\% & Roth, Karlsruhe \\
\hline Sequencing Grade Modified Trypsin & Promega, Madison, Wisconsin, USA \\
\hline Skim milk powder (Milchpulver) & Merck, Darmstadt \\
\hline Sodium Dodecyl Sulfat 10\% & Merck, Darmstadt \\
\hline Trifluoressigsäure & Merck, Darmstadt \\
\hline Tris Pufferan 99,9\% & Roth, Karlsruhe \\
\hline Tween 20 & Roth, Karlsruhe \\
\hline Urea for electrophoresis & Sigma-Aldrich, Steinheim \\
\hline
\end{tabular}

Tabelle 2.2: Primär- und Sekundärantikörper

\begin{tabular}{|c|c|c|}
\hline Antikörper & Herstellungstier & Hersteller \\
\hline $\begin{array}{l}\text { Alexa Fluor } 647 \text { donkey anti- } \\
\text { goat IgG }\end{array}$ & donkey & Invitrogen, Darmstadt \\
\hline $\begin{array}{l}\text { Alexa Fluor } 647 \text { donkey anti- } \\
\text { sheep IgG }\end{array}$ & donkey & Invitrogen, Darmstadt \\
\hline $\begin{array}{l}\text { Alexa Fluor } 647 \text { goat anti- } \\
\text { rabbit IgG }\end{array}$ & goat & Invitrogen, Darmstadt \\
\hline $\begin{array}{l}\text { Anti-Antithrombin III anti- } \\
\text { body }\end{array}$ & rabbit & Abcam, Cambridge \\
\hline Anti-Haptoglobin antibody & rabbit & Sigma, Steinheim \\
\hline Anti-Parvalbumin antibody & rabbit & Abcam, Cambridge \\
\hline Anti-Plasminogen antibody & sheep & Abcam, Cambridge \\
\hline SerpinA3k (sc-162174) & goat & $\begin{array}{l}\text { Santa Cruz Biotech- } \\
\text { nology, Santa Cruz }\end{array}$ \\
\hline $\begin{array}{l}\text { Anti-Serum amyloid } \mathrm{P} \text { anti- } \\
\text { body }\end{array}$ & rabbit & Abcam, Cambridge \\
\hline
\end{tabular}




\subsubsection{Verbrauchsmaterialien}

Tabelle 2.3: Verbrauchsmaterialien

\begin{tabular}{|l|l|}
\hline Verbrauchsmaterialien & Hersteller \\
\hline Amersham Hybond-ECL & GE Healthcare, München \\
\hline $\begin{array}{l}\text { Criterion XT Precast Gel } 12 \% \text { Bis-Tris } \\
\text { IPG }+1 \text { Well comb }\end{array}$ & Bio-Rad, München \\
\hline Eppendorf Cups & Eppendorf, Hamburg \\
\hline Gelfärbeschalen & Roth, Karlsruhe \\
\hline Halb-Mikroküvetten 10 x 4 x 45 mm & Sarstedt, Nümbrecht \\
\hline Model 583 Gel Dryer Filter Paper & Bio-Rad, München \\
\hline PH-Fix $7.5-9.5$ Indikatorstäbchen & Macherey-Nagel, Düren \\
\hline $\begin{array}{l}\text { Pipettenspitzen weiß } 10 \mu l, \text { gelb } 100 \mu l, \\
\text { blau } 1000 \mu l\end{array}$ & Sarstedt, Nümbrecht \\
\hline ReadyStrip IPG Strips $11 \mathrm{~cm}, \mathrm{pH} 4-7$ & Bio-Rad, München \\
\hline Röhre $15 \mathrm{ml}, 50 \mathrm{ml}$ & Sarstedt, Nümbrecht \\
\hline
\end{tabular}

\subsubsection{Geräte}

Tabelle 2.4: Geräte

\begin{tabular}{|l|l|l|}
\hline Geräte & Modell & Hersteller \\
\hline $\begin{array}{l}\text { Digitales Phosphor- } \\
\text { Oszilloskop }\end{array}$ & TDS520D & $\begin{array}{l}\text { Tektronix, Beaverton, } \\
\text { Oregon, USA }\end{array}$ \\
\hline $\begin{array}{l}\text { Electrophoresis Power } \\
\text { Supply }\end{array}$ & PS 3002 & $\begin{array}{l}\text { Life technologies, Carls- } \\
\text { bad, Kalifornien, USA }\end{array}$ \\
\hline Gelelektrophoresesystem & $13 \mathrm{~cm}$ x $8 \mathrm{~cm}$ & Bio-Rad, München \\
\hline $\begin{array}{l}\text { Isoelektrisches Fokussier- } \\
\text { system }\end{array}$ & Protean IEF Cell & Bio-Rad, München \\
\hline Kühlbare Tischzentrifuge & Sigma1-15PX, \\
Rotor 12132H & Sigma, Osterode \\
\hline Lab-Therm & Kühner & Braun, Burladingen \\
\hline Magnetrührer & Ikamag RCT & $\begin{array}{l}\text { IKA-Werke GmbH, } \\
\text { Staufen }\end{array}$ \\
\hline Massenspektrometer & $\begin{array}{l}\text { Voyager DE-STR } \\
\text { MALDI-TOF }\end{array}$ & $\begin{array}{l}\text { Applied Biosystems, } \\
\text { Kalifornien, USA }\end{array}$ \\
\hline PH-Meter & PB-11 & Sartorius, Göttingen \\
\hline
\end{tabular}




\begin{tabular}{|c|c|c|}
\hline Photometer & $\begin{array}{l}\text { Lambda } 25 \mathrm{UV} / \mathrm{VIS} \\
\text { Spektrometer }\end{array}$ & $\begin{array}{l}\text { Perkin-Elmer LAS } \\
\text { GmbH, Rodgau Jüges- } \\
\text { heim }\end{array}$ \\
\hline Rotationsschüttler & GFL 3005 & GFL, Burgwedel \\
\hline Sartorius-Laborwaage & Universal & Sartorius, Göttingen \\
\hline Scanner & $\begin{array}{l}\text { Fluorescent Image Anali- } \\
\text { zing System FLA-5100 }\end{array}$ & Fujifilm, Düsseldorf \\
\hline Speed-Vakuumzentrifuge & Univapo $150 \mathrm{H}$ & $\begin{array}{l}\text { UniEquip } \\
\text { Laborgerätebau- und } \\
\text { Vertriebs GmbH, } \\
\text { Planegg }\end{array}$ \\
\hline Thermomixer & Comfort & Eppendorf, Hamburg \\
\hline Ultraschallbad & Sonorex Super & $\begin{array}{l}\text { Bandelin electronic, } \\
\text { Berlin }\end{array}$ \\
\hline $\begin{array}{l}\text { Ungekühlte Tisch- } \\
\text { zentrifuge }\end{array}$ & $\begin{array}{l}\text { Centrifuge } 5415 \mathrm{D} \text {, } \\
\text { Rotor } 14198\end{array}$ & Eppendorf, Hamburg \\
\hline Vortexer & Reax 2000 & $\begin{array}{l}\text { Heidolph Instruments, } \\
\text { Schwabach }\end{array}$ \\
\hline Wärmebad & GFL 1083 & GFL, Burgwedel \\
\hline Wärmeinkubator & $\begin{array}{l}\text { IP } 1500 \text { Automatic } \\
\mathrm{CO}_{2} \text { Inkubator }\end{array}$ & $\begin{array}{l}\text { Flow Laboratories, } \\
\text { Kalifornien, USA }\end{array}$ \\
\hline
\end{tabular}

\subsubsection{Software}

Tabelle 2.5: Software

\begin{tabular}{|l|l|}
\hline Software & Hersteller \\
\hline Adobe Reader X & Adobe Systems GmbH \\
\hline Data Explorer TM & Matrix Science \\
\hline Decodon Delta2D 4.2 & Decodon GmbH, Greifswald \\
\hline Gnuplot & SourceForge \\
\hline Image J & National Institutes of Health \\
\hline Image Reader FLA 5000 V 3.0 & Fujifilm, Düsseldorf \\
\hline Inkscape & Freie, plattformunabhängige Software \\
\hline Lambda 25 & Perkin-Elmer, Rodgau Jügesheim \\
\hline LaTeX & Stanford University \\
\hline Mascot Wizzard & Matrix Science \\
\hline Microsoft Excel & Microsoft Deutschland GmbH \\
\hline Voyager Control Panel & Matrix Science \\
\hline
\end{tabular}




\subsection{Proteinbiochemische Methoden zur Vorbereitung der Gelelektrophorese}

Die Probenvorbereitung ist eine der sensibelsten und wichtigsten Schritte im Prozess der Biomarkersuche. Sie bildet die Grundlage für alle weiteren Methoden, die eine Urinprobe benötigen. Bei der Vorbereitung der Urinproben war zu beachten, dass sowohl die Vorbereitungszeit als auch die eigentliche Behandlung der Probe so kurz wie möglich gehalten wird, um Proteinverlust und Modifizierungen zu vermeiden (Westermeier und Naven 2002).

Vor jeder Trennung der Proteine wurden diese einer kompletten Solubilisierung und Denaturierung unterzogen. Dies sollte sicherstellen, dass alle kovalenten und nichtkovalenten Bindungen der Polypeptide untereinander und ebenfalls zu Nichtproteinanteilen gelöst wurden. Es sollte zudem gewährleistet sein, dass keine weiteren Modifikationen durch intrinsische Faktoren wie zum Beispiel in der Probe vorhandene Proteasen erfolgen konnten (Schrattenholz 2001).

Die Probenvorbereitung diente also der Aufbereitung und Reinigung der Probe sowie der Bestimmung der Proteinmenge, die essentiell für das weitere Vorgehen waren.

\subsubsection{Proteinfällung}

Die Proteinfällung erfolgte nach Wessel und Flügge (Wessel und Flügge 1984). Die Methanol-Chloroform-Fällung bezieht sich im Folgenden auf eine $100 \mu \mathrm{l}$ Probe. Je nach Urinmenge wurden die verwendeten Substanzen gemäß dem nachfolgenden Schema ins richtige Verhältnis umgerechnet.

Der $100 \mu \mathrm{l}$ Urinprobe wurde $400 \mu \mathrm{l}$ Methanol hinzugegeben und kurz mit dem Vortexer geschüttelt. Daraufhin wurden $100 \mu$ l Chloroform hinzugefügt und erneut kurz mit dem Vortexer geschüttelt. Nun wurden $300 \mu$ l destilliertes Wasser hinzugegeben und wieder sanft mit dem Vortexer geschüttelt, bevor es 1 Minute bei einer Temperatur von $4{ }^{\circ} \mathrm{C}$ zentrifugiert wurde.

Anschließend war das Protein zwischen den flüssigen Phasen, sodass die obere Phase vorsichtig mit der Pipette abgenommen wurde. Erneut wurden $400 \mu$ l Methanol hinzugefügt, mit dem Vortexer geschüttelt und 2 Minuten bei gleicher Einstellung zentrifugiert.

Das instabile Proteinpellet befand sich am Boden des Eppendorfgefäßes und die darüber befindliche flüssige Phase wurde vorsichtig entfernt. Ein weiteres Mal wurden $400 \mu \mathrm{l}$ Methanol auf das Proteinpellet gegeben, kurz mit dem Vortexer geschüttelt und 2 Minuten zentrifugiert. Die obere Phase wurde vorsichtig abgenommen und das Pellet für etwa 20 Minuten bei Raumtemperatur getrocknet. Mit dieser Zeitangabe der Trocknungsphase wurde gewährleistet, dass sich das Proteinpellet noch gut im Lysepuffer (9,5 M Urea und 2\% Chaps) lösen konnte (Westermeier und Naven 
2002).

\subsubsection{Proteinbestimmung nach Bradford}

Bevor die Proteinlösung im Falle der 2D-Gelelektrophorese auf die IPG-Streifen für die isoelektrische Fokussierung gegeben werden konnte, musste die absolute Proteinkonzentration bestimmt werden. Diese wurde in $\mu \mathrm{g} / \mu \mathrm{l}$ angegeben. Um in unbekannten Lösungen die Proteinkonzentration zu bestimmen, wurde sich photometrischer Techniken bedient. Im Folgenden wird das verwendete Protokoll zur Proteinbestimmung nach Bradford vorgestellt (Bradford 1976).

Coomassie Brilliant Blau G-250®, ein Triphenylmethanfarbstoff, bildete in saurer Lösung mit kationischen, nichtpolaren und hydrophoben Aminosäureketten der Proteine einen Komplex. Dies verursachte eine Verschiebung des Absorptionsmaximums des Farbstoffes von 465 zu 595 nm. Bei dieser Wellenlänge wurden Extinktionsänderungen im Photometer gemessen, die die Grundlage für die Errechnung der Proteinkonzentration bildeten.

Zunächst wurde im Verhältnis 1:5 eine Färbelösung angesetzt, die sich aus $10 \mathrm{ml}$ Protein Assay-Farbstoff von Biorad und $40 \mathrm{ml}$ destillierten Wasser zusammensetzte.

Tabelle 2.6: Bradford-

Pipettierschema

\begin{tabular}{|c|c|}
\hline Färbelösung $[\mu \mathrm{l}]$ & BSA $[\mu \mathrm{g} / \mu \mathrm{l}]$ \\
\hline 1000 & 0 \\
\hline 998 & 2 \\
\hline 996 & 4 \\
\hline 994 & 6 \\
\hline 992 & 8 \\
\hline 990 & 10 \\
\hline
\end{tabular}
Tabelle 2.6 beschriebenen Pipettierschema in Halbmikroküvetten hineingegeben und mit BSA versetzt. Die Extinktionen wurden mit dem Programm Lambda 25 und der Methode Wp HST-PROT.MWP $595 \mathrm{~nm}$ mit dem Photometer Lambda 25 UV/VIS dreifach bestimmt. Mittels Korrelation der Absorptionszunahme des Protein-Farbstoffgemisches im Vergleich zur bekannten BSA-Konzentration konnte eine Kalibrierkurve und somit mittels linearer Regression eine Funktionsgleichung erstellt werden. Mithilfe der Funktionsgleichung ließen sich unter Berücksichtigung der Verdünnung der Proben und dem Probenvolumen die Proteinkonzentration bestimmen. Die errechneten Proteinkonzentrationen waren für das Erstellen von 2D-Gelen und Western Blots notwendig. So wurden für die 2D-Gele $150 \mu \mathrm{g}$, für die 2D-DIGE-Gele jeweils $75 \mu \mathrm{g}$ und für die Western Blots $40 \mu \mathrm{g}$ Protein benötigt. Es wurden verschiedene Verdünnungen verwendet: 1:3, 2:3, 1:5, 2:5 und 3:5. Das Probenvolumen betrug 1 - $5 \mu$ l. Nach Bestimmung der Proteinkonzentration wurden die Proben aliquotiert und entweder direkt verarbeitet oder bei $-20^{\circ} \mathrm{C}$ aufbewahrt. 


\subsection{Zweidimensionale Elektrophorese in der Proteomforschung}

\subsubsection{Allgemeine Grundlagen der zweidimensionalen Elektrophorese}

Die zweidimensionale Polyacrylamid-Gelelektrophorese ist eine leistungsstarke Methode zur Trennung von Proteinen. Proteine tragen ein individuelles Muster geladener Aminosäurereste und werden als sogenannte Polyelektrolyte bezeichnet. Bei der 2D-Elektrophorese, ähnlich wie bei allen elektrophoretischen Methoden, werden elektrisch geladene Teilchen in einem elektrischen Feld durch die Gelmatrix bewegt und durch ihre unterschiedlichen Wanderungseigenschaften getrennt. Die Bewegungen durch die Gelmatrix unterliegen komplizierten Gesetzmäßigkeiten, die im Einzelnen kurz erläutert werden (Schrattenholz 2001).

\section{Ladungsunterschiede und pl-Wert}

Die Ladung der Proteine ist pH-abhängig und lässt sich als Zahl ausdrücken: der sogenannte pI-Wert. Der pI-Wert beschreibt denjenigen pH-Wert, bei welchem das Protein elektrisch neutral ist und somit sich die Summe der negativ und positiv geladenen Aminosäurereste gegenseitig aufhebt. In der ersten Dimension werden die Proteine nach Ladung aufgetrennt und verbleiben an ihrem für jedes Protein charakteristischen isoelektrischen Punkt (Schrattenholz 2001).

\section{Massenunterschiede}

Die unterschiedliche molekulare Masse stellt einen weiteren Parameter in der Trennung von Proteinen dar. So hat jedes Protein aufgrund seiner individuellen Aminosäuresequenz eine einmalige und charakteristische Masse. Die im Zusammenhang mit den Massenunterschieden stehenden Größenunterschiede zeigen sich als unterschiedliche Geschwindigkeiten der Proteinbewegung in polymeren Gelmatrices. In der zweiten Dimension werden die Proteine nach ihrer Masse getrennt (Schrattenholz 2001).

\section{Chemisch-physikalische Unterschiede}

Die Aminosäuresequenz bestimmt zudem die chemisch-physikalische Natur der Proteinoberfläche und damit die Zeitspanne der Proteininteraktionen mit einer bestimmten Matrix. Diese Wechselwirkungen zwischen den Proteinen und der Matrix zeigen sich als Affinitäts-, Retentions- und Bindungseigenschaften. Es gibt noch weitere Folgen der Aminosäuresequenz, wie zum Beispiel die räumliche Struktur eines 
Proteins, was jedoch im Rahmen der in diesem Projekt angewandten Methoden eine untergeordnete Rolle spielt (Schrattenholz 2001).

\subsubsection{Die erste Dimension: Isoelektrische Fokussierung (IEF)}

Die isoelektrische Fokussierung macht sich die Ladungseigenschaften der Proteine zunutze. Jedes Protein wandert zu seinem charakteristischen isoelektrischen Punkt, wo die Nettoladung eines Moleküls gleich Null ist und somit auch die elektrophoretische Mobilität. An seinem isoelektrischen Punkt wird das Protein immobil und reichert sich dort an (Schrattenholz 2001).

Die Durchführung der ersten Dimension erfolgte nach dem gängigen Arbeitsprotokoll (Dihazi et al. 2005). Vor Benutzen der Fokussierkammer wurde diese vernünftig mit Seife und Ethanol gereinigt und anschließend getrocknet, um Verunreinigungen zu minimieren. Derweil wurden dem Rehydratationspuffer (bestehend aus $8 \mathrm{M}$ Urea und 1\% Chaps) $15 \mathrm{mM}(2,15 \mathrm{mg})$ DTT, 0,2\% (2 $\mu \mathrm{l})$ Ampholyte (pH 3-10) und $0,25 \%(2,5 \mu \mathrm{l})$ Bromphenolblau hinzugefügt. DTT fungierte dabei zur Herstellung reduzierender Bedingungen und zur Spaltung von Disulfidbrücken (Schrattenholz 2001).

Die $150 \mu$ g Probe wurde einem Gel-Streifen aufgetragen. Dazu musste die Probe vorher mit Rehydratationspuffer zu einem Endvolumen von $175 \mu$ l verdünnt werden. Beim Hinzugeben dieser Lösung in die Fokussierkammer mussten Blasen vermieden werden, um eine gute Fokussierung gewährleisten zu können. Der IPG-Streifen (von $11 \mathrm{~cm}$ Länge mit einem pH-Bereich von 4-7) wurde mit seiner Gelseite der Lösung vorsichtig aufgelegt. Wichtig war die Einhaltung des Plus- und Minuspols. Damit der Gelstreifen die Lösung vollständig absorbieren konnte, musste dies 30 Minuten bei gelegentlichem Hin- und Herschwenken unter Raumtemperatur einziehen. Bevor die Fokussierkammer mit einem Deckel abgedeckt und im Fokussiergerät platziert werden konnte, wurden die Gelstreifen mit $2 \mathrm{ml}$ Mineralöl bedeckt, um Austrocknen der Streifen zu verhindern. Das Fokussiergerät wurde gestartet; der Fokussiervorgang dauerte etwa 18 Stunden, wobei die Rehydratationszeit passiv etwa 11 Stunden betrug. Die aktiven Schritte sind in Tabelle 2.7 beschrieben. Nach dem Fokussieren wurden die Streifen der Fokussierkammer entnommen und das Mineralöl auf Filterpapier abgetropft. Im Anschluss wurde die Equilibrierung durchgeführt.

\subsubsection{Equilibrierung}

Die Equilibrierung erfolgte in zwei Schritten. In einem ersten Schritt wurden $10 \mathrm{ml}$ Equilibrierpuffer I (6 M Urea, $30 \%$ Glycerin (w/v), 2\% SDS (w/v) und 0,05 M Tris$\mathrm{HCl}$ ) angesetzt, dem $2 \%$ (100 mg) DTT und 0,25\% (25 $\mu \mathrm{l})$ Bromphenolblau hinzugefügt wurden. Der Farbstoff diente dazu, den Verlauf der zweiten Dimension anzuzei- 
Tabelle 2.7: Fokussierprogramm für die erste Dimension

\begin{tabular}{|c|c|c|c|c|}
\hline Schritt & Spannung $[\mathrm{V}]$ & Gradient & Dauer & Funktion \\
\hline 1 & 200 & linear & $1 \mathrm{~h}$ & Proteineintritt \\
\hline 2 & 500 & rapid & $1 \mathrm{~h}$ & Proteineintritt \\
\hline 3 & 1000 & rapid & $1 \mathrm{~h}$ & Proteineintritt \\
\hline 4 & 2000 & rapid & $1 \mathrm{~h}$ & Fokussierung \\
\hline 5 & 8000 & rapid & $50000 \mathrm{Vh}$ & Fokussierung \\
\hline 6 & 500 & rapid & $12 \mathrm{~h}$ & Step and Hold \\
\hline
\end{tabular}

gen. $10 \mathrm{ml}$ Equilibrierpuffer II (6 M Urea, $30 \%$ Glycerin (w/v), $2 \%$ SDS (w/v) und $0,05 \mathrm{M}$ Tris- $\mathrm{HCl}$ ) hatten 2,5\% (400 mg) IAA und 0,25\% (25 $\mu \mathrm{l})$ Bromphenolblau zum Inhalt. Mit Iodacetamid wurden Cysteinreste alkyliert (Schrattenholz 2001). Der IGP-Streifen wurde zunächst für 20 Minuten mit Equilibrierpuffer I bedeckt und auf den Schüttler gestellt. In einem zweiten Schritt inkubierte der Gelstreifen für 20 Minuten in Equilibrierpuffer II ebenfalls mit Platzierung auf dem Schüttler. Die Equilibrierung ist notwendig um eine Wechselwirkung der Acrylamidmatrix mit den Proteinen während der zweiten Dimension zu verhindern. Hierdurch konnten reduzierte Disulfidbrücken sich nicht erneut verbinden (Schrattenholz 2001).

\subsubsection{Die zweite Dimension: SDS-Polyacrylamid-Gelelektrophorese (SDS-PAGE)}

Grundidee der SDS-PAGE ist die Überführung aller Proteine nach kompletter Denaturierung in einheitliche, vollständig entfaltete Polypeptidketten mit ähnlichen Ladungseigenschaften. Dies ermöglichte ein negativ geladenes, stark denaturierendes Detergens, das Natriumdodecylsulfat (SDS), welches alle nichtkovalenten Bindungen der Proteinstruktur aufhebte. So konnte mit der zweiten Dimension die Trennung der Proteine nach ihrer Masse erreicht werden (Schrattenholz|2001). Für den Ablauf der zweiten Dimension wurde sich dem gängigen Protokoll bedient (Dihazi et al. 2005).

Es wurden kommerziell verfügbare Criterion®-Gele $(12 \%$ ige Bis-Tris-Gele mit einer Vertiefung für die $11 \mathrm{~cm}$ langen IPG-Streifen) verwendet. Die 2D-Elektrophoresebox wurde mit einer Lösung befüllt, in der $50 \mathrm{ml}$ Criterion XT MOPS Running Buffer in $950 \mathrm{ml}$ destilliertem Wasser gelöst waren. Das Ganze wurde mit Eis umgeben um dem Gel optimale Laufbedingungen mit weniger Wärmeentstehung zu gewährleisten. $7 \mu \mathrm{l}$ Markerprotein wurden in den als schraffiert gekennzeichneten Bereich eingebracht. Anschließend wurden die in der ersten Dimension verwendeteten IPGStreifen so in die Gelkammer eingefügt, dass der Pluspol dem Markerprotein anlag. 
Das Programm durchlief verschiedene Schritte: 10 Minuten bei 160 V, weitere 10 Minuten bei $180 \mathrm{~V}$ und etwa 40 Minuten bei $200 \mathrm{~V}$. Das Markerprotein diente erneut dazu, den Verlauf anzuzeigen. Dieses Programm wurde bei allen 2D-Gelen einheitlich durchgeführt. Am Ende der Fokussierung mussten die Gele über Nacht in Fixierlösung bestehend aus $500 \mathrm{ml}$ Methanol, $120 \mathrm{ml}$ Essigsäure und $380 \mathrm{ml}$ destilliertem Wasser inkubieren (Pesic et al. 2011).

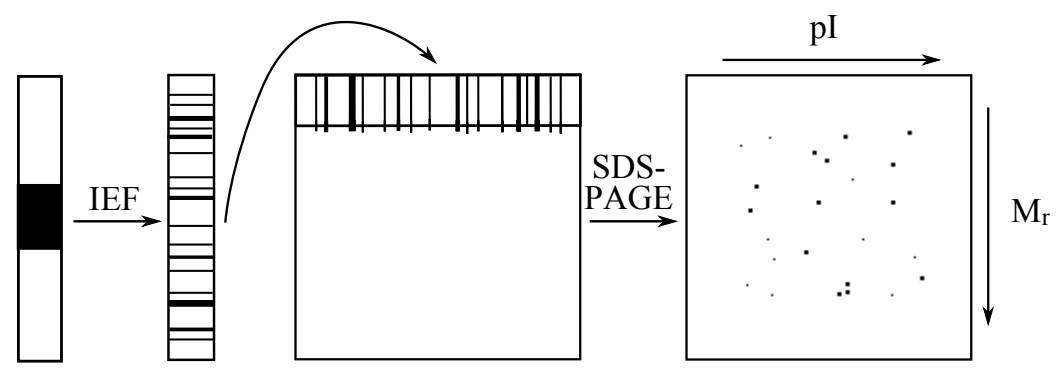

Abbildung 2.1: Schematische Darstellung der 2D-Gelelektrophorese.

Im Rahmen der isolelektrischen Fokussierung (IEF) wurden die Proteine nach ihrem isoelektrischen Punkt (pI-Wert) aufgetrennt. Die SDS-Polyacrylamid-Gelelektrophorese (SDS-PAGE) separierte die Proteine nach ihrer Masse $\left(\mathrm{M}_{\mathrm{r}}\right)$. Als Ergebnis entstand ein 2D-Gel (Schrattenholz 2001 .

\subsection{Färbungsmethoden für 2D-Gele}

Für die Darstellung der in der 2D-Elektrophorese aufgetrennten Proteine wurden verschiedene Färbemethoden angewandt. Sie werden im Folgenden vorgestellt.

\subsubsection{Flamingofärbung}

Die Flamingo®-Färbung dient dem Fluoreszenzvermögen der Proteine. $20 \mathrm{ml}$ des Flamingo®-Farbstoffs wurden mit destilliertem Wasser auf $200 \mathrm{ml}$ aufgefüllt, um eine 1:10-Verdünnung zu erreichen. Für mindestens 5 Stunden mussten die Gele mit Alufolie abgedeckt in dieser Lösung inkubieren. Im Anschluss wurden die 2D-Gele bei $600 \mathrm{~V}$ mit dem Fuji-FLA-5100-Scanner digitalisiert (Pesic et al. 2011).

\subsubsection{Coomassiefärbung}

Nach dem Scannen wurden die Gele für mindestens 12 Stunden in CoomassieFärbelösung gegeben. Für diese wurden $120 \mathrm{ml}$ destilliertes Wasser, $40 \mathrm{ml}$ Methanol und $40 \mathrm{ml}$ Roti-Blue®-Farbstoff verwendet. Durch die Coomassiefärbung wurden Proteinspots im Gel sichtbar und konnten im weiteren Prozess ausgeschnitten und identifiziert werden (Pesic et al. 2011). 


\subsubsection{D-DIGE}

Eine besondere Färbungsmethode war die 2D-DIGE (difference in gel electrophoresis). Sie ermöglichte den quantitativen Vergleich der Gele. Mit diesem Verfahren konnten zwei verschiedene Proteinproben auf einem Gel aufgetragen werden, wobei pro Probe $75 \mu \mathrm{g}$ Protein nötig waren. Die Proben wurden wie in Abschnitt 2.2 vorbereitet. Die 2D-DIGE ließ sich in vier Abschnitte untergliedern (Dihazi et al. 2009). Im ersten Schritt fand die Präparation der Fluoreszenzfarbstoffe, der sogenannten Cy Dyes, statt. Diese waren als Stammlösung mit $1 \mathrm{nmol} / \mu \mathrm{l}$ erhältlich. In dieser Arbeit wurde von zwei verschiedenen Dyes Gebrauch gemacht: Cy 3 (rot) und Cy 5 (blau). Jeweils $4 \mu \mathrm{l}$ der beiden Farbstoffe wurde mit $6 \mu \mathrm{l}$ DMF vermischt, mit dem Vortexer geschüttelt und kurz zentrifugiert. Anschließend wurden diese beiden Arbeitslösungen unter Alufolie mithilfe von Eis kühl gehalten.

In einem zweiten Schritt erfolgte die Proteinmarkierung mit den Dyes. Die beiden zu untersuchenden Proteinproben mit jeweils $75 \mu \mathrm{g}$ Protein wurden in separate Eppendorfgefäße pipettiert. 1,5 $\mu \mathrm{l}$ von der Cy 3-DMF-Lösung wurden der einen Probe, 1,5 $\mu \mathrm{l}$ von der Cy 5-DMF-Lösung der anderen Probe hinzugefügt. Die Proben wurden mit Lysepuffer (bestehend aus 9,5 M Urea und 2\% Chaps) auf $15 \mu$ l aufgefüllt. Dabei wurde der Lysepuffer nicht mit DTT und Ampholyten versetzt, sondern mit Tris-HCl-Puffer ( $\mathrm{pH} 8,8$ ). Nach Zugabe von Tris-HCl-Puffer musste der pH 8,5 betragen, was mit einem pH-Fix-Indikatorstäbchen bestätigt wurde. Die beiden Proben wurden kurz mit dem Vortexer vermischt und für 30 Minuten im Dunkeln auf Eis gestellt.

Als nächstes erfolgte der Reaktionsstopp. Dieser wurde durch Hinzugabe von 1,5 $\mu \mathrm{l}$ Lysin in beide Proben erreicht. Beide Proben mussten für weitere 10 Minuten auf Eis im Dunkeln inkubieren.

Bevor die isoelektrische Fokussierung beginnen konnte, wurden die beiden Proben gemischt und mit Rehydratationspuffer (8 M Urea und 1\% Chaps) auf $175 \mu$ l aufgefüllt, d.h. der Probe wurden $175 \mu \mathrm{l}-(16,5 \mu \mathrm{l}+16,5 \mu \mathrm{l})=142 \mu$ l Rehydratationspuffer hinzugegeben. Der Rehydratationspuffer wurde zuvor mit $10 \mu \mathrm{l}$ Ampholyte $(\mathrm{pH} 3-$ 10) und $20 \mathrm{mg}$ DTT versetzt. Die erste und zweite Dimension verlief wie in Abschnitt 2.3, wobei beide Dimensionen im Dunkeln stattfanden und den Equilibrierpuffern kein Bromphenolblau hinzugefügt wurde.

Im Anschluss an die zweite Dimension wurde das Gel bei $700 \mathrm{~V}$ mit dem FujiFLA-5100-Fluoreszenz-Laserscanner digitalisiert. Hierbei wurden zwei unterschiedliche Wellenlängen des Lasers zur Detektion der Fluoreszenzfarbstoffsignale eingestellt: Cy 3-markierte Proteine wurden bei einer Wellenlänge von $532 \mathrm{~nm}$ erfasst, Cy 5-markierte Proteine mit einer Wellenlänge von $635 \mathrm{~nm}$ gescannt. Mithilfe des Programms Delta 2D wurden die digitalisierten Gelbilder ausgewertet (Pesic et al. 2011). 


\subsection{Trypsin-Verdau von Proteinen}

Nachdem die zweidimensionale Gelelektrophorese erfolgreich durchgeführt wurde, konnten die Proteine nun für die Identifizierung vorbereitet werden.

Dazu wurden die mit Roti-Blue ${ }^{\circledR}$-Farbstoff angefärbten Proteinspots aus den 2DGelen ausgeschnitten, eluiert und gezielt gespalten. Entscheidend war, dass die Fragmente nicht zufällig entstanden. So wurde in dieser Arbeit die Protease Trypsin verwendet. Sie hydrolysierte Peptidverbindungen immer nach zwei basischen Aminosäuren. Es entstand ein für jedes Protein typisches Peptidgemisch, welches von der individuellen Verteilung der Lysine und Arginie im untersuchten Protein abhängig war (Schrattenholz 2001).

Das Trypsinverdau-Schema wird im Folgenden dargestellt (Hellman et al. 1995; Dihazi et al. 2009). Hierbei war zu beachten, dass möglichst ordentlich gearbeitet und die Arbeitsschritte so kurz wie möglich gehalten wurden, um Kontamination mit Keratin zu vermeiden.

Die zu identifizierenden Proteinspots wurden mit einer $2 \mathrm{~mm}$-Stanze aus dem Gel ausgestochen. Jeder ausgeschnittene Gelspot wurde dreimal mit destilliertem Wasser umspült. Danach inkubierte der Gelspot zunächst 15 Minuten in 50 \% igem, anschließend in $100 \%$ igem ACN. Das ACN wurde entfernt und auf den Gelspot wurden für 5 Minuten $10 \mu \mathrm{l} 100 \mathrm{mM}$ Ambic gegeben. Anschließend wurden $10 \mu \mathrm{l}$ vom $100 \%$ igem ACN hinzugegeben, sodass eine 1:2-Lösung entstand. Die Inkubationszeit betrug 15 Minuten. Nach Entfernen der Lösung mussten die Gelspots eine Stunde bei Raumtemperatur unter dem Abzug trocknen. Wurden die Proben zu diesem Zeitpunkt nicht weiter behandelt, so mussten sie bei $-20{ }^{\circ} \mathrm{C}$ eingefroren werden.

Der nächste fundamentale Abschnitt war die eigentliche Verdauung. Es wurde Verdauungspuffer ohne Trypsin angesetzt, der sich aus $1940 \mu \mathrm{l}$ destilliertem Wasser, $10 \mu \mathrm{l} 1 \mathrm{M}$ Calciumchlorid-Dihydrat und $50 \mu \mathrm{l} 1 \mathrm{M}$ Ambic zusammensetzte. Für den Erhalt einer klaren Lösung musste diese Reihenfolge zwingend eingehalten werden. $100 \mu \mathrm{l}$ vom Verdauungspuffer wurden mit 12,5 $\mu \mathrm{l}$ Trypsin vermischt. Trypsin wurde seinerseits vom Hersteller mit einem Puffer geliefert. Dabei wurden $200 \mu$ l von diesem Puffer in Trypsin gelöst, sodass eine Trypsinkonzentration von $0,1 \mu \mathrm{g} / \mu \mathrm{l}$ entstand. Auf die getrockneten Gelspots wurden $7 \mu$ l Trypsin-Verdauungspuffer gegeben, dies inkubierte 45 Minunten auf Eis. Die Gelspots wurden nach Entfernen der Lösung mit $7 \mu \mathrm{l}$ Verdauungspuffer ohne Trypsin bedeckt und anschließend zum Inkubieren über Nacht in die $37^{\circ} \mathrm{C}$-Kammer platziert.

Es wurden neue Eppendorfgefäße beschriftet, in denen die Lösung hineinpipettiert wurde. Die Gelspots wurden mit $15 \mu$ l einer Lösung bestehend aus $30 \%$ ACN und $70 \%$ 0,1\%ige TFA versetzt und für 30 Minuten in ein Ultraschallbad gestellt. Erneut wurde die Lösung abgenommen und in die Eppendorfgefäße pipettiert, denen zuvor die abpipettierte Lösung hinzugegeben wurde. Danach wurden den Gelspots 
$15 \mu \mathrm{l}$ einer zu $60 \%$ aus ACN und $40 \%$ aus $0,1 \%$ iger TFA bestehenden Lösung hinzugefügt. Die Inkubationszeit im Ultraschallbad betrug ebenfalls 30 Minuten. Die Lösung wurde den anderen Eppendorfgefäßen hinzupipettiert und die Gelspots wurden entfernt. Eppendorfgefäße mit der für den Verdau relevanten Lösung wurden für etwa 40 Minunten in der Speed-Vakuumzentrifuge getrocknet. Die Proben wurden anschließend, sofern sie nicht sofort weiter verarbeitet wurden, bis zur Analyse eingefroren.

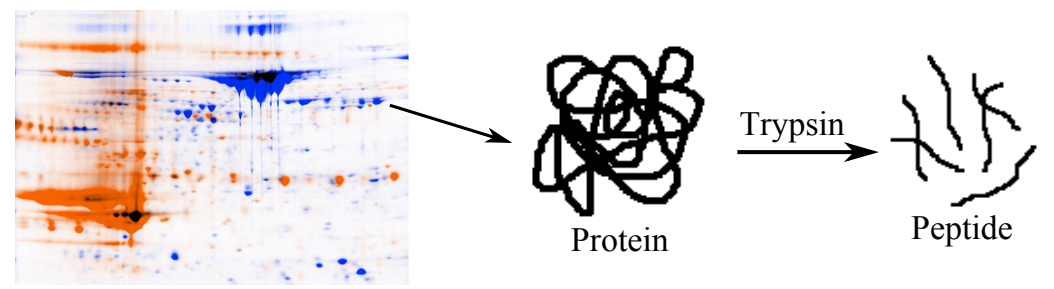

Abbildung 2.2: Trypsin-Verdau von Proteinen als erster Schritt zur Proteinidentifikation mit dem Massenspektrometer.

Nach der SDS-PAGE und dem Ausschneiden der Proteinspots erfolgte der Verdau mit der Protease Trypsin. Sie hydrolysierte Peptidverbindungen immer nach zwei basischen Aminosäuren, sodass ein für jedes Protein typisches Peptidgemisch entstand. Das Muster dieser Peptidgemische war für jedes Protein einmalig und konnte mit dem Massenspektrometer identifiziert werden (Schrattenholz 2001).

\subsection{Massenspektrometrische Methoden}

Massenspektrometrische Methoden sind eine der wichtigsten analytischen Methoden und dienen unter anderem der Identifizierung von Proteinen. Im Folgenden soll vereinfacht die Funktionsweise eines massenspektrometrischen Apparates erläutert werden (Schrattenholz 2001). Zwar gibt es verschiedene Typen von Massenspektrometer, doch erfüllen alle die Grundprinzipien. Diese werden im Folgenden erläutert. Die Funktionselemente eines Massenspektrometers sind in Abbildung 2.3 schematisch dargestellt.

Das Massenspektrometer besitzt verschiedene Bauelemente. Beginnend mit dem

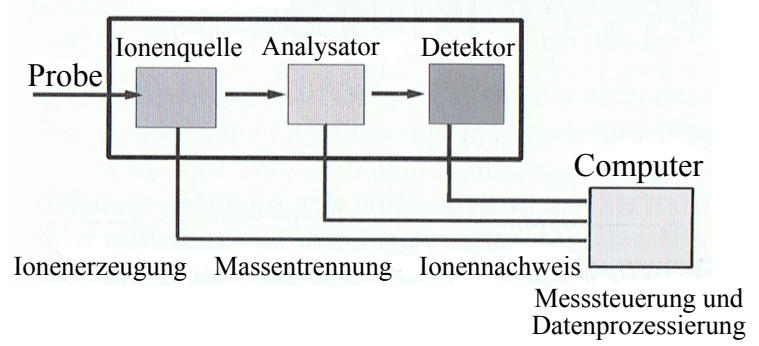

Abbildung 2.3: Funktionselemente eines Massenspektrometers (Schrattenholz 2001, S. 172)

Einlasssystem bzw. der Probenschleuse findet der Probentransfer in das Hochvakuumsystem des Massenspektrometers statt. Die Peptide werden in die Gasphase 
überführt und ionisiert. Durch eine Beschleunigungsspannung werden sie in Richtung Analysator bewegt. Die erzeugten Ionen sind dabei durch ihre spezifische Ladung $\mathrm{m} / \mathrm{z}$, ihre Geschwindigkeit und die Intensität bzw. Häufigkeit der einzelnen Ionensorte charakterisiert. Der Ionenquelle und dem Detektorsystem ist ein Massenanalysator zwischengeschaltet. Dieser lenkt die sich bewegenden Ionen durch ein senkrecht zur Beschleunigungsrichtung angelegtes Magnetfeld proportional zu ihrem m/z-Verhältnis ab und gewährleistet damit die Trennung nach Masse. Am Detektor werden die Intensitäten der Ionenströme wahrgenommen. Die Informationen aus der Ionenquelle, dem Analysator und dem Detektor werden zur Messsteuerung und Datenprozessierung an den Computer weitergeleitet (Schrattenholz 2001).

\subsubsection{MALDI-TOF-MS}

In diesem Projekt wurde die MALDI-TOF-MS (matrix assisted laser desorption ionisation time-of-flight mass spectrometry), eine sehr sensible Methode zur Identifizierung von Proteinen, benutzt. MALDI stellt eine schonende Ionisierungsmethode dar und zerstört die Moleküle beim Ionisierungsprozess nicht. Bei der MALDIMethode wird die Probe gemäß Abbildung 2.4 in eine kristalline Matrix, welche in diesem Projekt 2,5-Dihydroxybenzoesäure war, eingebettet. Diese wurde mit einem gepulsten Laserstrahl beschossen, dessen Licht sie aber stark absorbierte. Dies führte zum Verdampfen der Matrix. Dabei wurden die in der Matrix eingeschlossenen Probenmoleküle schonend und fragmentierungsarm in die Gasphase überführt. Die Analyse von Peptidgemischen mittels MALDI-TOF-MS ergibt Spektren, die Fingerabdruckqualität haben und so Proteine mittels Datenbankabgleich identifizieren können (Schrattenholz 2001).

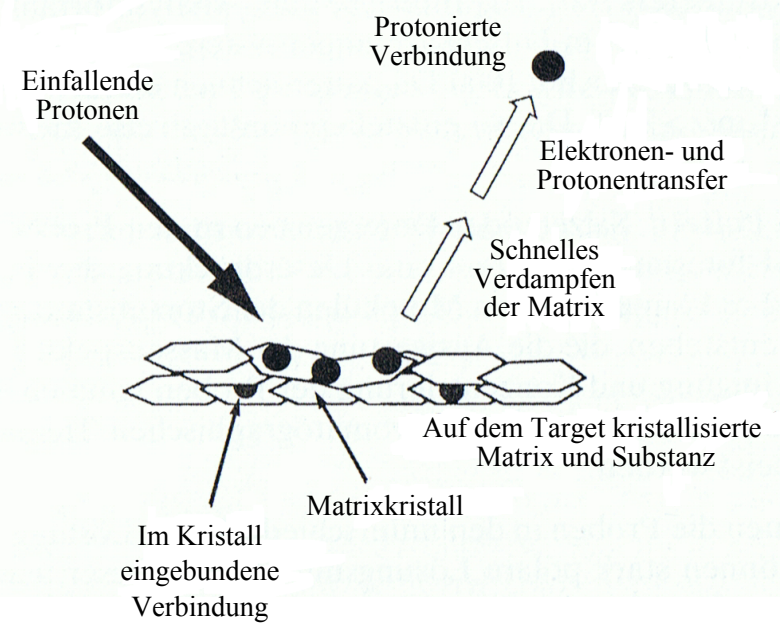

Abbildung 2.4: Die MALDI-Ionisierungsmethode (Schrattenholz 2001, S. 179) 


\subsubsection{Targetvorbereitung}

Die Vorbereitung des Targets, auf dem die Proben aufgetragen wurden, erfolgte nach dem nachfolgenden Protokoll (Hellman et al. 1995; Dihazi et al. 2009).

Die getrockneten Proben wurden in $4 \mu \mathrm{l}$ System A (0,3\%ige TFA) gelöst. Derweil wurde das Target abwechselnd mit $50 \%$ igem ACN, $100 \%$ igem ACN und Methanol gereinigt. Danach wurde das Target mit System A bedeckt, welches für einige Minuten einzog. Ein weiteres Mal wurde es mit 50 \%igem ACN und $100 \%$ igem ACN gespült. Nach vollständigem Trocknen wurde auf das Target zunächst 0,7 $\mu \mathrm{l}$ DHB pipettiert und in diese 1,4 $\mu$ l Probe gemischt. Zur Vorbereitung der Matrix wurden $20 \mathrm{mg} / \mathrm{ml}$ DHB, 0,1 \%ige TFA und $30 \%$ iges ACN gemischt, 1 Stunde inkubiert, zentrifugiert und schließlich der Überstand als Matrix verwendet. Das Target war mit Nummern versehen, sodass eine Tabelle mit Targetnummer und dazugehöriger Probe erstellt werden konnte. Das Target war bereit für das MALDI-TOF-MS, nachdem es ganz getrocknet war und sich kristalline Strukturen ausbildeten.

\subsubsection{Spektrenerfassung und Proteinidentifikation}

Mit dem Voyager-DE-STR-Massenspektrometer der Firma Applied Biosystems erfolgte die Messung der Peptidspektren. Dabei wurde mit einer Beschleunigungsspannung von $20 \mathrm{kV}$ gemessen.

Nach Messung und Anhäufung mehrerer Spektren jedes Gelspots fand eine Verarbeitung der Daten in verschiedenen Datenbanken (SwissProt, NCBInr) statt. Dabei wurde die Vorverarbeitung der Spektren von dem halbautomatischen Programm Mascot Wizzard übernommen. Der p-Wert wurde auf $<0,05$ festgelegt. Ein Protein galt als identifiziert, wenn es in der SwissProt-Datenbank die Signifikanzgrenze von 55, in der NCBInr-Datenbank von 66 überschritten hatte (Takemori et al. 2006).

\subsection{Western Blot}

Western Blot stellt eine Methode dar, bei der Proteine von einer Gelmatrix mittels elektrophoretischem Transfer auf eine Trägermembran aufgebracht werden. Dieser Vorgang wird als Blotten bezeichnet. Mithilfe dieser Methode wurden Proteine, die als interessant für das Alport Syndrom erachtet wurden, in Urinproben einzelner Mäuse analysiert. Eine Proteinkonzentration von $40 \mu \mathrm{g} / \mu \mathrm{l}$ wurden für eine gute Analyse benötigt. Es wurde sich dem gängigen Protokoll zweier Arbeitsgruppen bedient (Towbin et al. 1979; Dihazi et al. 2009).

Für die Western Blots wurden eigene Gele hergestellt. Diese bestanden aus $12 \%$ igem Trenngel und $4 \%$ igem Sammelgel. Für das Erstellen von vier $12 \%$ igen Trenngelen wurden $7 \mathrm{ml}$ destilliertes Wasser, $5 \mu \mathrm{l} 1,5 \mathrm{M}$ Tris $/ \mathrm{HCl}(\mathrm{pH}$ von 8,8) und $8 \mathrm{ml}$ 
Acrylamid unter leichtem Schwenken in einem Trichterglas gemischt. Nach Entgasen des Gefäßes wurde dieser Lösung $125 \mu \mathrm{l} 10 \%$ iges APS, $200 \mu 1$ 10\%iges SDS und $15 \mu \mathrm{l}$ TEMED zum Start der Polymerisierung hinzugegeben. Diese Lösung wurde zwischen zwei Glasplatten pipettiert, welche in einem Gestell befestigt waren. Nach vollständiger Polymerisierung wurde das $4 \%$ ige Sammelgel auf das Trenngel pipettiert. Dieses setzte sich aus $15 \mathrm{ml}$ destilliertem Wasser, 6,3 $\mathrm{ml}$ 0,5 M Tris/HCl (pH von 6,8) und 3,9 ml Acrylamid zusammen, welchem nach Entgasung $250 \mu \mathrm{l} 10 \%$ iges SDS, $125 \mu \mathrm{l} 10 \%$ iges APS und $25 \mu \mathrm{l}$ TEMED hinzugefügt wurden. In das Sammelgel wurde ein Trennkamm eingesteckt, um 10 Geltaschen mit einer Breite von $10 \mathrm{~mm}$ zu erzeugen. In diese Geltaschen wurden die Proben pipettiert, die zuvor wie folgt vorbereitet werden mussten. Die in Lysepuffer (9,5 M Urea und 2\% Chaps) gelösten Proteinproben wurden jeweils mit destilliertem Wasser auf $10 \mu \mathrm{l}$ aufgefüllt. Dieser Lösung wurden $10 \mu \mathrm{l}$ 2fach-Probenpuffer hinzugegeben, kurz zentrifugiert und 10 Minuten bei $96^{\circ} \mathrm{C}$ denaturiert. Anschließend erfolgte ein kurzes Abkühlen der Proben auf Eis.

Zuvor wurde dem $950 \mu \mathrm{l}$ umfassenden 4fach-Probenpuffer $50 \mu \mathrm{l}$ 2-Mercaptoethanol hinzugefügt. Der 4fach-Probenpuffer bestand seinerseits aus 4,3 $\mathrm{ml}$ destilliertem Wasser, 2,5 ml 0,5 M Tris/HCl (pH von 6,8), $5 \mathrm{ml}$ Glycerin, $8 \mathrm{ml} 10 \%$ iges SDS und $200 \mu \mathrm{l}$ $1 \%$ igem Bromphenolblau. Nun wurden $500 \mu \mathrm{l}$ 4fach-Probenpuffer zusammen mit $500 \mu \mathrm{l}$ destilliertem Wasser in einem neuen Eppendorfgefäß gemischt und somit ein 2fach-Probenpuffer hergestellt.

Die Gelkassetten wurden in die Elektrophoresebox eingesteckt und mit Elektrophoresepuffer innen ganz und außen zur Hälfte aufgefüllt. Der 1fach-Elektrophoresepuffer setzte sich aus $800 \mathrm{ml}$ destilliertem Wasser und $200 \mathrm{ml}$ 5fach-Elektrophoresepuffer zusammen, der seinerseits aus $30 \mathrm{~g}$ Tris, $144 \mathrm{~g}$ Glycin und $10 \mathrm{~g}$ SDS bestand, die in 21 destilliertem Wasser gelöst waren. $8 \mu \mathrm{l}$ Markerprotein wurden in die äußerste Geltasche auf der linken Seite pipettiert, die Proben in die weiteren acht Geltaschen, sodass eine frei blieb. Nun wurde die Elektrophorese begonnen, welche die zweite Dimension gemäß Proteomics darstellte. Das Elektrophoreseprogramm beinhaltete ein kurzes Anlaufen bei einer Spannung von 150 V, 10 Minuten bei $180 \mathrm{~V}$ und etwa 40 - 60 Minuten bei $200 \mathrm{~V}$.

Nun begann die Vorbereitung für das Blotten. Ein Gelkassettenhalter wurde nach dem Sandwich-Prinzip bestückt. So war es notwendig folgende Reihenfolge einzuhalten: Schwarze Seite des Gelkassettenhalters, Vlies, Filterpapier, Polyacrylamidgel, Nitrozellulosemembran, Filterpapier, Vlies und schließlich die weiße Seite des Gelkassettenhalters. Dabei war zu beachten, dass Luftblasen durch vorsichtiges Ausstreichen des Filterpapiers auf der Membran mittels einer kleinen Rolle entfernt wurden. Der bestückte Kassettenhalter wurde mit seiner schwarzen Seite so in eine weitere Elektrophoresebox gesteckt, dass die schwarze Seite dem gefrorenen Eis 
zugewandt war. Die Box wurde mit einfachem Transferpuffer befüllt. Beim Herstellen des Transferpuffers war es wichtig, $200 \mathrm{ml} 5$ fach-Transferpuffer sowohl mit $600 \mathrm{ml}$ destilliertem Wasser als auch mit $200 \mathrm{ml}$ Methanol zu mischen. In 21 ffachTranferpuffer waren $144 \mathrm{~g}$ Glycin, $5 \mathrm{~g}$ SDS und 30,3 g Tris gelöst. Der Vorgang des Blottens fand über Nacht bei $40 \mathrm{~V}$ und $4{ }^{\circ} \mathrm{C}$ in der Kühlkammer statt.

Nach dem Blotten wurden die Blots mit Ponceau-Lösung für 2 Minuten gefärbt, danach kurz in $5 \%$ ige Essigsäure getaucht und in Waschpuffer geschwenkt. Anschließend wurden die Blots zum Trocknen unter dem Abzug platziert. Der 1fache Waschpuffer setzte sich aus $800 \mathrm{ml}$ destilliertem Wasser und $200 \mathrm{ml}$ 5fach-Waschpuffer zusammen. Beim Erstellen des 5fach-Waschpuffers war darauf Acht zu geben, dass nach Lösen von 12,11 g Tris und 58,44 g Natriumchlorid in einem Liter destilliertem Wasser der $\mathrm{pH}$ durch vorsichtige Titrierung mit Salzsäure auf 7,5 eingestellt wurde. Die Lösung wurde auf eine Menge von 21 mit destilliertem Wasser aufgefüllt.

Die getrockneten Blots mussten zwei Stunden in Blockpuffer (5 g Milchpulver und $100 \mathrm{ml}$ Waschpuffer) in der $37^{\circ} \mathrm{C}$-Wärmekammer inkubieren. Primärantikörper wurden in Blockpuffer gelöst; dies erfolgte sowohl nach Herstellerangabe als auch nach Austestung der Antikörper in verschiedenen Verdünnungen. Der Primärantikörper musste über Nacht den Blot bedecken. Am nächsten Tag wurde die Membran drei Mal à 15 Minuten in der $37^{\circ} \mathrm{C}$-Wärmekammer in Waschpuffer geschwenkt. Dann wurde der Sekundärantikörper mit Blockpuffer auf 1:2000 verdünnt und für 2 Stunden bei $37^{\circ} \mathrm{C}$ auf die Membran gegeben. Es wurden Anti-Rabbit-, Anti-Goat- und Anti-Sheep-Sekundärantikörper verwendet. Ein weiteres Mal wurde die Membran dreimal à 15 Minuten mit Waschpuffer gewaschen, bevor diese mittels Druckluft getrocknet und mit dem Fuji-FLA-5100-Fluoreszenz-Laserscanner bei $635 \mathrm{~nm}$ gescannt werden konnte. Dabei wurden der rote Laser und der LPR-Filter verwendet. Die Auswertung der Western Blots erfolgte mit dem Programm ImageJ.

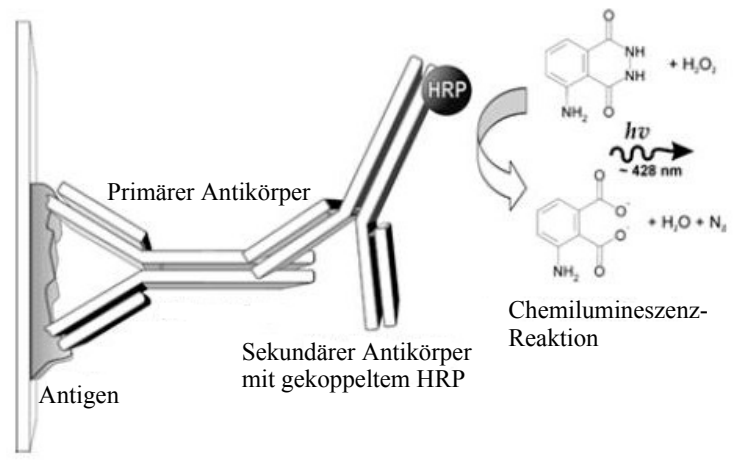

Abbildung 2.5: Schematische Darstellung der Immundetektion.

Zunächst bindet ein Primärantikörper an sein spezifisches Antigen, welches auf einer Membran fixiert ist. Der Sekundärantikörper ist mit dem Enzym HRP (Peroxidase aus dem Meerrettich) gekoppelt und bindet an den Primärantikörper. Hierdurch wird die sogenannte Chemilumineszenz-Reaktion ausgelöst, bei der HRP die Umsetzung von Luminol in seine oxidierte Form unter Freisetzung von Licht katalysiert. Das hier entstehende Fluoreszenzsignal des nachzuweisenden Proteins wird mit dem Scanner detektiert. Bildquelle: http://upload.wikimedia.org/wikipedia/commons/b/b3/ECL.jpg, abgerufen am 09.06.2012 


\section{Ergebnis}

In dieser Doktorarbeit soll der Urin von Wildtyp- und COL4A3-Knockout-Mäusen zum frühen Krankheitszeitpunkt von 4,5 und 6 Wochen untersucht werden. Das Ziel dieser Arbeit besteht darin, Proteinmarker zu finden, die im Urin von COL4A3Knockout-Mäusen klinisch relevant hochreguliert und spezifisch für das AlportSyndrom sind.

Die Ergebnisse der Arbeit lassen sich in verschiedene Teilbereiche gliedern: Zunächst wird mit der Darstellung von histologischen und elektronenmikroskopischen Schnitten begonnen. Es folgen die Ergebnisse der Proteomic-Analysen. Hierbei werden zuerst die 2D-Gele präsentiert und die identifizierten Proteine tabellarisch aufgeführt. Danach wird auf die Auswertung der 2D-DIGE-Gele eingegangen. Nach der Auswertung der Proteinregulation in den 2D-DIGE-Gelen folgen die Ergebnisse der Western Blots.

Die Ergebnisse dieser Arbeit wurden mit einem Statistiker der Universität Göttingen besprochen; dieser hat seine Zustimmung erteilt.

\subsection{Darstellung der histologischen und elektronenmikroskopischen Präparate}

In diesem Kapitel werden histologische Nierenpräparate von Wildtyp- und COL4A3Knockout-Mäusen im Stadium von 4,5 und 6 Wochen sowie deren Aufnahmen zum Zeitpunkt von 4,5 Wochen mithilfe eines Elektronenmikroskops vorgestellt. Die histologischen Schnitte wurden freundlicherweise von unserer Medizinisch-technischen Assistentin Andrea Bernhard angefertigt und für diese Arbeit zur Verfügung gestellt. Die elektronenmikroskopischen Bilder stammen aus unserer Arbeitsgruppe, der Arbeitsgruppe von Prof. Dr. med. Oliver Gross, Abteilung Nephrologie und Rheumatologie in Göttingen.

In Abbildung 3.1 sind histologische Schnittpräparate von Wildtyp- und COL4A3Knockout-Nieren zum Zeitpunkt von 4,5 Wochen, in Abbildung 3.2 zum Zeitpunkt von 6 Wochen dargestellt. In beiden Abbildungen entsprechen die Wildtyp-Nieren normalen histologischen Gegebenheiten. Der Nierenkortex besitzt Glomerula ohne Zell- oder Matrixvermehrung mit typischen Basalmembranen. Das Mesangium ist nicht zellvermehrt. Die proximalen Nierentubuli sind aus isoprismatischem Epithel 


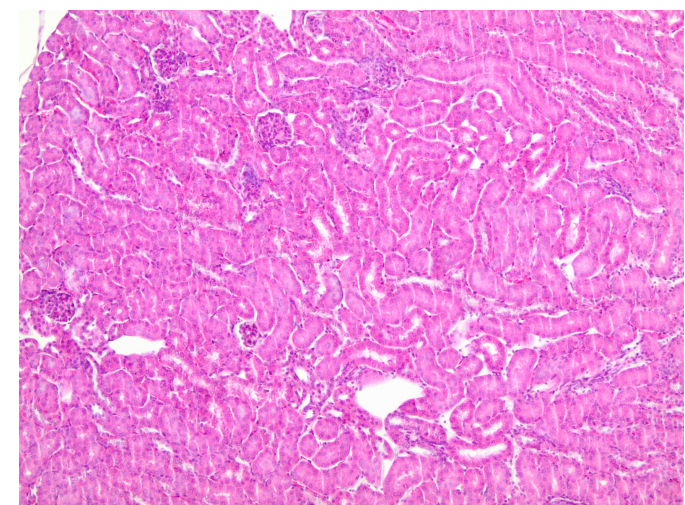

(a) Wildtyp bei 10-facher Vergrößerung

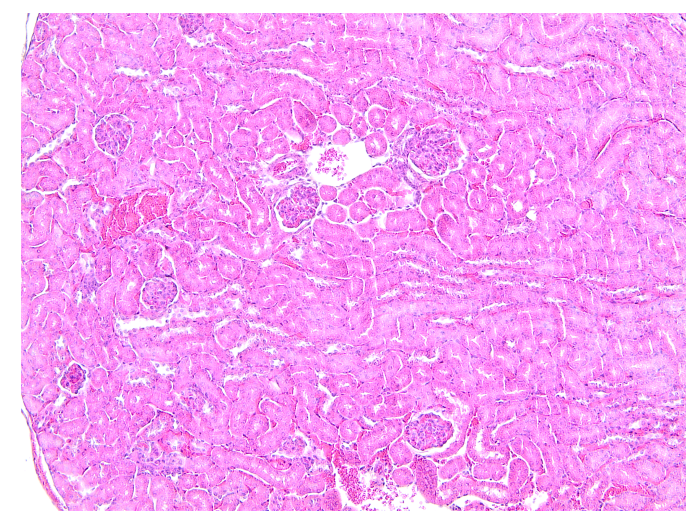

(c) COL4A3 -/- bei 10-facher Vergrößerung

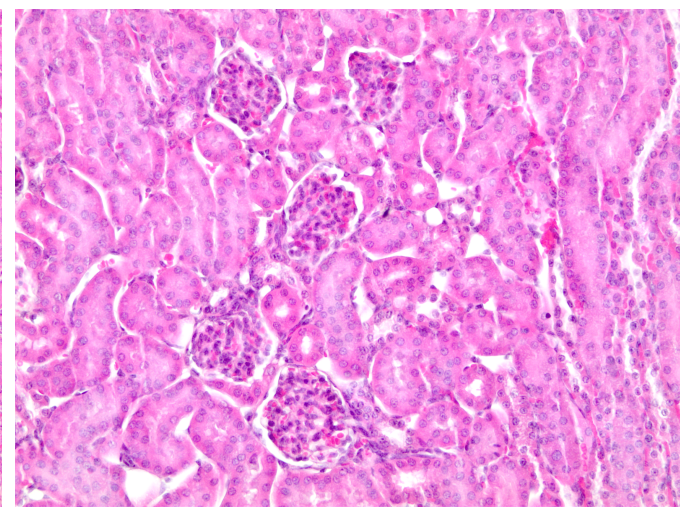

(b) Wildtyp bei 20-facher Vergrößerung

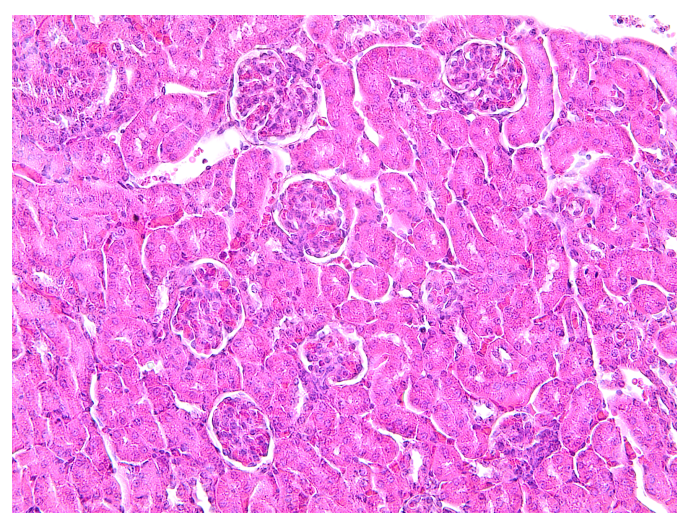

(d) COL4A3 -/- bei 20-facher Vergrößerung

Abbildung 3.1: Histologische Nierenschnitte von Wildtyp- und COL4A3-Knockout-Mäusen zum Zeitpunkt von 4,5 Wochen.

Die Präparate sind mit HE (Hämatoxylin-Eosin) gefärbt. In (a) und (c) sind die histologischen Schnitte bei 10-facher Vergrößerung digitalisiert, was der Übersicht dient. Die Unterabbildungen (b) und (d) zeigen eine 20-fache Vergrößerung.

aufgebaut. Lumenwärts ist ihr typischer hoher Bürstensaum sichtbar, was einen ausgefransten Eindruck hervorruft. Ihr basales Labyrinth bestehend aus $\mathrm{Na}^{+} / \mathrm{K}^{+}$ATPasen ist durch die eosinophile Mehrverfärbung zu erkennen. Die distalen Tubuli besitzen ebenfalls isoprismatisches Epithel, sind allerdings regelrecht zum Lumen hin glatt begrenzt. Ihr basales Labyrinth ist erkennbar. Im Interstitium lassen sich keine Infiltrate aus Lymphozyten, Monozyten oder Granulozyten beobachten.

Die Schnittpräparate der COL4A3-Knockout-Nieren in den Abbildungen 3.1c und 3.1d zeigen ein regelrechtes Nierenparenchym. In diesem Stadium sind noch keine interstitiellen Fibrinablagerungen und nur wenige vakuoläre Strukturen im Tubuluslumen der proximalen oder distalen Tubuli erkennbar. Die Nieren sind in diesem frühen Erkrankungsstadium noch verhältnismäßig unversehrt.

Die COL4A3-Knockout-Nieren im Stadium von 6 Wochen weichen stärker von der gesunden Nierenparenchymstruktur ab. In den Abbildungen 3.2c und 3.2d wird deutlich, dass viele Glomerula einen strukturellen Wandel erfahren. Die Mesangiumzellen proliferieren und die Struktur der Glomerula wirkt an manchen Stellen aufgehoben. 


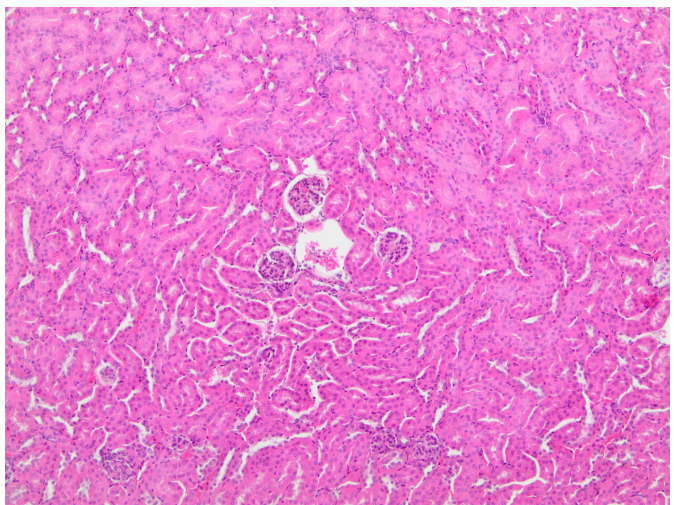

(a) Wildtyp bei 10-facher Vergrößerung

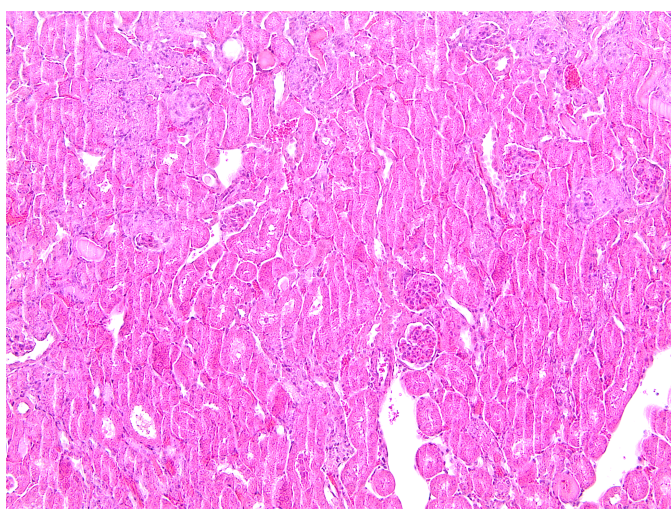

(c) COL4A3 -/- bei 10-facher Vergrößerung

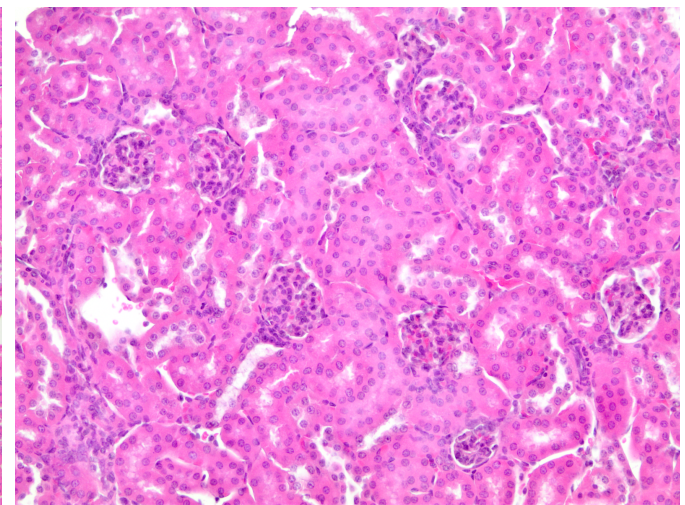

(b) Wildtyp bei 20-facher Vergrößerung

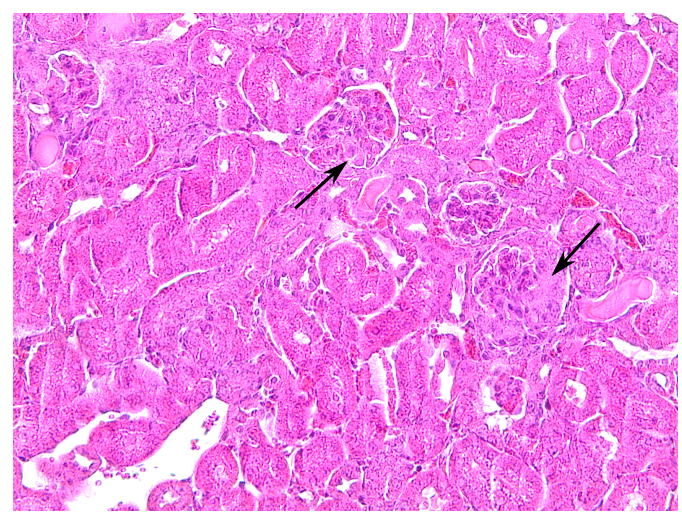

(d) COL4A3 -/- bei 20-facher Vergrößerung

Abbildung 3.2: Histologische Nierenschnitte von Wildtyp- und COL4A3-Knockout-Mäusen zum Zeitpunkt von 6 Wochen.

Die Präparate sind HE-gefärbt. Die Pfeile zeigen auf den beginnenden strukturellen Wandel der Glomerula, bei denen eine Halbmondbildung mit Fibrinablagerungen und eine Akkumulation der extrazellulären Matrix zu verzeichnen ist.

Es lässt sich ein glomerulärer Halbmond mit beginnender Fibrinablagerung und eine Akkumulation der extrazellulären Matrix erkennen. Zudem sind Vakuolen-artige Einschlüsse in vielen Tubuluslumen zu sehen, in welchen sich Proteine befinden. Darüber hinaus sind extrakapilläre Fibrinablagerungen als eosinophile, teilweise zylinderförmige Strukturen im Parenchym zu finden. Dennoch sind noch keine interstitiellen Entzündungszellen sichtbar.

Die in Abbildung 3.3a und 3.3c PAS-gefärbten Wildtyp-Schnitte zeigen jeweils ein regelrechtes Nierenparenchym. Auch das Schnittpräparat der gezeigten 4,5 Wochen alten COL4A3-Knockout-Niere in Abbildung 3.3b weist keine besonderen pathologischen Veränderungen auf. Die Nierenglomerula wirken homogen ohne mesangiale Proliferationen. Es sind gelegentlich schwarze punktförmige Artefarkte im Parenchym zu finden.

Der histologische Schnitt durch eine COL4A3-Knockout-Niere im Stadium von 6 Wochen in Abbildung $3.3 \mathrm{~d}$ zeigt pathologische Veränderungen. Wie in Abbildung 3.2d verändert sich die Architektur der Glomerula. Die Mesangiumzellen proliferie- 


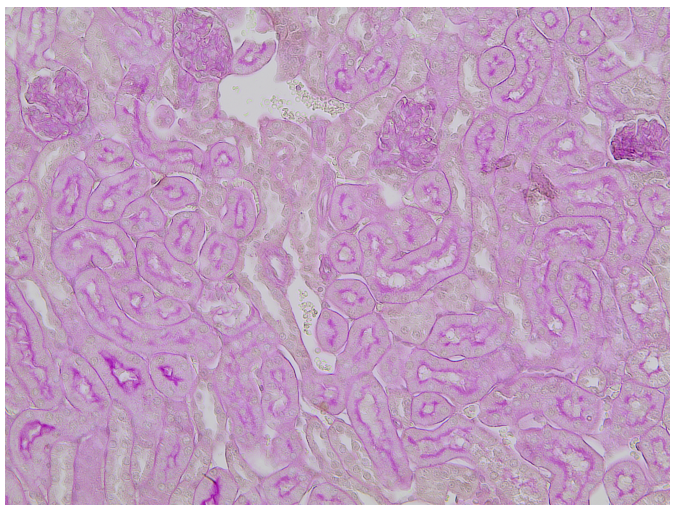

(a) Wildtyp von 4,5 Wochen bei 20-facher Vergrößerung

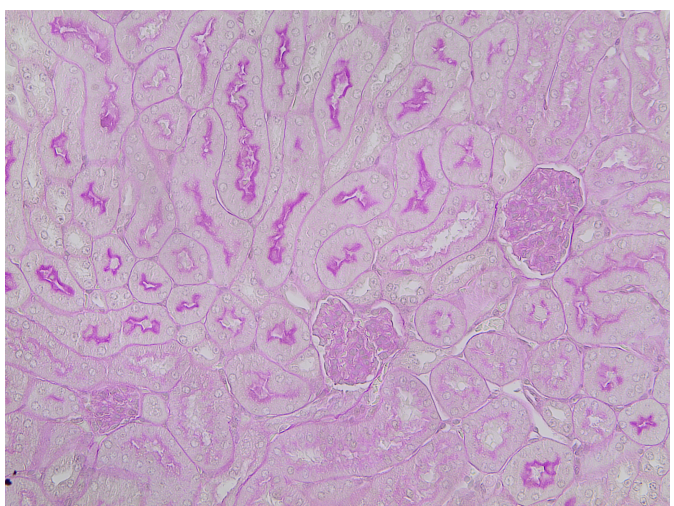

(c) Wildtyp von 6 Wochen bei 20-facher Vergrößerung

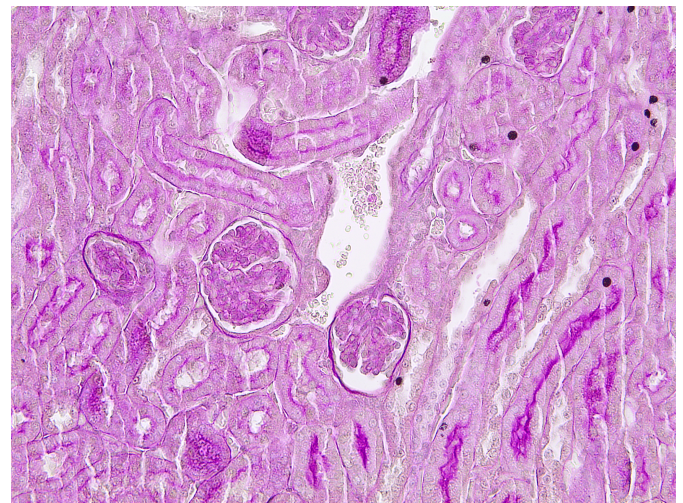

(b) COL4A3 -/- von 4,5 Wochen bei 20facher Vergrößerung

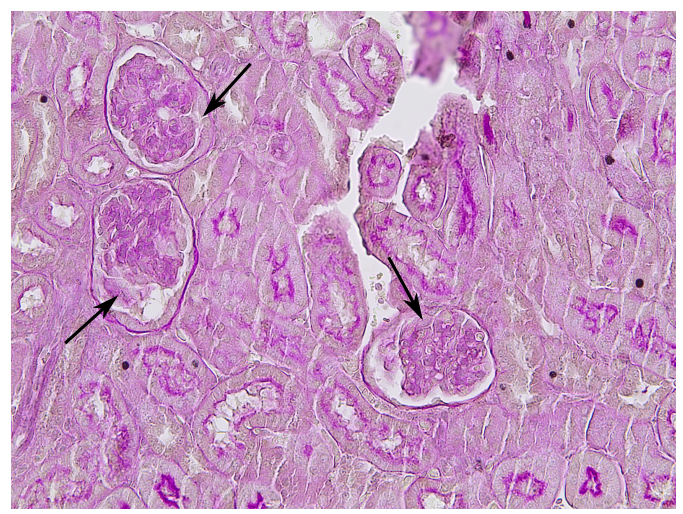

(d) COL4A3 -/- von 6 Wochen bei 20-facher Vergrößerung

Abbildung 3.3: Histologische Nierenschnitte von Wildtyp- und COL4A3-Knockout-Mäusen zum Zeitpunkt von 4,5 und 6 Wochen.

Die Präparate sind mit PAS (Perjodsäure-Schiffsches Reagenz) gefärbt. Die Pfeile weisen auf die veränderte Struktur der Glomerula hin.

ren. Zudem sind vakuoläre Strukturen in einigen Tubuluslumen zu erkennen, welche Proteine enthalten. Weder extrakapilläre Fibrinablagerungen noch interstitielle Entzündungszellen sind erkennbar. Auch hier sind gelegentlich dunkle, kreisförmige Artefarke ohne pathologische Konsequenz zu sehen.

Zusammenfassend lässt sich sagen, dass die Nierenanschnitte von COL4A3-KnockoutMäusen im Stadium von 4,5 Wochen den Präparaten gesunder Mäuse noch sehr ähneln. Erst im Stadium von 6 Wochen ändert sich das Nierenparenchym durch pathologische Matrixvermehrung, erhöhter mesangialer Zellzahl und beginnenden tubulären Schäden.

Auf den elektronenmikroskopischen Aufnahmen einer COL4A3-Knockout-Niere im Stadium von 4,5 Wochen (Abb. 3.4b) sind keine pathologischen Veränderungen feststellbar. Die Podozyten-Fußfortsätze sind noch erhalten. Die glomeruläre Basalmembran ist noch nicht signifikant verdünnt, verdickt oder aufgesplittert und weist ihr typisches streifenförmiges Muster aus Lamina rara interna, Lamina densa und La- 
mina rara externa auf. Zudem ist keine Fibrose oder ein Einbau von fibrillärem Kollagen zu verzeichnen.

Weder ein histologisches noch elektronenmikroskopisches Präparat zeigt im frühen Stadium sichere Hinweise einer Nierenschädigung im Rahmen des Alport-Syndroms. Im nächsten Abschnitt wird sich zeigen, dass im Gegensatz zu diesen geringen histopathologischen Veränderungen bereits zum frühen Krankheitszeitpunkt Proteine im Urin auftreten, die als mögliche Biomarker fungieren könnten.

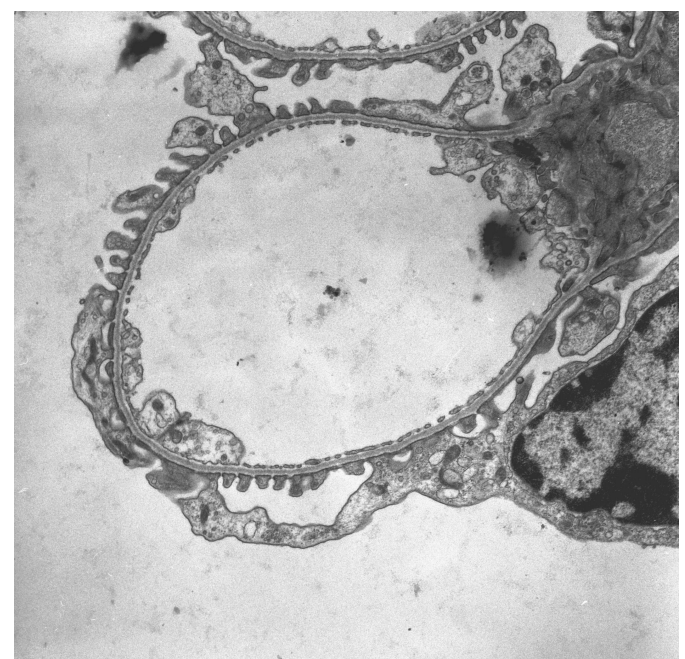

(a) Wildtyp bei 7000-facher Vergrößerung

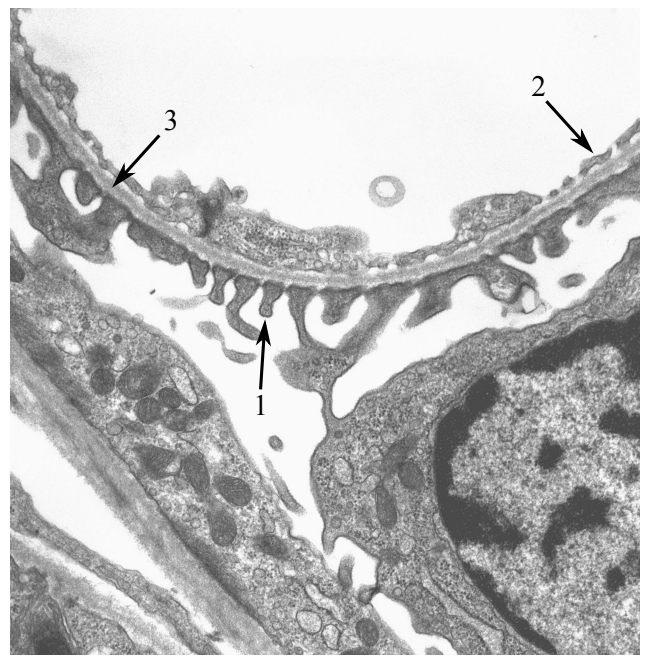

(b) COL4A3 -/- bei 12000-facher VergröBerung

Abbildung 3.4: Elektronenmikroskopische Nierenschnitte von Wildtyp- und COL4A3-Knockout-Mäusen zum Zeitpunkt von 4,5 Wochen.

Selbst im elektronenmikroskopischen Präparat ist es schwierig, im frühen Stadium pathologische Veränderungen festzustellen. Dieses Bild wurde von unserer Arbeitsgruppe, der Arbeitsgruppe von Prof. Dr. med. Oliver Gross, Abteilung Nephrologie und Rheumatologie in Göttingen, zur Verfügung gestellt. 1 Podozyten-Fußfortsatz, 2 Endothel, 3 Glomeruläre Basalmembran.

\subsection{Darstellung der 2D-Gele}

In der Arbeit werden jeweils drei 2D-Gele aus den Wildtyp- und den COL4A3Knockout-Urinproben in den Stadien 4,5 und 6 Wochen erstellt. Nur einige 2D-Gele werden als repräsentative Gele im Rahmen dieser Arbeit vorgestellt. Für die 2DGel-Erstellung wird jeweils der Mäuseurin gepoolt, d.h. der Urin von vier Mäusen wird zu gleichen Anteilen in ein gemeinsames Eppendorfgefäß gegeben, gemischt und die Proteinkonzentration nach Bradford bestimmt. Für ein 2D-Gel sind $150 \mu \mathrm{g}$ Proteinprobe nötig. Demnach ist für die Erstellung von 2D-Gelen aus Wildtyp-Urin eine höhere Urinmenge erforderlich, da Wildtyp-Mäuse natürlicherweise sehr wenig Protein in den Urin ausscheiden. Die COL4A3-Knockout-Mäuse haben pathophysiologisch eine Proteinurie, was eine geringere Urinmenge erfordert. Die Erstellung 
jedes 2D-Gels unterzieht sich gleichen Bedingungen und Arbeitsschritten, um einen guten Vergleich zu gewährleisten. Im Folgenden werden die Urinproteomprofile überlappt dargestellt, was mit dem Programm Delta 2D möglich ist. Dies erleichtert den Vergleich zwischen den Proteinmustern der 2D-Gele.

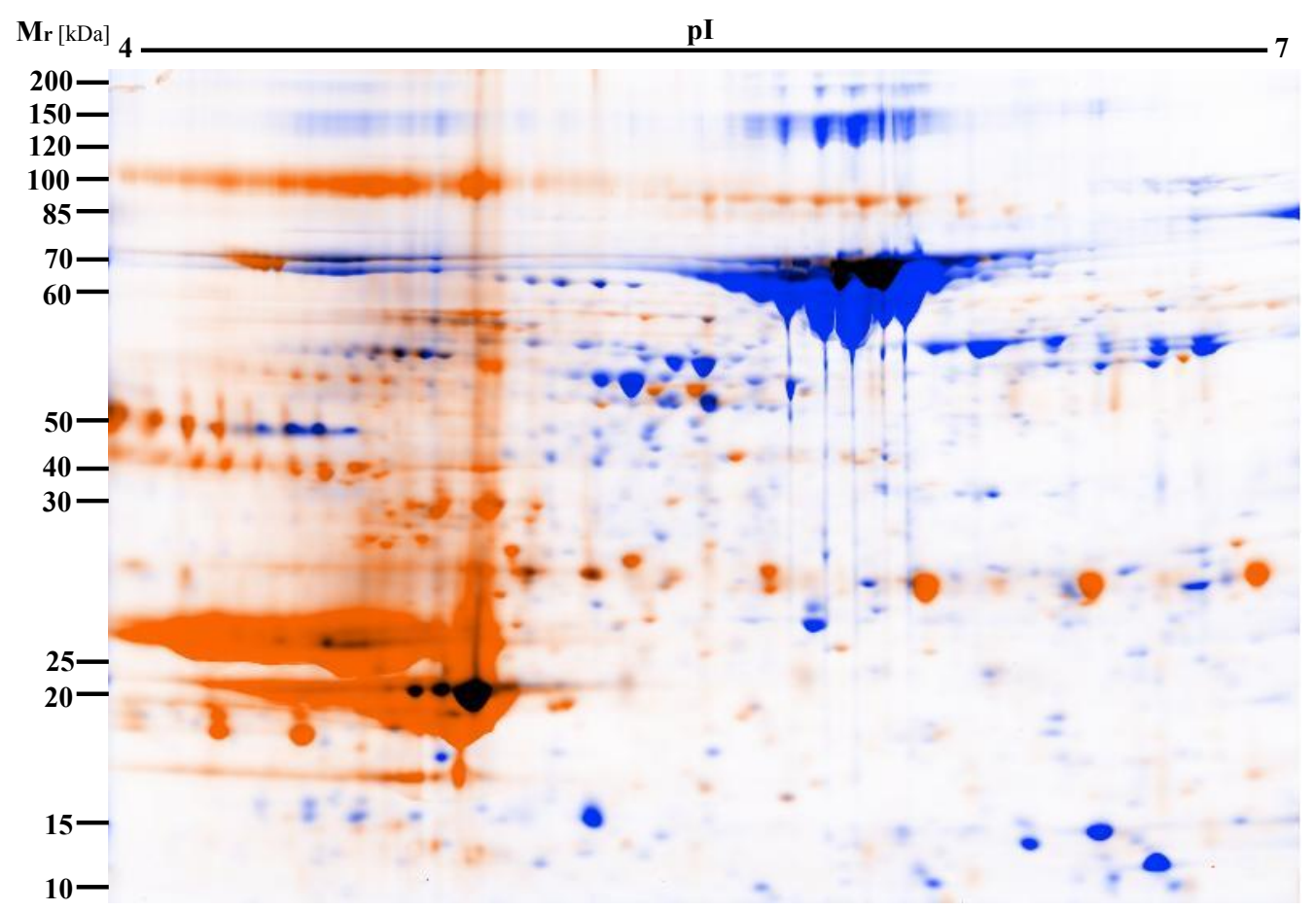

Abbildung 3.5: Urinproteomprofil der Wildtyp- und COL4A3-Knockout-Mäuse im Stadium von 4,5 Wochen. Die Abbildung zeigt die Urinproteomprofile von Wildtyp-Mäusen (orange dargestellt) und COL4A3-Knockout-Mäusen (blau dargestellt) im Vergleich. Dazu wird der Urin von jeweils vier Mäusen zuvor gepoolt. Pro 2D-Gel werden $150 \mu \mathrm{g}$ benötigt. Die Proteine werden zunächst nach ihrem isoelektrischen Punkt (pI), im Anschluss nach ihrer Masse $\left(\mathrm{M}_{\mathrm{r}}\right)$ getrennt. Dieses 2D-Gel macht deutlich, dass sich das Urinproteomprofil von Wildtyp-Mäusen stark von dem der COL4A3-Knockout-Mäuse im Stadium von 4,5 Wochen unterscheidet. Nur wenige Proteine überlappen sich vollständig (schwarzer Bereich).

Das Proteomprofil des Wildtyp-Urins zum Zeitpunkt von 4,5 Wochen unterscheidet sich kaum von dem zum Zeitpunkt der 6. Lebenswoche. Es zeigt sich dennoch ein großer Unterschied beim Vergleich zwischen Wildtyp- und COL4A3-KnockoutUrinproben im Stadium von 4,5 Wochen in Abbildung 3.5. Das Überlappen dieser 2D-Gele mit dem Programm Delta 2D ist schwierig, da die Urinproteomprofile sehr voneinander abweichen. Das Urinproteomprofil der COL4A3-Knockout-Mäuse (blau markiert) weist andere Proteinspots auf im Vergleich zum Wildtyp-Urinproteom (orange markiert). Nur wenige als schwarz dargestellte Bereiche lassen sich in beiden Urinproteomprofilen wiederfinden. Ähnliches ist im Stadium von 6 Wochen in Abbildung $3.6 \mathrm{zu}$ beobachten. Hier unterscheiden sich die Urinproteomprofile von Wildtyp- und COL4A3-Knockout-Mäusen ebenfalls deutlich. Nur wenige Proteine lassen sich vollständig überlappen. 


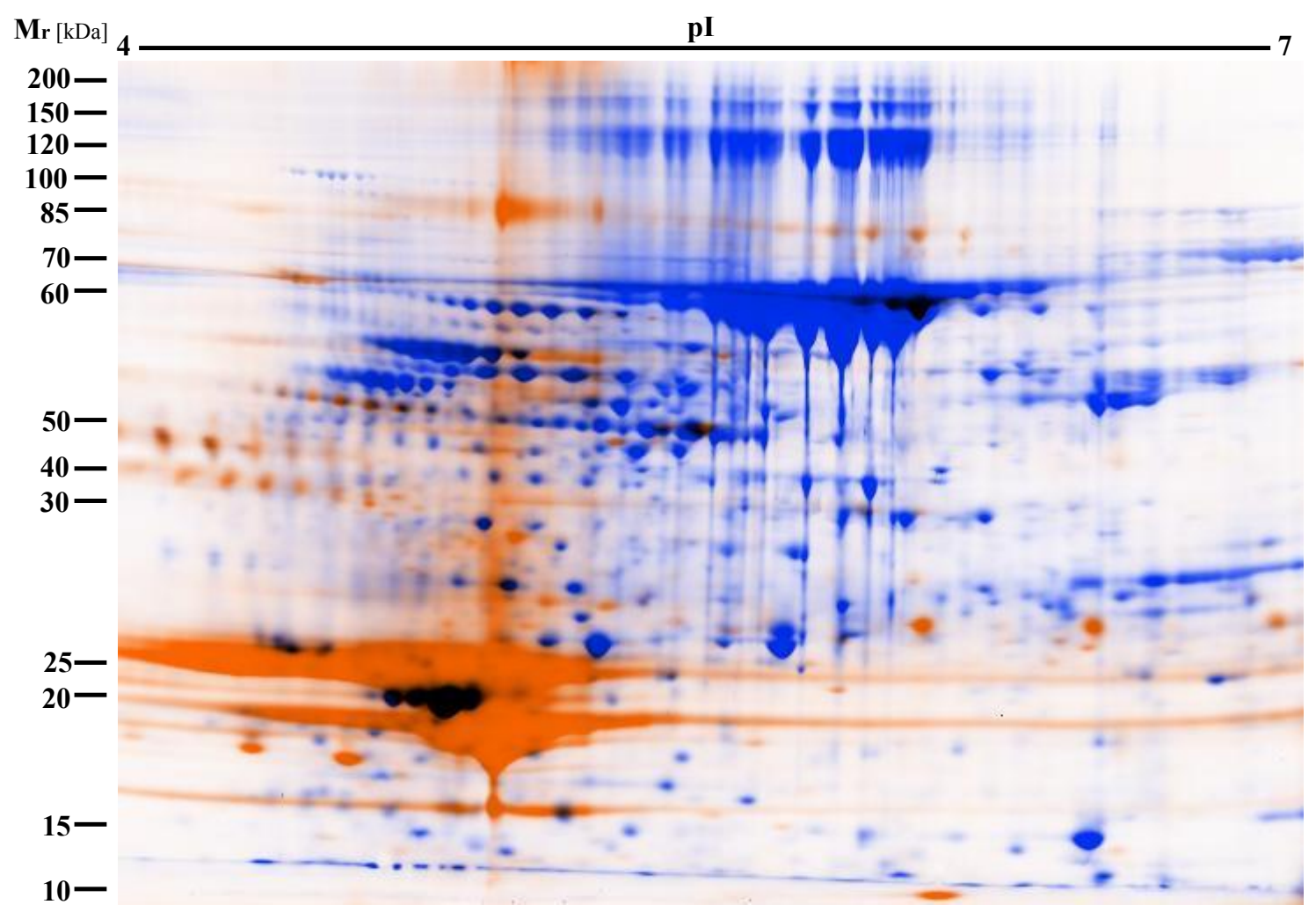

Abbildung 3.6: Urinproteomprofil der Wildtyp- und COL4A3-Knockout-Mäuse im Stadium von 6 Wochen im Vergleich.

Blau sind Proteine der COL4A3-Knockout-Mäuse und orange Proteine der Wildtyp-Mäuse. Überlappende Bereiche stellen sich schwarz dar. Zur Erstellung der 2D-Gele werden jeweils $150 \mu \mathrm{g}$ Protein auf einem $11 \mathrm{~cm}$ langen IPG-Streifen ( $\mathrm{pH} \mathrm{4-7,} \mathrm{Bio-Rad)} \mathrm{fokussiert,} \mathrm{dessen}$ Proteine anschließend mittels SDS-PAGE nach ihrer Masse $\left(\mathrm{M}_{\mathrm{r}}\right)$ aufgetrennt werden. Es lässt sich eine erhebliche Abweichung zwischen den beiden Proteomprofilen feststellen.

Die Urinproteomprofile von COL4A3-Knockout-Mäusen in den Stadien 4,5 und 6 Wochen stimmen der Überlappung nach weitgehend miteinander überein (siehe Abb. 3.7). Nur wenige Proteinspots lassen sich nicht vollständig übereinander legen. In der Abbildung fällt jedoch auf, dass in manchen Arealen die orange markierten Proteine überwiegen, hingegen in anderen Arealen blau markierte Proteine im Vordergrund stehen.

Es lassen sich Proteinspots feststellen, die zwar in den 2D-Gelen des COL4A3Knockout-Urins zu finden sind, sich aber nicht in den 2D-Gelen des Wildtyp-Urins zeigen. Diese und viele weitere Proteinspots werden in einem nächsten Schritt identifiziert. 


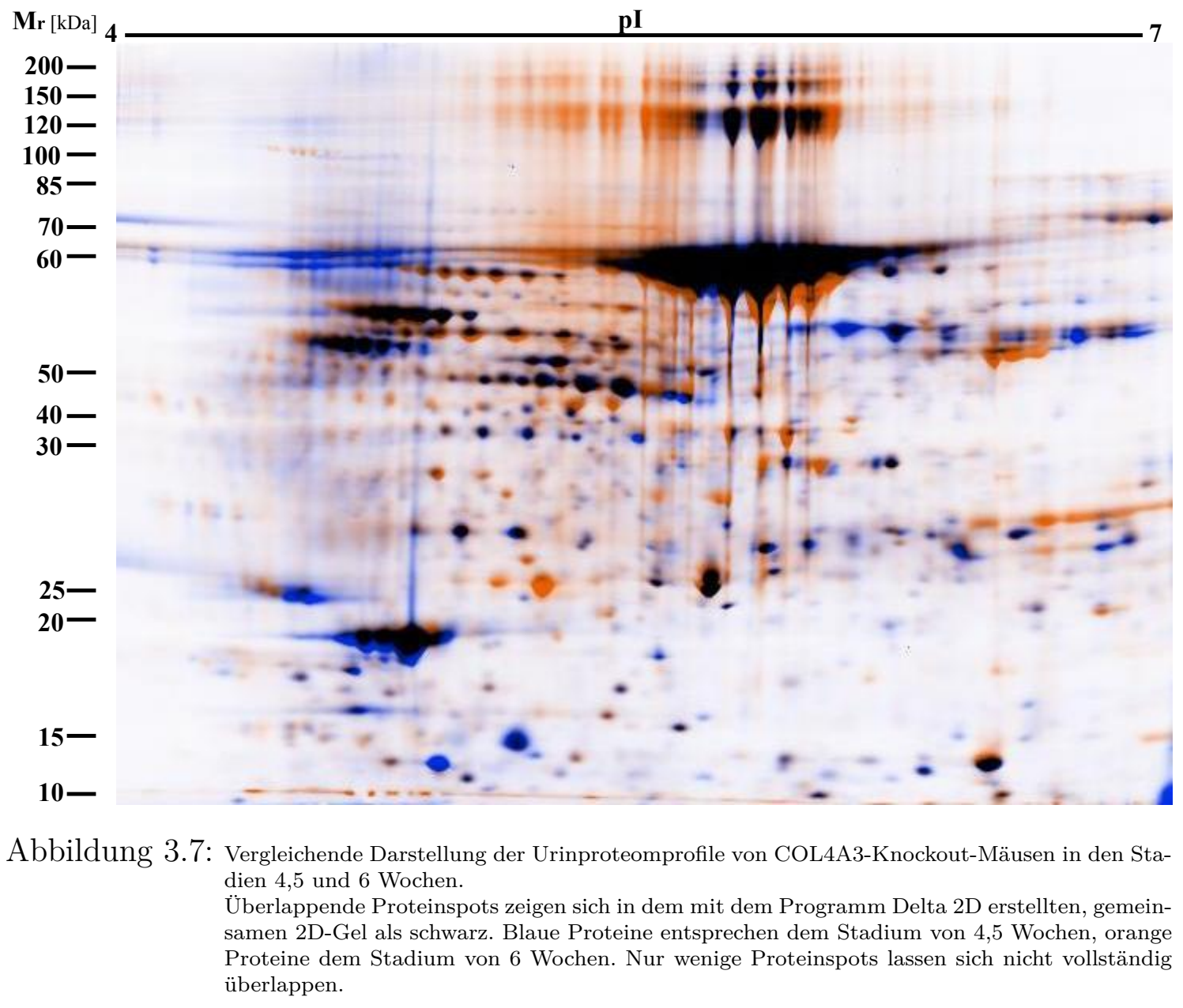

\subsubsection{Identifizierung der Urinproteine mit MALDI-TOF-MS}

Insgesamt können 207 Proteinspots mit MALDI-TOF-MS identifiziert werden. Der Begriff Spot meint dabei ein aus dem 2D-Gel ausgeschnittenes Protein, welches Trypsin-verdaut und mit dem Massenspektrometer identifiziert wird. Im Folgenden sind die Proteinspots in den 2D-Gelen mit Nummern markiert. Dessen dazugehörige identifizierte Proteine sind der Tabelle 3.1 auf Seite 55 zu entnehmen.

Es ist auffällig, dass verschiedene Proteinspots in einem 2D-Gel das gleiche Protein ergeben, obwohl die Proteinspots unterschiedlich im Gel positioniert sind. Zum einen handelt es sich dabei um modifizierte Proteine, die sich in ihrem pI-Wert nur minimal differenzieren. Sie entstehen durch posttranslationale Modifizierung. Es resultieren unterschiedlich geladene Proteinseitenketten. Heterogene Phosphorylierungen eines Proteins ergeben eine Serie von Proteinspots, die die gleiche Masse haben, in ihrem pI-Wert aber etwas voneinander abweichen (Seo und Lee 2004). Dies ist in allen Abbildungen 3.8-3.11 zu beobachten. Als Beispiel lässt sich in Abbildung 3.10 die Proteinspot-Serie 180-183 nennen. Dabei handelt es sich um Alpha-1-antitrypsin $1-1$. 
Zudem existieren modifizierte Proteine, dessen Proteinspots sich sowohl in ihrer Masse als auch in ihrem isoelektrischen Punkt unterscheiden. Sie entstehen beispielsweise durch posttranslationale Glykosylierung (Seo und Lee 2004). Ein Vertreter wäre Vitamin D-binding protein in den Abbildungen 3.9 und 3.10. Desweiteren existieren Proteinfragmente des Albumins, die sich in Masse und pI-Wert unterscheiden. In Abbildung 3.9 sind insgesamt 32 Proteinspots als Albumin identifiziert.

Aufgrund der verschiedenen modifizierten Proteine und der vielen Albuminfragmente können insgesamt mehr Proteine mit MALDI-TOF-MS analysiert als unterschiedliche Proteine identifiziert werden.

Mithilfe der Überlappungstechnik lassen sich bereits in Kapitel 3.2 Proteinspots finden, die nur in den 2D-Gelen von COL4A3-Knockout-Mäusen zu beiden untersuchten Zeitpunkten vorkommen, jedoch nicht bei den Wildtyp-Mäusen. Mittels MALDI-TOF-MS können diese Proteine identifiziert werden: Plasminogen, Serum amyloid P-component, Antithrombin III, Serine protease inhibitor A3K, Haptoglobin und Parvalbumin. So wird bereits eine erste Auswahl möglicher Biomarker getroffen.

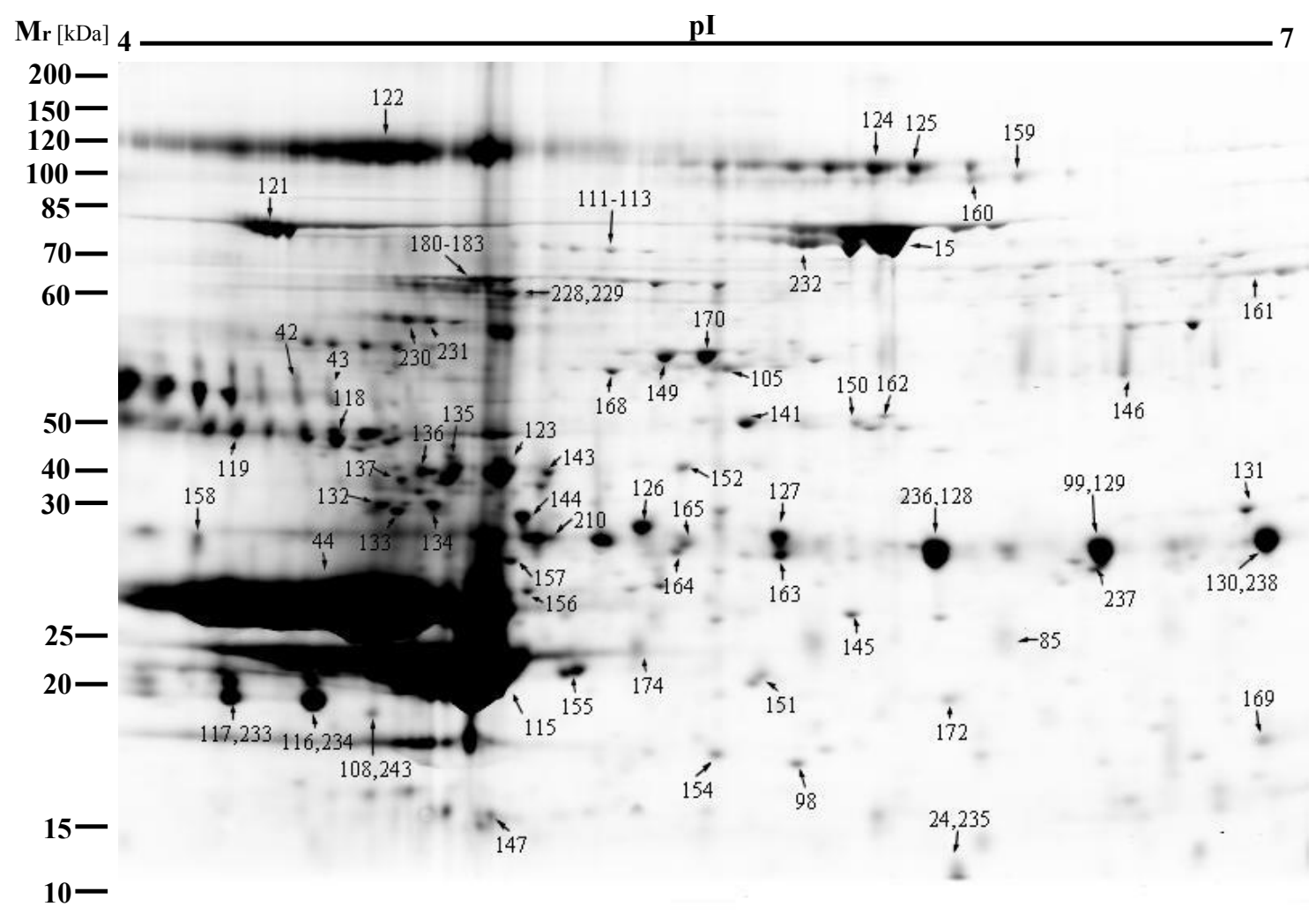

Abbildung 3.8: Proteinidentifikation des Wildtyp-Urinproteoms zum Zeitpunkt von 4,5 Wochen. Zur Erstellung des 2D-Gels werden $150 \mu \mathrm{g}$ Protein auf einem $11 \mathrm{~cm}$ langen IPG-Streifen (pH 4-7, Bio-Rad) fokussiert und mittels SDS-PAGE nach Masse $\left(\mathrm{M}_{\mathrm{r}}\right)$ getrennt. Die einzelnen Proteine werden zur Identifikation nummeriert und mit MALDI identifiziert. Tabelle 3.1 auf Seite 55 zeigt die Identifikationsergebnisse. Teilweise sind Proteinspots auf mehreren Gelen doppelt bestimmt. Dies stellt die korrekte Identifizierung der Proteinspots sicher. 


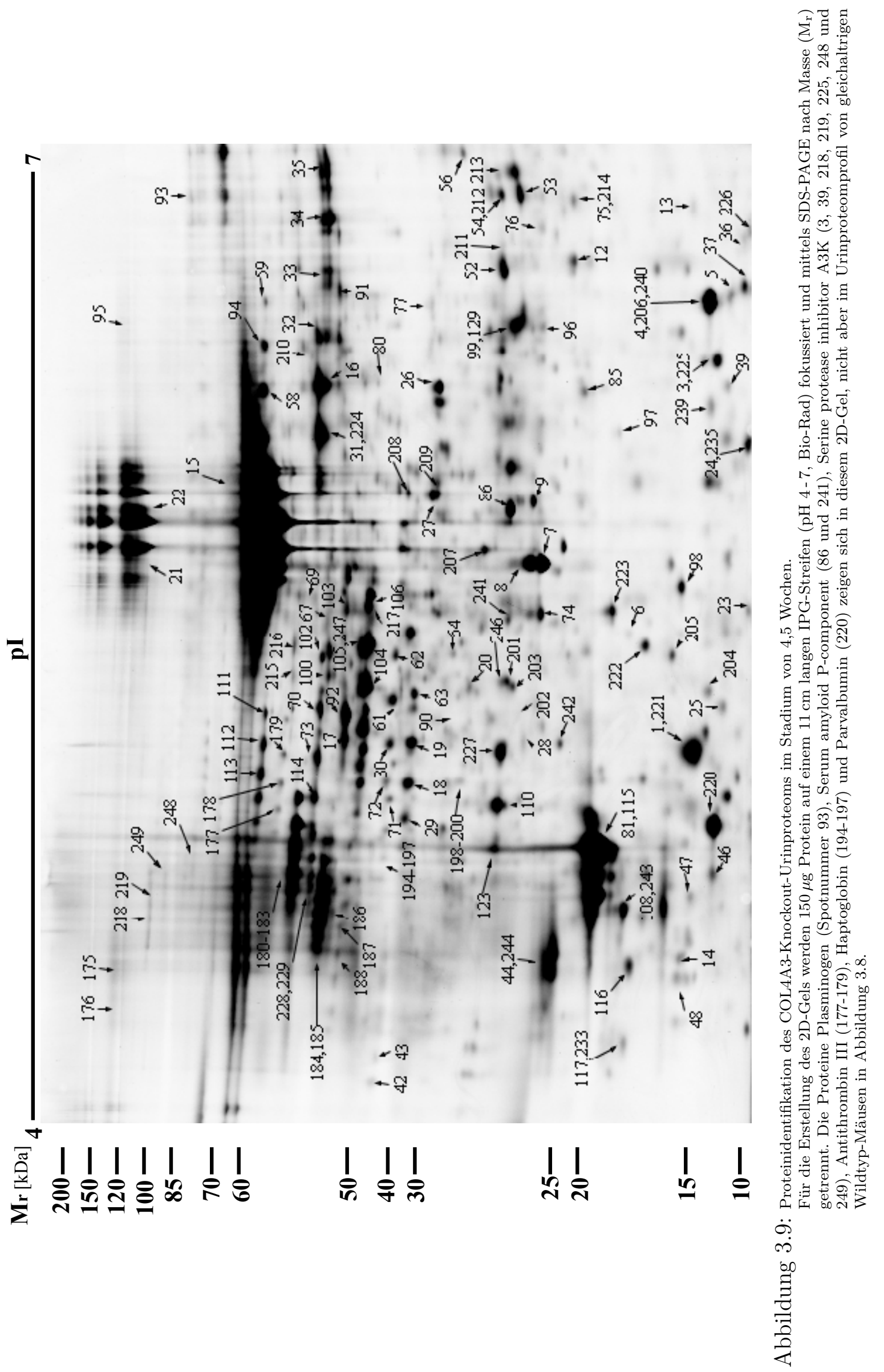




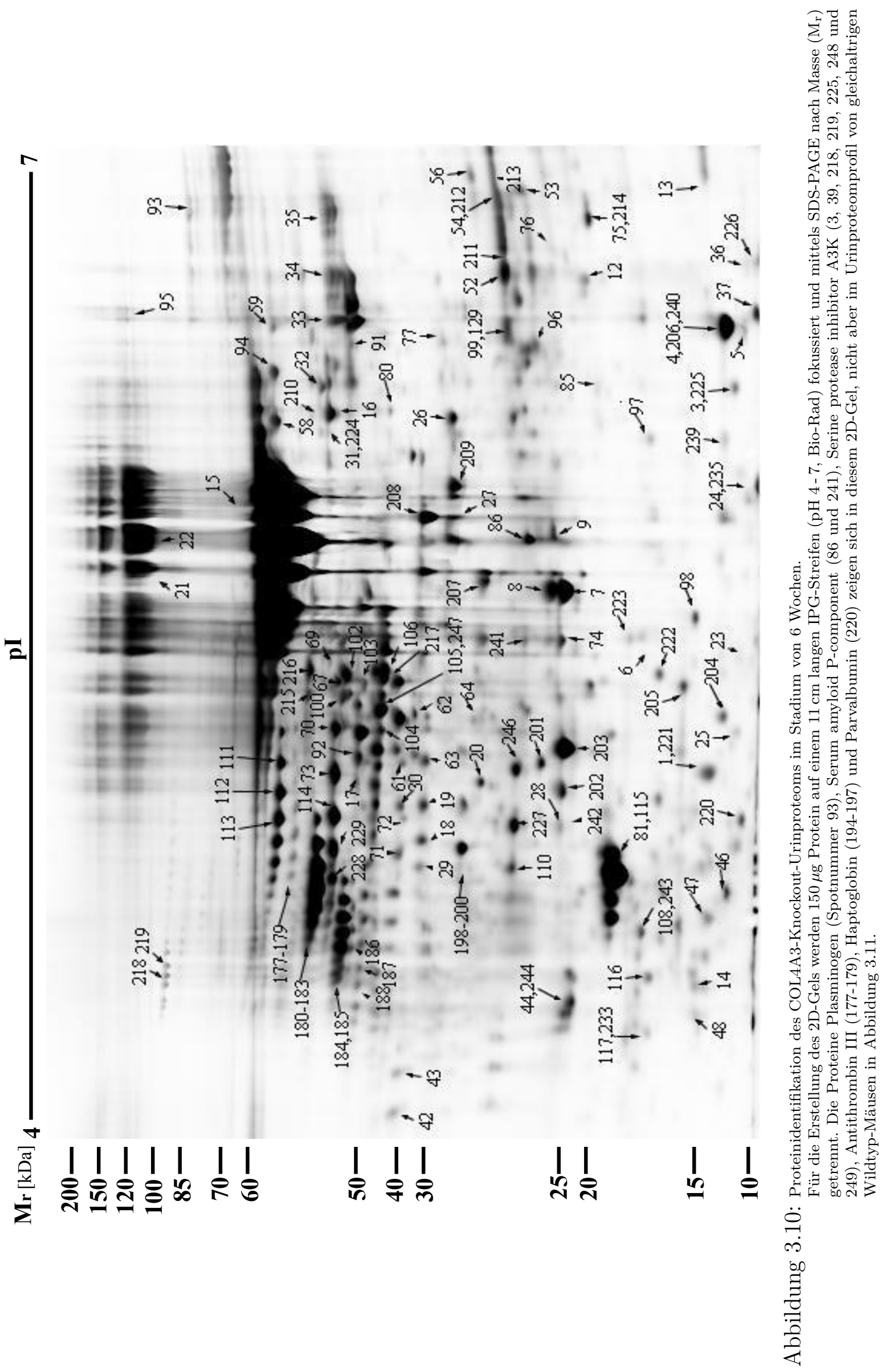




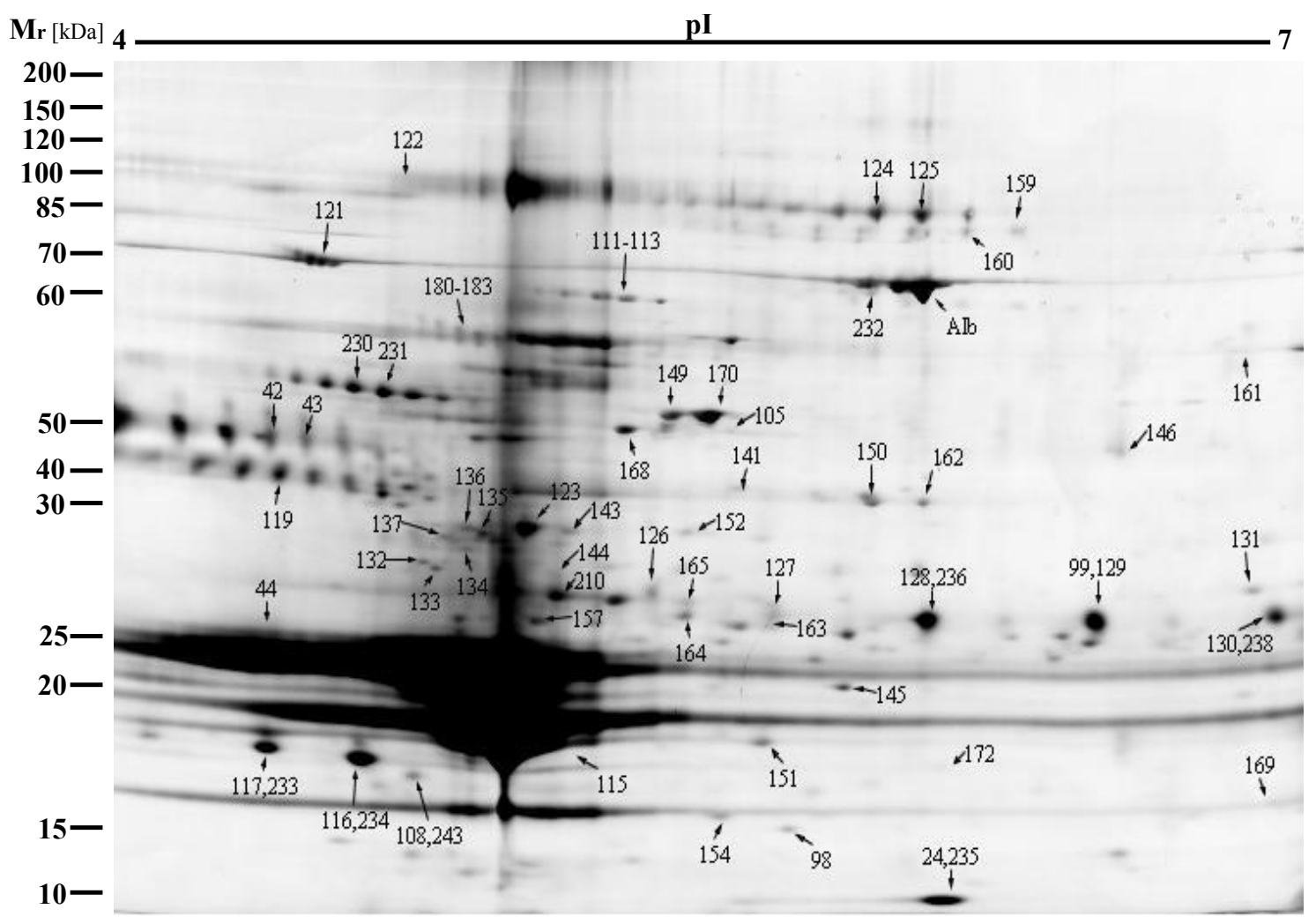

Abbildung 3.11: Proteinidentifikation des Wildtyp-Urinproteoms zum Zeitpunkt von 6 Wochen.

Die Erstellung des 2D-Gels wird nach dem in Kapitel 3.2 auf Seite 45 beschriebenen Protokoll durchgeführt. Das Proteinmuster ähnelt dem in Abbildung 3.8 dargestellten Urinproteinmuster von Wildtyp-Mäusen zum Zeitpunkt von 4,5 Wochen sehr.

Tabelle 3.1: Identifizierung der Proteinspots.

Die letzte Spalte der Tabelle soll die verwendete Datenbank anzeigen, wobei hier unterschiedliche Scores für eine signifikante Protein-

identifikation gegeben sind: Bei *1 (SwissProt) zeigt ein Score $>55$, bei *2 (NCBInr) > 66 und bei *3 (SwissProt) > 29 Proteinidentität an.

\begin{tabular}{|c|c|c|c|c|c|c|c|}
\hline Spot & Name des Proteins & Genname & Accession & $\mathrm{M}_{\mathbf{r}}[\mathbf{D a}]$ & pI & Score & \\
\hline 1 & Serum albumin & Alb & ALBU_MOUSE & 68648 & 5,75 & 275 & $* 3$ \\
\hline 2 & Liver transferrin & & gi I $19 \overline{88} 48$ & 14872 & 6,88 & 65 & $*_{2}$ \\
\hline 3 & Serine protease inhibitor A3K & Serpina3k & SPA3K_MOUSE & 46850 & 5,05 & 215 & $* 3$ \\
\hline 4 & Transthyretin & Ttr & TTHY_MOUSE & 15880 & 5,77 & 73 & $* 1$ \\
\hline 5 & Seminal vesicle secretory protein 6 & Svs6 & SVS6 $\overline{M O U S E}$ & 11475 & 5,93 & 56 & $* 1$ \\
\hline 6 & Transthyretin & Ttr & TTHY MOUSE & 15766 & 5,77 & 46 & $* 3$ \\
\hline 7 & Apolipoprotein A-1 & ApoA1 & APOA $\overline{1}$ MOUSE & 30569 & 5,64 & 151 & $* 1$ \\
\hline 8 & Apolipoprotein A-1 & ApoA1 & APOA1 MOUSE & 30569 & 5,64 & 97 & $* 1$ \\
\hline 9 & Apolipoprotein A-1 & ApoA1 & APOA1 MOUSE & 30569 & 5,64 & 82 & $* 1$ \\
\hline 12 & Apolipoprotein A-1 & ApoA1 & APOA1 MOUSE & 30569 & 5,64 & 60 & $* 1$ \\
\hline 13 & Seminal vesicle secretory protein 4 & Svs4 & SVS4 $\overline{\text { MOUSE }}$ & 12507 & 8,04 & 119 & $* 3$ \\
\hline 14 & Alpha-1-antitrypsin 1-1 & Serpina1a & A1AT1_MOUSE & 45974 & 5,44 & 30 & $* 3$ \\
\hline 15 & Serum albumin & Alb & ALBU_MOUSE & 70700 & 5,75 & 132 & $* 1$ \\
\hline 16 & Serum albumin & Alb & ALBU_MOUSE & 70700 & 5,75 & 166 & $* 1$ \\
\hline 17 & Serum albumin & Alb & ALBU MOUSE & 68648 & 5,75 & 652 & $* 3$ \\
\hline 18 & Alpha-1-antitrypsin 1-3 & Serpina1c & A1AT3 MOUSE & 45966 & 5,25 & 56 & $* 1$ \\
\hline 19 & Alpha-1-antitrypsin 1-3 & Serpina1c & A1AT3_MOUSE & 45966 & 5,25 & 108 & $* 1$ \\
\hline 20 & Alpha-fetoprotein & Afp & gi I 191765 & 48792 & 5,47 & 94 & $*_{2}$ \\
\hline 21 & Serum albumin & Alb & ALBU_MOUSE & 70700 & 5,75 & 226 & $* 1$ \\
\hline 22 & Serum albumin & Alb & ALBU_MOUSE & 68648 & 5,75 & 60 & $* 1$ \\
\hline 23 & Serum albumin & Alb & ALBU_MOUSE & 70700 & 5,75 & 90 & $* 3$ \\
\hline 24 & Guanylate cyclase activator $2 \mathrm{~B}$ & Guca2b & GUC2B_MOUSE & 11962 & 6,07 & 59 & $* 1$ \\
\hline 25 & $\begin{array}{l}\text { Peptidyl-prolyl cis-trans isomerase- } \\
\text { like } 3\end{array}$ & Ppil3 & PPIL_MOUSE & 18344 & 6,29 & 57 & $* 1$ \\
\hline 26 & Alpha-2-macroglobulin & $\mathrm{A} 2 \mathrm{~m}$ & A2M_MOUSE & 165748 & 6,24 & 206 & $* 3$ \\
\hline 27 & Alpha-2-macroglobulin & $\mathrm{A} 2 \mathrm{~m}$ & A2M MOUSE & 165748 & 6,24 & 269 & $* 3$ \\
\hline 28 & Vitamin D-binding protein & Gc & VTDB MOUSE & 53565 & 5,39 & 114 & $* 3$ \\
\hline 29 & Alpha-1-antitrypsin 1-1 & Serpina1a & A1AT1_MOUSE & 45974 & 5,44 & 82 & $* 3$ \\
\hline 30 & Alpha-1-antitrypsin 1-3 & Serpina1c & A1AT3 MOUSE & 45966 & 5,25 & 97 & $* 1$ \\
\hline 31 & Serum albumin & Alb & MOUSE & 68648 & 5,75 & 170 & $* 3$ \\
\hline
\end{tabular}




\begin{tabular}{|c|c|c|c|c|c|c|c|}
\hline 32 & Serotransferrin & $\mathrm{Tf}$ & TRFE_MOUSE & 78841 & 6,94 & 74 & $* 1$ \\
\hline 33 & Serotransferrin & $\mathrm{Tf}$ & TRFE MOUSE & 78841 & 6,94 & 103 & $* 1$ \\
\hline 34 & Serotransferrin & $\mathrm{Tf}$ & TRFE_MOUSE & 78841 & 6,94 & 160 & $* 1$ \\
\hline 35 & Serotransferrin & $\mathrm{Tf}$ & TRFE_MOUSE & 78841 & 6,94 & 190 & $* 1$ \\
\hline 36 & Serotransferrin & $\mathrm{Tf}$ & TRFE_MOUSE & 76674 & 6,94 & 61 & $* 3$ \\
\hline 37 & Transthyretin & Ttr & TTHY_MOUSE & 15880 & 5,77 & 69 & $*_{1}^{* 1}$ \\
\hline 39 & Serine protease inhibitor A3K & Serpina3k & SPA3K_MOUSE & 46850 & 5,05 & 36 & $* 3$ \\
\hline 42 & Alpha-1-antitrypsin 1-3 & Serpina1c & A1AT3 MOUSE & 45966 & 5,25 & 183 & $* 1$ \\
\hline 43 & Alpha-1-antitrypsin 1-3 & Serpina1c & A1AT3_MOUSE & 45966 & 5,25 & 144 & $* 1$ \\
\hline 44 & Major urinary protein 3 & Mup3 & MUP3 MOUSE & 21736 & 4,8 & 124 & $* 1$ \\
\hline 46 & Nucleoporin GLE1 & Gle1 & GLE1_MOUSE & 79981 & 7,31 & 57 & $* 1$ \\
\hline 47 & Liver carboxylesterase $\mathrm{N}$ & Es1 & ESTN MOUSE & 61017 & 4,97 & 79 & $* 3$ \\
\hline 48 & Alpha-1-antitrypsin 1-3 & Serpina1d & A1AT3_MOUSE & 45966 & 5,24 & 62 & $* 1$ \\
\hline 52 & Alpha-1-antitrypsin 1-1 & Serpinala & A1AT1_MOUSE & 46145 & 5,44 & 61 & $* 1$ \\
\hline 53 & Alpha-1-antitrypsin 1-1 & Serpinala & A1AT1_MOUSE & 46145 & 5,44 & 69 & $* 1$ \\
\hline 54 & Serum albumin & Alb & ALBU MOUSE & 70700 & 5,75 & 98 & $* 1$ \\
\hline 56 & Alpha-1-antitrypsin 1-2 & Serpina1b & A1AT2_MOUSE & 45946 & 5,32 & 61 & $* 3$ \\
\hline 58 & Hemopexin & Hpx & HEMO_MOUSE & 52026 & 7,92 & 98 & $* 1$ \\
\hline 61 & Vitamin D-binding protein & Gc & VTDB_MOUSE & 55162 & 5,39 & 82 & $* 1$ \\
\hline 62 & Serum albumin & Alb & ALBU MOUSE & 68648 & 5,75 & 351 & $* 3$ \\
\hline 63 & Alpha-1-antitrypsin 1-3 & Serpina1c & A1AT3_MOUSE & 45966 & 5,25 & 132 & $* 1$ \\
\hline 64 & Alpha-1-antitrypsin 1-1 & Serpinala & A1AT1 MOUSE & 45974 & 5,44 & 64 & $* 3$ \\
\hline 67 & Serum albumin & Alb & ALBU MOUSE & 70700 & 5,75 & 147 & $* 1$ \\
\hline 69 & Serum albumin & Alb & ALBU_MOUSE & 70700 & 5,75 & 86 & $* 1$ \\
\hline 70 & Serum albumin & Alb & ALBU MOUSE & 70700 & 5,75 & 113 & $* 1$ \\
\hline 71 & Alpha-2-HS-glycoprotein & Ahsg & FETUA_MOUSE & 38100 & 6,04 & 77 & $* 1$ \\
\hline 72 & Nucleobindin-2 & Nucb2 & NUCB2_MOUSE & 50387 & 5,05 & 88 & $* 1$ \\
\hline 73 & Alpha-1-antitrypsin 1-1 & Serpina1a & A1AT1_MOUSE & 45974 & 5,44 & 49 & $* 3$ \\
\hline 74 & Apolipoprotein A-1 & ApoA1 & APOA1_MOUSE & 30569 & 5,64 & 87 & $* 1$ \\
\hline 75 & Retinol-binding protein 4 & Rbp4 & RET4_MOUSE & 23533 & 5,69 & 86 & $* 1$ \\
\hline 76 & Alpha-1-antitrypsin 1-2 & Serpina1b & A1AT2_MOUSE & 46177 & 5,32 & 95 & $* 1$ \\
\hline 77 & Serum albumin & Alb & ALBU_MOUSE & 70700 & 5,75 & 59 & $* 1$ \\
\hline 80 & Serotransferrin & Tf & TRFE MOUSE & 78841 & 6,94 & 120 & $* 1$ \\
\hline 81 & Major urinary protein 2 & Mup2 & MUP2_MOUSE & 20650 & 5,02 & 621 & $* 3$ \\
\hline 85 & Alpha-1-antitrypsin 1-3 & Serpina1c & A1AT3 MOUSE & 45966 & 5,25 & 67 & $* 1$ \\
\hline 86 & Serum amyloid P-component & Apcs & SAMP MOUSE & 26401 & 5,97 & 72 & $* 1$ \\
\hline 90 & Nucleoporin GLE1 & Gle1 & GLE1 MOUSE & 79981 & 7,31 & 57 & $* 1$ \\
\hline 91 & Serum albumin & Alb & ALBU_MOUSE & 68648 & 5,75 & 108 & $* 3$ \\
\hline 92 & Serum albumin & Alb & ALBU MOUSE & 70700 & 5,75 & 114 & $* 1$ \\
\hline 93 & Plasminogen & Plg & PLMN_MOUSE & 93486 & 6,21 & 136 & *1 \\
\hline 94 & Hemopexin & $\mathrm{Hpx}$ & HEMO_MOUSE & 52026 & 7,92 & 62 & $* 1$ \\
\hline 95 & Serum albumin & Alb & ALBU MOUSE & 70700 & 5,75 & 80 & $* 1$ \\
\hline 96 & Alpha-1-antitrypsin 1-1 & Serpina1a & gi I 192094 & 22884 & 5,98 & 66 & $* 2$ \\
\hline 97 & Alpha-1-antitrypsin 1-3 & Serpina1c & A1AT3_MOUSE & 45966 & 5,25 & 88 & $* 1$ \\
\hline 98 & Lithostathine-1 & Reg1 & LIT1_MOUSE & 18906 & 6,08 & 76 & $* 1$ \\
\hline 99 & Prostaglandin-H2 D-isomerase & Ptgds & PTGDS_MOUSE & 21053 & 8,39 & 34 & $* 3$ \\
\hline 100 & Serum albumin & Alb & ALBU_ $\bar{M} O U S E$ & 70700 & 5,75 & 68 & $* 1$ \\
\hline 102 & Serum albumin & Alb & ALBU MOUSE & 70700 & 5,75 & 115 & $* 1$ \\
\hline 103 & Serum albumin & Alb & ALBU_MOUSE & 70700 & 5,75 & 94 & $* 1$ \\
\hline 104 & Alpha-1-antitrypsin 1-3 & Serpina1c & A1AT3_MOUSE & 45966 & 5,25 & 138 & $* 1$ \\
\hline 105 & Serum albumin & Alb & ALBU MOUSE & 70700 & 5,75 & 66 & $* 1$ \\
\hline 106 & Alpha-1-antitrypsin 1-2 & Serpina1b & A1AT3_MOUSE & 45966 & 5,25 & 68 & $* 1$ \\
\hline 108 & Apolipoprotein A-1 & ApoA1 & APOA1_MOUSE & 30569 & 5,64 & 60 & $* 1$ \\
\hline 110 & Protein AMBP & Ambp & AMBP_MOUSE & 39004 & 5,96 & 49 & $* 3$ \\
\hline 111 & Kininogen-1 & Kng1 & KNG1_MOUSE & 74140 & 6,05 & 81 & $* 3$ \\
\hline 112 & Kininogen-1 & Kng1 & KNG1_MOUSE & 74140 & 6,05 & 76 & $* 1$ \\
\hline 113 & Kininogen-1 & Kng1 & KNG1_MOUSE & 74140 & 6,05 & 80 & $* 1$ \\
\hline 114 & Alpha-2-HS-glycoprotein & Ahsg & FETUA_MOUSE & 38100 & 6,04 & 34 & *3 \\
\hline 115 & Major urinary protein 2 & Mup2 & MUP2_MOUSE & 20935 & 5,04 & 88 & $* 1$ \\
\hline 116 & Alpha-2-HS-glycoprotein & Ahsg & FETUA MOUSE & 38100 & 6,04 & 43 & $* 3$ \\
\hline 117 & Alpha-2-HS-glycoprotein & Ahsg & FETUA_MOUSE & 38100 & 6,04 & 56 & $* 1$ \\
\hline 118 & Deoxyribonuclease-1 & Dnase1 & DNAS1_MOUSE & 32007 & 4,76 & 42 & $* 3$ \\
\hline 119 & Complement factor D & Cfd & CFAD MOUSE & 28552 & 6,18 & 56 & $* 1$ \\
\hline 121 & Serum albumin & Alb & ALBU MOUSE & 70700 & 5,75 & 104 & $* 1$ \\
\hline 122 & Uromodulin & Umod & UROM_MOUSE & 73535 & 4,75 & 82 & $* 1$ \\
\hline 123 & Major urinary protein 2 & Mup2 & MUP2 MOUSE & 20935 & 5,04 & 78 & $* 1$ \\
\hline 124 & Meprin A subunit alpha & Mepla & MEP1A_MOUSE & 85261 & 5,81 & 151 & $* 1$ \\
\hline 125 & Meprin A subunit alpha & Mepla & MEP1A_MOUSE & 85261 & 5,81 & 126 & $* 1$ \\
\hline 126 & Prostaglandin-H2 D-isomerase & Ptgds & PTGDS MOUSE & 21224 & 8,39 & 82 & $* 1$ \\
\hline 127 & Prostaglandin-H2 D-isomerase & Ptgds & PTGDS_MOUSE & 21224 & 8,39 & 83 & *1 1 \\
\hline 128 & Prostaglandin-H2 D-isomerase & Ptgds & PTGDS MOUSE & 21224 & 8,39 & 56 & $* 1$ \\
\hline 129 & Prostaglandin-H2 D-isomerase & Ptgds & PTGDS MOUSE & 21224 & 8,39 & 75 & $* 1$ \\
\hline 130 & Prostaglandin-H2 D-isomerase & Ptgds & PTGDS MOUSE & 21224 & 8,39 & 102 & $* 1$ \\
\hline 131 & Serum albumin & Alb & ALBU MOUSE & 70700 & 5,75 & 129 & $* 1$ \\
\hline 132 & Coronin-1B & Corolb & 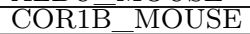 & 54505 & 5,54 & 77 & $* 1$ \\
\hline 133 & Major urinary protein 2 & Mup2 & MUP2_MOUSE & 20935 & 5,04 & 72 & $* 1$ \\
\hline 134 & Major urinary protein 2 & Mup2 & MUP2 MOUSE & 20935 & 5,04 & 69 & $* 1$ \\
\hline 135 & Kallikrein-1 & Klk1 & KLK1 MOUSE & 29326 & 4,96 & 88 & *3 \\
\hline 136 & Kallikrein-1 & Klk1 & KLK1_MOUSE & 29326 & 4,96 & 47 & *3 \\
\hline 137 & Major urinary protein 2 & Mup2 & MUP2_MOUSE & 20935 & 5,04 & 57 & $* 1$ \\
\hline 139 & $\begin{array}{l}\text { Coiled-coil and } \mathrm{C} 2 \text { domain- } \\
\text { containing protein } 1 \mathrm{~B}\end{array}$ & Cc2d1b & C2D1B_MOUSE & 93490 & 5,29 & 56 & 1 \\
\hline 141 & Gelsolin & Gsn & GELS MOUSE & 86287 & 5,83 & 59 & $* 1$ \\
\hline 143 & Kallikrein-1 & Klk1 & KLK1_MOUSE & 29326 & 4,96 & 118 & *3 \\
\hline 144 & Prostaglandin-H2 D-isomerase & Ptgds & PTGDS_MOUSE & 21224 & 8,39 & 64 & $* 3$ \\
\hline
\end{tabular}




\begin{tabular}{|c|c|c|c|c|c|c|c|}
\hline 145 & $\begin{array}{l}\text { Basement membrane-specific hepa- } \\
\text { ran sufate proteogylcan core protein }\end{array}$ & Hspg2 & PGBM_MOUSE & 398039 & 6,04 & 164 & $* 3$ \\
\hline 146 & Napsin-A & Napsa & MOUSE & 45516 & 7,13 & 42 & \\
\hline 147 & Major urinary protein 1 & Mup1 & MUP1_MOUSE & 20920 & 5,02 & 79 & $* 1$ \\
\hline 149 & Gelsolin & Gsn & GELS MOUSE & 86287 & 5,83 & 142 & $* 1$ \\
\hline 150 & Serum albumin & Alb & ALBU_MOUSE & 70700 & 5,75 & 103 & $* 1$ \\
\hline 151 & $\begin{array}{l}\text { Neuron-specific vesicular protein } \\
\text { calcyon }\end{array}$ & Caly & CALY_MOUSE & 24849 & 5,77 & 57 & \\
\hline 152 & Gelsolin & Gsn & GELS_MOUSE & 86287 & 5,83 & 97 & $* 1$ \\
\hline 154 & Odorant binding protein Ia & Obp1a & gi I 1835143 & 17044 & 5,24 & 170 & \\
\hline 155 & Major urinary protein 1 & Mup1 & MUP1 MOUSE & 20920 & 5,02 & 134 & *1 \\
\hline 156 & Major urinary protein 3 & Mup3 & MUP3_MOUSE & 21736 & 4,8 & 58 & $* 1$ \\
\hline 157 & Major urinary protein 2 & Mup2 & MUP2_MOUSE & 20935 & 5,04 & 115 & \\
\hline 158 & Gap junction alpha-10 protein & Jja10 & CXA10_MOUSE & 57889 & 8,58 & 56 & $* 1$ \\
\hline 159 & Meprin A subunit alpha & Mep1a & MEP1A_MOUSE & 85261 & 5,81 & 68 & $* 1$ \\
\hline 160 & Meprin A subunit alpha & Mep1a & MEP1A_MOUSE & 85261 & 5,81 & 57 & \\
\hline 161 & Alpha-amylase 1 & Amy1 & AMY1 MOUSE & 58291 & 6,5 & 200 & $* 1$ \\
\hline 162 & Serum albumin & Alb & ALBU_MOUSE & 70700 & 5,75 & 63 & $* 1$ \\
\hline 163 & Prostaglandin-H2 D-isomerase & Ptgds & PTGDS_MOUSE & 21224 & 8,39 & 76 & \\
\hline 164 & Protein AMBP & Ambp & AMBP MOUSE & 39916 & 5,96 & 68 & $* 1$ \\
\hline 165 & Protein AMBP & Ambp & AMBP_MOUSE & 39916 & 5,96 & 71 & \\
\hline 168 & Gelsolin & Gsn & GELS MOUSE & 86287 & 5,83 & 71 & $* 1$ \\
\hline 169 & Cystatin-B & Cst6 & gi I 20381496 & 16654 & 8,44 & 86 & $* 2$ \\
\hline 170 & Gelsolin & Gsn & GELS MOUSE & 86287 & 5,83 & 155 & $* 1$ \\
\hline 172 & Nucleoporin GLE1 & Gle1 & GLE1_MOUSE & 79981 & 7,31 & 56 & $* 1$ \\
\hline 174 & Major urinary protein 2 & Mup2 & MUP2_MOUSE & 20935 & 5,04 & 68 & $* 1$ \\
\hline 175 & Serum albumin & Alb & ALBU_MOUSE & 70700 & 5,75 & 145 & $* 1$ \\
\hline 176 & Serum albumin & Alb & ALBU MOUSE & 70700 & 5,75 & 70 & $* 1$ \\
\hline 177 & Antithrombin-III & Serpinc1 & ANT3_MOUSE & 52484 & 6,1 & 124 & $* 1$ \\
\hline 178 & Antithrombin-III & Serpinc1 & ANT3_MOUSE & 52484 & 6,1 & 176 & $* 1$ \\
\hline 179 & Antithrombin-III & Serpinc1 & ANT3_MOUSE & 52484 & 6,1 & 183 & $* 1$ \\
\hline 180 & Alpha-1-antitrypsin 1-1 & Serpina1a & A1AT1_MOUSE & 46145 & 5,44 & 150 & $* 1$ \\
\hline 181 & Alpha-1-antitrypsin 1-1 & Serpinala & A1AT1_MOUSE & 46145 & 5,44 & 90 & $* 1$ \\
\hline 182 & Alpha-1-antitrypsin 1-1 & Serpinala & A1AT1_MOUSE & 46145 & 5,44 & 58 & $* 1$ \\
\hline 183 & Alpha-1-antitrypsin 1-1 & Serpina1a & A1AT1_MOUSE & 46145 & 5,44 & 97 & $* 1$ \\
\hline 184 & Alpha-1-antitrypsin 1-3 & Serpinalc & A1AT3_MOUSE & 45966 & 5,25 & 62 & $* 1$ \\
\hline 185 & Alpha-1-antitrypsin 1-3 & Serpinalc & A1AT3_MOUSE & 45966 & 5,25 & 56 & $* 1$ \\
\hline 186 & Alpha-1-antitrypsin 1-1 & Serpina1a & A1AT1_MOUSE & 46145 & 5,44 & 69 & $* 1$ \\
\hline 187 & Leucine-rich alpha-2-glycoprotein & Lrg1 & gi I 16418335 & 37807 & 6,14 & 66 & $*_{2}$ \\
\hline 188 & Protein FAM195B & Fam195b & F195B_MOUSE & 11152 & 9,2 & 56 & $* 1$ \\
\hline 194 & Haptoglobin & $\mathrm{Hp}$ & HPT_MOUSE & 39241 & 5,88 & 73 & $* 1$ \\
\hline 195 & Haptoglobin & $\mathrm{Hp}$ & HPT_MOUSE & 39241 & 5,88 & 82 & *1 \\
\hline 196 & Haptoglobin & $\mathrm{Hp}$ & HPT_MOUSE & 39241 & 5,88 & 93 & $* 1$ \\
\hline 197 & Haptoglobin & $\mathrm{Hp}$ & HPT_MOUSE & 39241 & 5,88 & 56 & $* 1$ \\
\hline 198 & Fibrinogen beta chain & Fgb & FIBB MOUSE & 54718 & 8,54 & 273 & $* 3$ \\
\hline 199 & Fibrinogen beta chain & $\mathrm{Fgb}$ & FIBB_MOUSE & 54718 & 8,54 & 109 & $* 3$ \\
\hline 200 & Fibrinogen beta chain & $\mathrm{Fgb}$ & FIBB MOUSE & 54718 & 8,54 & 92 & $* 3$ \\
\hline 201 & Vitamin D-binding protein & $\mathrm{Gc}$ & VTDB_MOUSE & 53565 & 5,39 & 108 & $* 3$ \\
\hline 202 & Serum albumin & Alb & ALBU_MOUSE & 70700 & 5,75 & 70 & $* 1$ \\
\hline 203 & Serum albumin & Alb & ALBU_MOUSE & 70700 & 5,75 & 57 & $* 1$ \\
\hline 204 & Vitamin D-binding protein & $\mathrm{Gc}$ & VTDB MOUSE & 55162 & 5,39 & 74 & $* 1$ \\
\hline 205 & Serum albumin & Alb & ALBU_MOUSE & 70700 & 5,75 & 114 & $* 1$ \\
\hline 206 & Transthyretin & Ttr & TTHY MOUSE & 15880 & 5,77 & 92 & $* 1$ \\
\hline 207 & Serum albumin & Alb & ALBU MOUSE & 70700 & 5,75 & 185 & $* 1$ \\
\hline 208 & Serum albumin & Alb & ALBU_MOUSE & 70700 & 5,75 & 161 & $* 1$ \\
\hline 209 & Serum albumin & Alb & ALBU_MOUSE & 70700 & 5,75 & 122 & $* 1$ \\
\hline 210 & Serum albumin & Alb & ALBU_MOUSE & 70700 & 5,75 & 198 & $* 1$ \\
\hline 211 & Serum albumin & Alb & ALBU MOUSE & 70700 & 5,75 & 164 & $* 1$ \\
\hline 212 & Serum albumin & Alb & ALBU_MOUSE & 70700 & 5,75 & 114 & $* 1$ \\
\hline 213 & Serum albumin & Alb & ALBU MOUSE & 70700 & 5,75 & 81 & $* 1$ \\
\hline 214 & Retinol-binding protein 4 & Rbp4 & RET4_MOUSE & 23533 & 5,69 & 64 & $* 1$ \\
\hline 215 & Serum albumin & Alb & ALBU_MOUSE & 70700 & 5,75 & 75 & $* 1$ \\
\hline 216 & Vitamin D-binding protein & Gc & VTDB_MOUSE & 55162 & 5,39 & 162 & $* 1$ \\
\hline 217 & Serum albumin & Alb & ALBU_MOUSE & 70700 & 5,75 & 147 & $* 1$ \\
\hline 218 & Serine protease inhibitor A3K & Serpina3k & SPA3K_MOUSE & 47021 & 5,05 & 128 & 1 \\
\hline 219 & Serine protease inhibitor A3K & Serpina3k & SPA3K MOUSE & 47021 & 5,05 & 94 & $* 1$ \\
\hline 220 & Parvalbumin alpha & Pvalb & PRVA_MOUSE & 11923 & 5,02 & 60 & *1 \\
\hline 221 & Serum albumin & Alb & ALBU_MOUSE & 68648 & 5,75 & 160 & ${ }^{*} 3$ \\
\hline 222 & General transcription factor IIE & Gtf2e2 & T2EB_MOUSE & 33038 & 9,65 & 57 & $k 7$ \\
\hline 223 & Major urinary protein 4 & Mup4 & MUP4_MOUSE & 20814 & 5,55 & 56 & 1 \\
\hline 224 & Serum albumin & Alb & ALBU $\mathrm{MO}$ & 70700 & 5,75 & 191 & $* 1$ \\
\hline 225 & Serine protease inhibitor A3K & Serpina3k & SPA3K MOUSE & 47021 & 5,05 & 112 & $* 1$ \\
\hline 226 & Transthyretin & Ttr & TTHY_MOUSE & 15880 & 5,77 & 59 & $* 1$ \\
\hline 227 & Protein AMBP & Ambp & AMBP MOUSE & 39916 & 5,96 & 60 & 1 \\
\hline 228 & Alpha-2-HS-glycoprotein & Ahsg & FETUA_MOUSE & 38100 & 6,04 & 61 & $* 1$ \\
\hline 229 & Alpha-2-HS-glycoprotein & Ahsg & FETUA_MOUSE & 38100 & 6,04 & 60 & \\
\hline 230 & Alpha-1-antitrypsin 1-3 & Serpina1c & A1AT3_MOUSE & 45966 & 5,25 & 103 & $* 1$ \\
\hline 231 & Alpha-1-antitrypsin 1-3 & Serpina1c & A1AT3_MOUSE & 45966 & 5,25 & 107 & $* 1$ \\
\hline 232 & Serum albumin & Alb & ALBU_MOUSE & 68648 & 5,75 & 221 & $* 1$ \\
\hline 233 & Alpha-2-HS-glycoprotein & Ahsg & FETUA_MOUSE & 38100 & 6,04 & 65 & $* 1$ \\
\hline 234 & Alpha-2-HS-glycoprotein & Ahsg & FETUA_MOUSE & 38100 & 6,04 & 61 & $* 1$ \\
\hline 235 & Guanylate cyclase activator $2 \mathrm{~B}$ & Guca2b & GUC2B_MOUSE & 11962 & 6,07 & 58 & $* 1$ \\
\hline 236 & Prostaglandin-H2 D-isomerase & Ptgds & PTGDS MOUSE & 21224 & 8,39 & 58 & (* \\
\hline 237 & Prostaglandin-H2 D-isomerase & Ptgds & PTGDS_MOUSE & 21224 & 8,39 & 56 & 1 \\
\hline
\end{tabular}




\begin{tabular}{|l|l|l|l|l|l|l|l|}
\hline 238 & Prostaglandin-H2 D-isomerase & Ptgds & PTGDS_MOUSE & 21224 & 8,39 & 56 & ${ }^{*} 1$ \\
\hline 239 & Transthyretin & Ttr & TTHY_MOUSE & 15880 & 5,77 & 104 & ${ }^{*} 1$ \\
\hline 240 & Transthyretin & Ttr & TTHY_MOUSE & 15880 & 5,77 & 72 & ${ }^{*} 1$ \\
\hline 241 & Serum amyloid P-component & Apcs & SAMP_MOUSE & 26401 & 5,98 & 57 & ${ }^{*} 1$ \\
\hline 242 & Serum albumin & Alb & ALBU_MOUSE & 70700 & 5,75 & 65 & ${ }^{*} 1$ \\
\hline 243 & Apolipoprotein A-1 & ApoA1 & APOA_ MOUSE & 30569 & 5,64 & 105 & ${ }^{*} 1$ \\
\hline 244 & Major urinary protein 3 & Mup3 & MUP3_MOUSE & 21736 & 4,8 & 68 & ${ }^{*} 1$ \\
\hline 246 & Protein AMBP & Ambp & AMBP_MOUSE & 39916 & 5,96 & 64 & ${ }^{*} 1$ \\
\hline 247 & Serum albumin & Alb & ALBU_MOUSE & 70700 & 5,75 & 205 & ${ }^{*} 1$ \\
\hline 248 & Serine protease inhibitor A3K & Serpina3k & SPA3K_MOUSE & 47021 & 5,05 & 65 & ${ }^{*} 1$ \\
\hline 249 & Serine protease inhibitor A3K & Serpina3k & SPA3K_MOUSE & 47021 & 5,05 & 72 & ${ }^{*} 1$ \\
\hline 250 & Nucleoporin GLE1 & Gle1 & GLE1_MOUSE & 79981 & 7,31 & 56 & ${ }^{*} 1$ \\
\hline
\end{tabular}

\subsubsection{Quantitative Auswertung der 2D-DIGE-Gele mit Delta 2D}

Zur quantitativen Auswertung der normierten Spotintensitäten werden 2D-DIGEGele verwendet. DIGE-Gele sind die Gele der Wahl bei der Auswertung mit Delta 2D. Für die Auswertung werden jeweils drei DIGE-Gele von Wildtyp- und COL4A3Knockout-Urinproben in den Stadien 4,5 und 6 Wochen benötigt. Im Vorfeld wird der Urin von jeweils vier Mäusen gepoolt. Bei der Auswertung wird der Augenmerk auf folgende Proteine gelegt: Plasminogen, Serum amyloid P-component, Antithrombin III, Serine protease inhibitor A3K, Haptoglobin und Parvalbumin. Die Werte der anderen Proteinspots sind der Tabelle 6.1 auf Seite 89 im Anhang zu entnehmen.

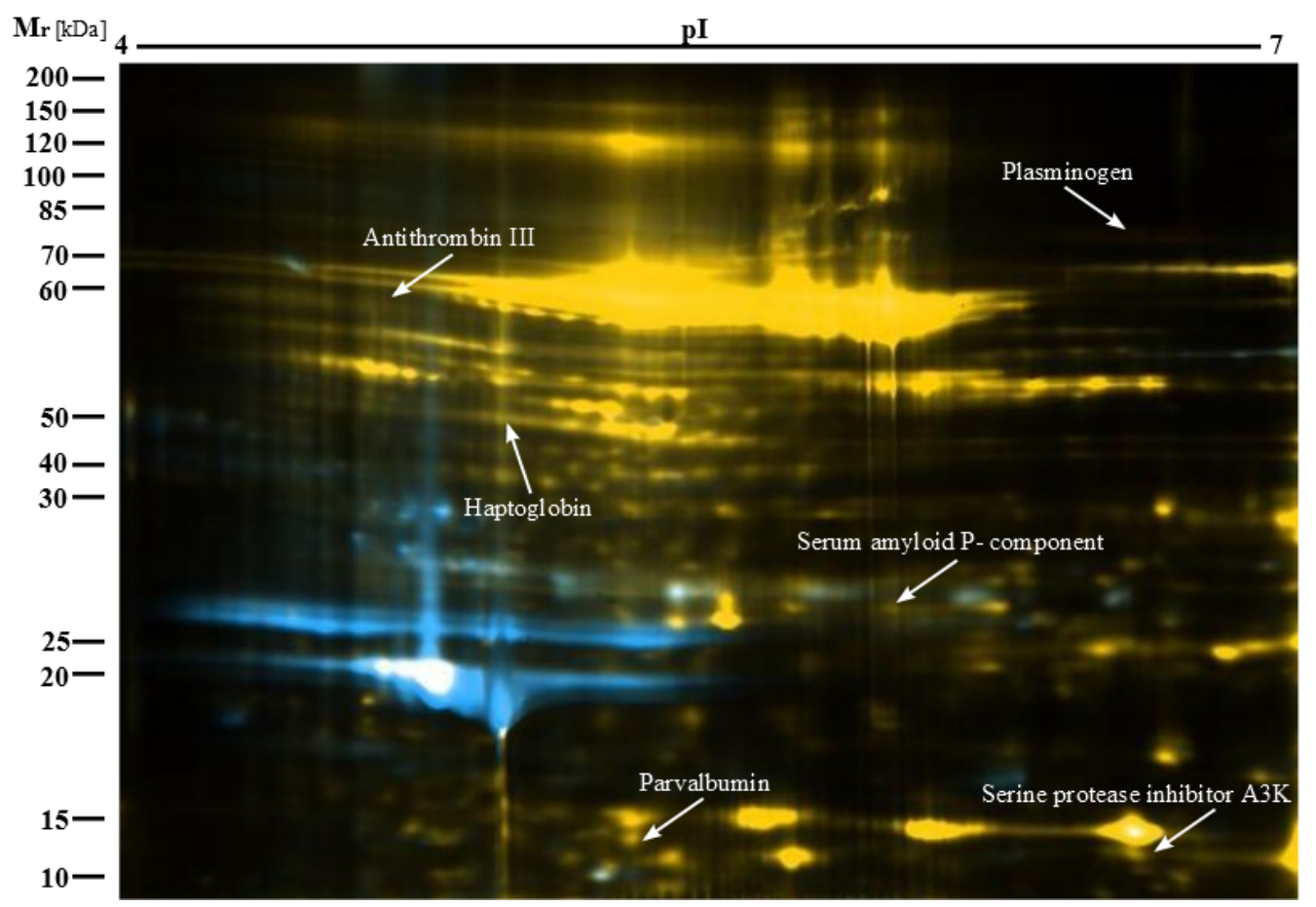

Abbildung 3.12: Analyse des Urin-Proteoms von COL4A3-Knockout-Mäusen zum Zeitpunkt von 4,5 Wochen. Blau gefärbte Spots stellen Urinproteine der Wildtyp-Mäuse und gelb gefärbte Spots Urinproteine der COL4A3-Knockout-Mäuse dar. Gleich stark vorhandene Proteine sind weiß gefärbt. Im 2D-DIGE-Gel sind die Proteinspots mit Namen markiert, die im Stadium von 4,5 Wochen bei COL4A3-Knockout-Mäusen, nicht aber bei Wildtyp-Mäusen hochreguliert sind. 


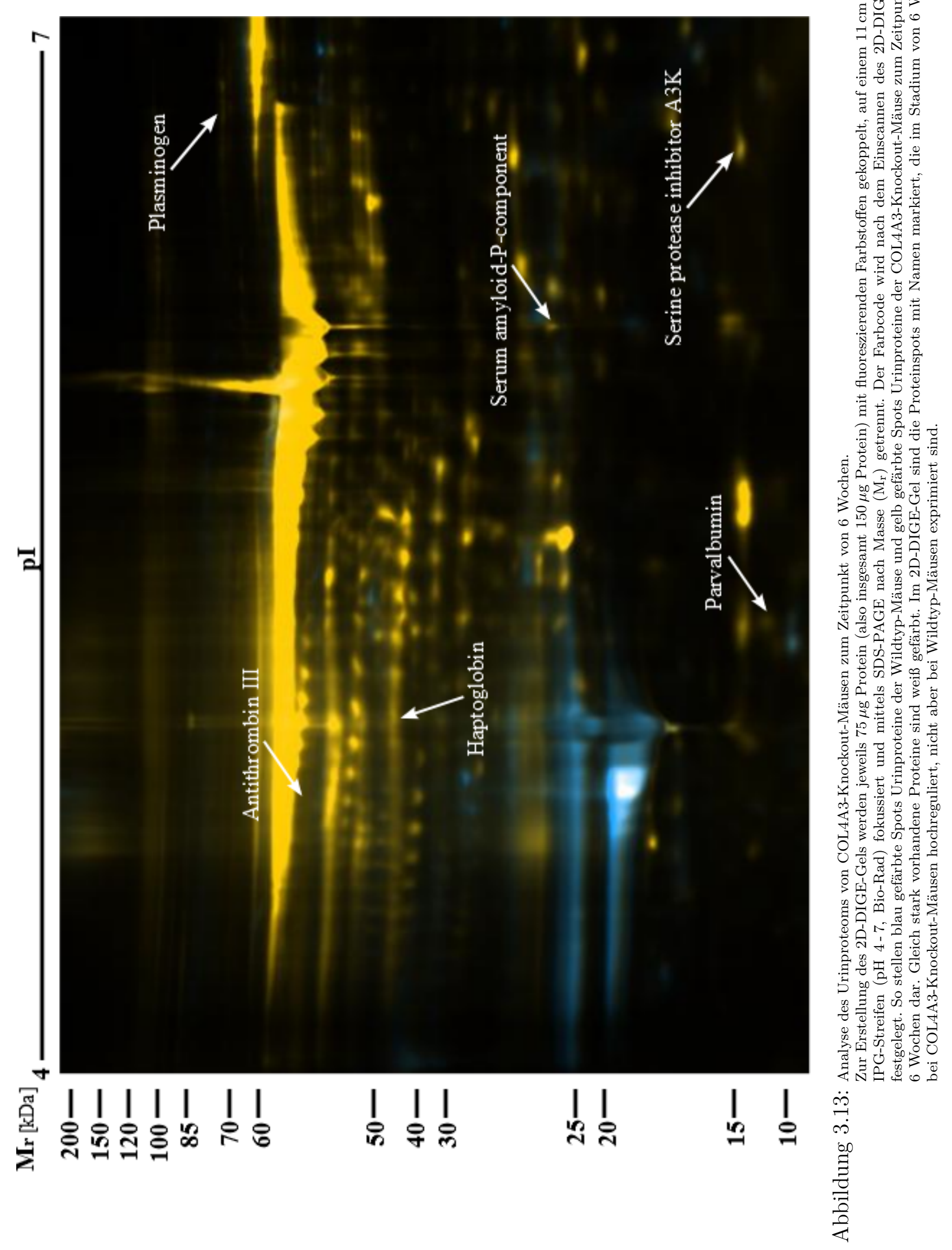




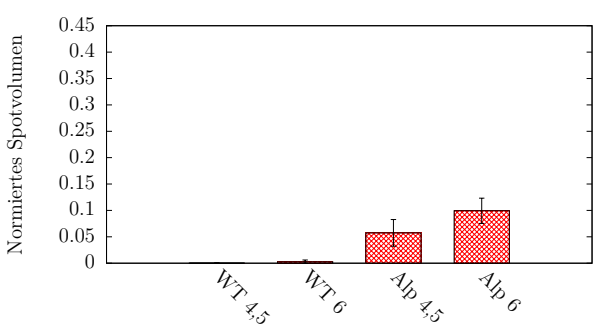

(a) Plasminogen

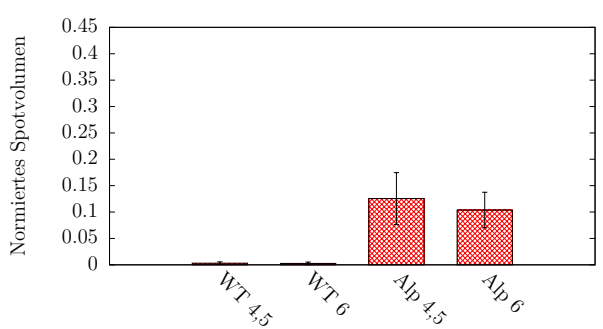

(c) Antithrombin III

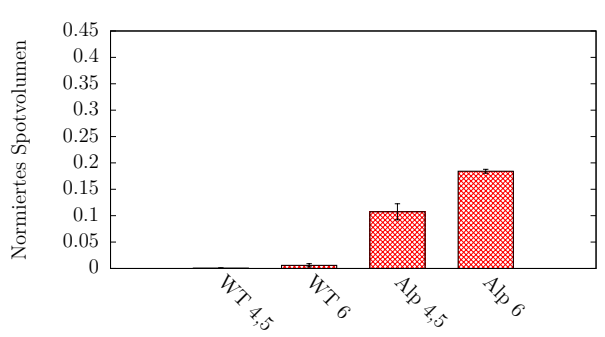

(e) Haptoglobin

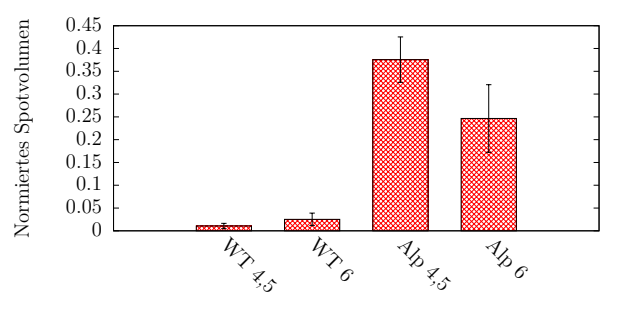

(b) Serum amyloid P-component

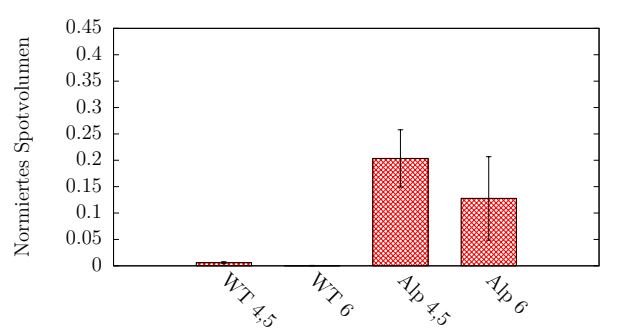

(d) Serine protease inhibitor A3K

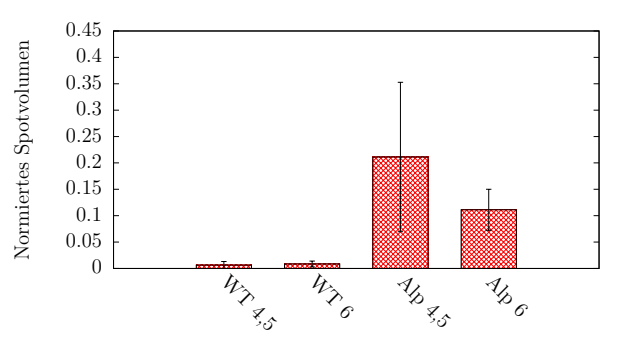

(f) Parvalbumin

Abbildung 3.14: Quantitative Auswertung der normierten Spotvolumen.

Es sind die Mittelwerte der normierten Spotvolumen verschiedener Proteine in (a) - (f) von Wildtyp- und COL4A3-Knockout-Mäusen zum Zeitpunkt von 4,5 und 6 Wochen graphisch aufgetragen. Den Graphen ist zu entnehmen, dass es große Proteinexpressionsunterschiede im Urin zwischen Wildtyp- und COL4A3-Knockout-Mäusen in beiden Stadien gibt. Die an Alport erkrankten Mäuse scheiden deutlich mehr Proteine in den Urin aus als Wildtyp-Mäuse.

Im Folgenden wird intensiver auf die in Abbildung 3.14 dargestellten normierten Spotvolumen eingegangen. Die relativen Proteinexpressionsunterschiede im Urin von Wildtyp- und COL4A3-Knockout-Mäusen lassen sich als Verhältnis R darstellen. Die Verhältnisse

$$
R_{4,5}=\frac{\langle\mathrm{WT} 4,5\rangle}{\langle\operatorname{Alp} 4,5\rangle} \text { und } R_{6}=\frac{\langle\mathrm{WT} 6\rangle}{\langle\operatorname{Alp} 6\rangle}
$$

beziehen sich auf die Mittelwerte der normierten Spotvolumen im Stadium von 4,5 und 6 Wochen. Als Kriterium für eine klinisch relevante Proteinregulation gilt für den Quotient der normierten Spotvolumen $\mathrm{R}<0,5$.

Für Plasminogen in Abbildung 3.14a betragen $R_{4,5}=0,0052$ und $R_{6}=0,0272$. Das bedeutet, dass Plasminogen im Wildtyp-Urinproteom 0,5\% bzw. 2,7\% des normierten Spotvolumens in COL4A3-Knockout-Urin beträgt. So ist Plasminogen im COL4A3-Knockout-Urinproteom im Stadium von 4,5 Wochen 191-fach mehr vor- 
handen als im Wildtyp-Urinproteom zum gleichen Zeitpunkt. Zudem ist die Expression von Plasminogen im Urin von COL4A3-Knockout-Mäusen 36-fach höher als im Wildtyp-Urin zum Zeitpunkt von 6 Wochen.

Beim Serum amyloid P-component in Abbildung 3.14bzeigen die COL4A3-KnockoutMäuse zum Zeitpunkt von 4,5 Wochen eine 35-fache Zunahme der Regulation mit $\mathrm{R}_{4,5}=0,0282$. Im Stadium von 6 Wochen beträgt $\mathrm{R}_{6}=0,1019$. In diesem Stadium ist Serum amyloid P-component im Urin der COL4A3-Knockout-Mäuse 9-fach mehr vorhanden als im Urin der Wildtyp-Mäuse.

Eine klinisch relevante Proteinregulation ist auch in Abbildung $3.14 \mathrm{c}$ bei Antithrombin III gegeben, wobei $\mathrm{R}_{4,5}=0,0247$. Antithrombin III ist im Urin an Alport erkrankter Knockout-Mäuse 40-fach mehr vertreten als in Wildtyp-Mäusen. Zum Zeitpunkt von 6 Wochen ist $\mathrm{R}_{6}=0,0260$. Im Vergleich zum Urin von Wildtyp-Mäusen ist $A n$ tithrombin III im Urin von COL4A3-Knockout-Mäusen um das 38-Fache hochreguliert.

In Abbildung $3.14 \mathrm{~d}$ entsprechen für Serine protease inhibitor A3K die relativen Proteinexpressionsunterschiede $\mathrm{R}_{4,5}=0,0290$ und $\mathrm{R}_{6}=0,0031$. Im 4,5 Wochen-Stadium ist Serine protease inhibitor A3K im COL4A3-Knockout-Urinproteom 34-fach und im Stadium von 6 Wochen sogar 319-fach mehr exprimiert als im Urinproteom der Wildtypen.

Haptoglobin ist in Abbildung 3.14e in einem Verhältnis von $\mathrm{R}_{4,5}=0,0065153$-fach mehr im Urin von Alport-Mäusen vorhanden als im Wildtyp-Urin. Mit einem Verhältnis von $\mathrm{R}_{6}=0,0326$ und 30-facher Hochregulierung der Proteinexpression ist Haptoglobin im Urin der COL4A3-Knockout-Mäuse im Vergleich zu Wildtyp-Mäusen deutlich erhöht.

Zudem gibt es eine klinisch relevante Proteinregulation von Parvalbumin in Abbildung $3.14 \mathrm{f}$ mit $\mathrm{R}_{4,5}=0,0298$ und $\mathrm{R}_{6}=0,0764$. Das normierte Spotvolumen von Parvalbumin im Urin von Alport-Mäusen ist zum Zeitpunkt von 4,5 Wochen 33-fach und im Stadium von 6 Wochen 13-fach höher als im Wildtyp-Urin.

Die quantitative Auswertung der Spotvolumen mit Delta 2D ergibt, dass Plasminogen, Serum amyloid P-component, Antithrombin III, Serine protease inhibitor A3K, Haptoglobin und Parvalbumin im Urin von Alport-Mäusen um ein Vielfaches hochreguliert und nur sehr wenig im Urin von Wildtyp-Mäusen exprimiert sind. Bisher sind für die Erstellung von 2D-SDS-PAGE- und 2D-DIGE-Gelen gepoolter Urin verwendet worden, um eine tendenzielle Aussage treffen zu können. Im nächsten Schritt werden mittels Western Blot einzelne Mäuse betrachtet, um die bisherigen Ergebnisse zu überprüfen. 


\subsection{Ergebnisdarstellung der 1D-Western Blots}

Nachdem bei der Auswertung der 2D-DIGE-Gele mit Delta 2D gezeigt werden kann, dass die Proteine Plasminogen, Serum amyloid P-component, Antithrombin III, Serine protease inhibitor A3K, Haptoglobin und Parvalbumin im Urin von COL4A3Knockout-Mäusen hochreguliert sind, werden zur Verifizierung dieser Ergebnisse 1DWestern Blots durchgeführt. Die Analyse mit 1D-Western Blot erfordert Urinproben von einzelnen Mäusen. Es stehen jeweils vier COL4A3-Knockout-Mäuse und vier Wildtyp-Mäuse in jeweils beiden Stadien zur Verfügung. Zur Erstellung der Western Blots ist eine Proteinkonzentration von $40 \mu \mathrm{g}$ verschiedener Mäuse nötig.

Im 1D-Western Blot wird mit spezifischen Antikörpern gegen die vermehrt vorhandenen Proteine auf Wiederholbarkeit der Proteinregulation getestet. Zudem kann geprüft werden, ob die Proteine auch im Wildtyp-Urin vorkommen. Pro Western Blot werden acht Proben aufgetragen. Da jeder Western Blot zur statistischen Auswertung mindestens dreimal angefertigt werden muss, sind mindestens 12 1D-Gele erforderlich. Zuvor wird jeder Antikörper getestet, um seine optimale Konzentration zu erfassen. Die Auswertung erfolgt mithilfe der Software ImageJ.

An dieser Stelle soll schon vorweggenommen werden, dass aufgrund der limitierten Anzahl von Mäusen und begrenzten Menge an Urin einer einzelnen Maus nicht immer die Urinproteine derselben Maus zum Zeitpunkt von 4,5 und 6 Wochen im Verlauf betrachtet werden können. Es wird davon ausgegangen, dass alle Mäuse genetisch identisch sind und somit in jedem Stadium der Erkrankung die gleichen Proteine ausscheiden. Es wird sich zeigen, dass Mäuse untereinander variieren können und eine unterschiedliche Anzahl modifizierter Formen eines Proteins ausscheiden. Das Ziel dieser Arbeit besteht darin, einen Marker für alle Mäuse und nicht für eine spezifische Maus zu finden.

\subsubsection{Auswertung der Bandenintensitäten zum Zeitpunkt von 4,5 Wochen}

In den Abbildungen 3.15-3.20 wird jeweils in (a) ein repräsentativer Western BlotAusschnitt des jeweiligen Proteins gezeigt und in (b) die dazu erfolgte statistische Auswertung. In (c) sind die gewichteten Mittelwerte der Intensitäten der 1. und 2. Bande des jeweiligen Proteins graphisch dargestellt. Die relativen Bandenintensitäten im Urin von Wildtyp- und COL4A3-Knockout-Mäusen lassen sich als Verhältnis $\mathrm{R}$ darstellen. Die Verhältnisse

$$
R_{1}=\frac{\langle\mathrm{WT}\rangle}{\langle\mathrm{Alp}\rangle} \text { und } R_{2}=\frac{\langle\mathrm{WT}\rangle}{\langle\mathrm{Alp}\rangle}
$$


werden im Folgenden näher erläutert. Als Kriterium für eine klinisch relevante Proteinregulation gilt für den Quotient der Bandenintensitäten $\mathrm{R}<0,5$. Zudem werden mögliche Gruppenunterschiede zwischen Wildtyp- und COL4A3-Knockout-Mäusen mittels unverbundenen t-Tests untersucht. Es soll betrachtet werden, ob bereits bei einer geringen Fallzahl von jeweils vier Mäusen pro Gruppe eine statistische Signifikanz gezeigt werden kann. Aufgrund der sehr geringen Fallzahl wird auf die Verwendung nichtparametrischer Verfahren verzichtet. Es wurde sich dabei in Absprache mit einem Statistiker der Universität Göttingen für den t-Test entschieden. Alle Analysen werden mithilfe der Statistik-Software Statistica 10 ausgewertet. Die Ergebnisse des t-Tests sind der Tabelle 6.2 auf Seite 89 im Anhang zu entnehmen. Das Hauptaugenmerk ist dennoch auf die klinisch relevante Proteinregulation gerichtet.

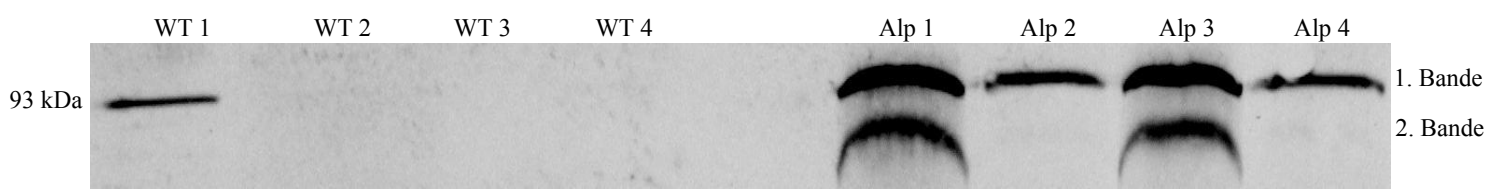

(a) Western Blot-Ausschnitt von Plasminogen

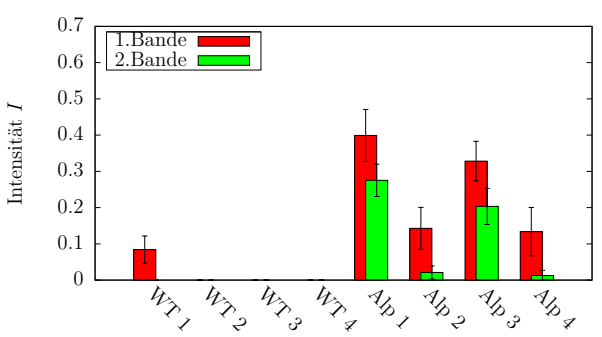

(b) Statistische Auswertung

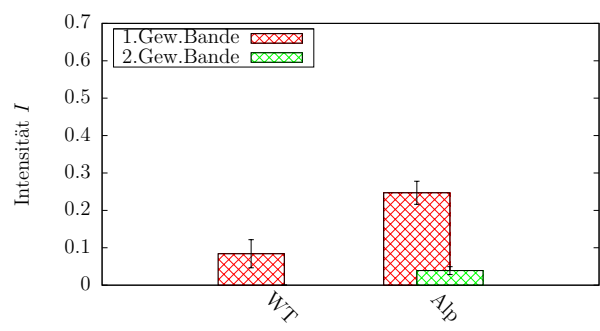

(c) Gewichtete Mittelwerte

Abbildung 3.15: Statistische Auswertung der Bandenintensitäten von Plasminogen zum Zeitpunkt von 4,5 Wochen.

Die Durchführung des Western Blots erfolgt nach dem gängigen Protokoll (Dihazi et al.|2009). In (a) ist ein Western Blot-Ausschnitt von Plasminogen dargestellt. Der Abbildung ist zu entnehmen, dass Plasminogen bei $93 \mathrm{kDa}$ mit bis zu zwei Banden exprimiert ist. Plasminogen zeigt eine vermehrte Intensität bei den COL4A3-Knockout-Mäusen, wie es in (b) statistisch belegt ist. Nur eine Wildtyp-Maus zeigt eine mäßige Intensität. In (c) sind die gewichteten Mittelwerte der in Abbildung (b) gezeigten Mittelwerte graphisch dargestellt.

Der Abbildung 3.15 ist zu entnehmen, dass Plasminogen vermehrt in den Urin einzelner COL4A3-Knockout-Mäuse ausgeschieden wird. Mit $R_{1}=0,3401$ ist es klinisch relevant hochreguliert. Der gewichtete Mittelwert der 1. Bande ist bei den AlportMäusen etwa 3-fach höher als bei den Wildtyp-Mäusen. Nur eine Wildtyp-Maus zeigt eine mäßige Intensität in der 1. Bande. Eine 2. Bande ist bei keiner zu messen. 


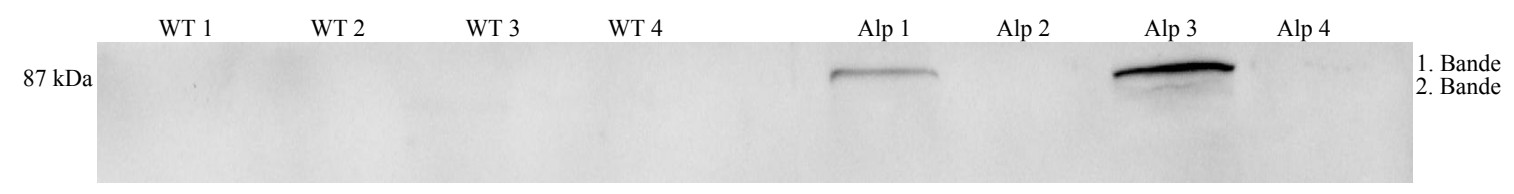

(a) Western Blot-Ausschnitt von Serum amyloid P-component

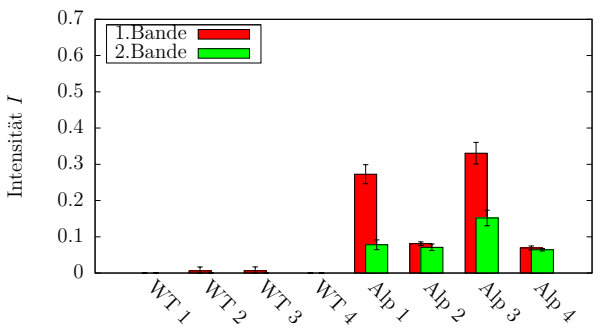

(b) Statistische Auswertung

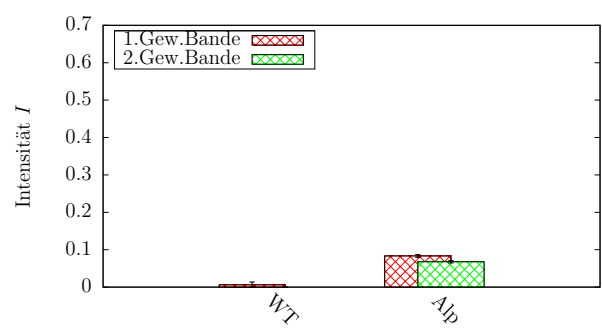

(c) Gewichtete Mittelwerte

Abbildung 3.16: Statistische Auswertung der Bandenintensitäten von Serum amyloid P-component zum Zeitpunkt von 4,5 Wochen.

In (a) ist ein Western Blot-Ausschnitt von Serum amyloid P-component dargestellt. Die Abbildung zeigt, dass Serum amyloid P-component bei $87 \mathrm{kDa}$ mit zum Teil zwei Banden exprimiert ist. Das Protein hat eine erhöhte Intensität bei den COL4A3-Knockout-Mäusen, wie es in (b) statistisch belegt ist. In (c) sind die gewichteten Mittelwerte der in Abbildung (b) gezeigten Mittelwerte graphisch dargestellt. Serum amyloid P-component ist im Urin von Alport-Mäusen gegenüber Wildtyp-Mäusen klinisch relevant hochreguliert.

Gemäß Abbildung 3.16 ist Serum amyloid P-component im Urin von Alport-Mäusen in einem Verhältnis von $\mathrm{R}_{1}=0,074422 \mathrm{mal}$ mehr vorhanden als im Urin einzelner Wildtyp-Mäuse. Die 2. Bande ist bei den Wildtyp-Mäusen nicht exprimiert.
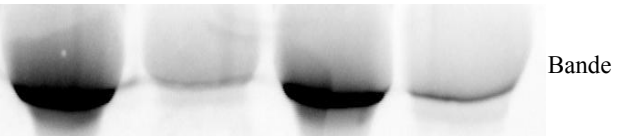

(a) Western Blot-Ausschnitt von Antithrombin III

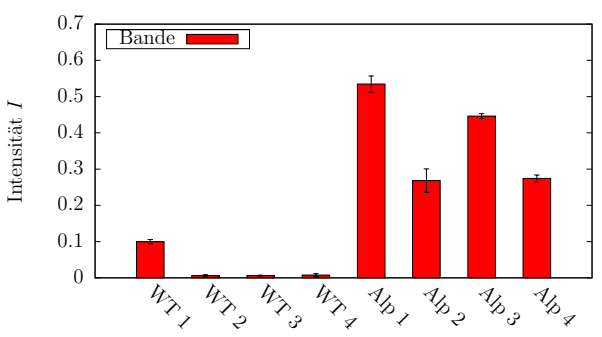

(b) Statistische Auswertung

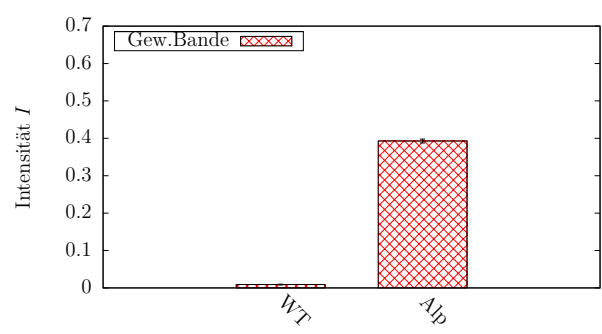

(c) Gewichtete Mittelwerte

Abbildung 3.17: Statistische Auswertung der Bandenintensitäten von Antithrombin III zum Zeitpunkt von 4,5 Wochen.

In (a) ist ein Western Blot-Ausschnitt von Antithrombin III dargestellt. Antithrombin III ist bei $52 \mathrm{kDa}$ mit einer Bande exprimiert. Die Bandenintensitäten bei den COL4A3-KnockoutMäusen sind sehr hoch, wie es in (b) statistisch veranschaulicht ist. In (c) sind die gewichteten Mittelwerte der in Abbildung (b) dargestellten Mittelwerte graphisch aufgezeigt. Das Protein hat eine klinisch relevante Proteinregulation bei den COL4A3-Knockout-Mäusen.

Auf der Abbildung 3.17 ist zu sehen, dass Antithrombin III mit $\mathrm{R}_{1}=0,0229$ 43-fach mehr im Urin von COL4A3-Knockout-Mäusen exprimiert ist.

Serine protease inhibitor A3K wird gemäß Abbildung 3.18 von COL4A3-Knockout- 


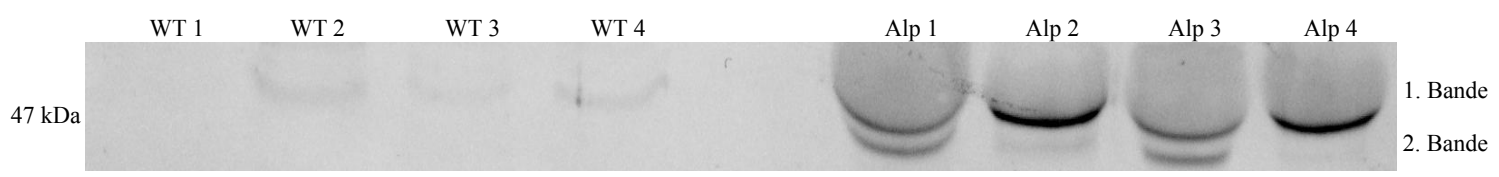

(a) Western Blot-Ausschnitt von Serine protease inhibitor A3K

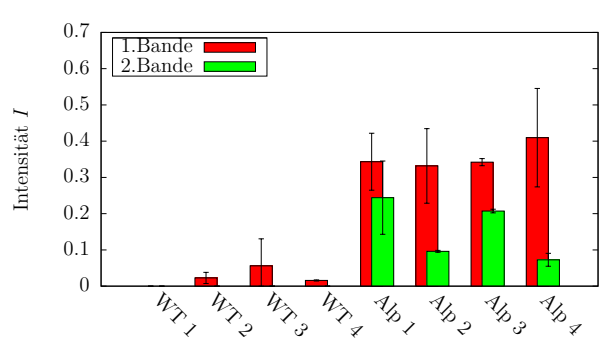

(b) Statistische Auswertung

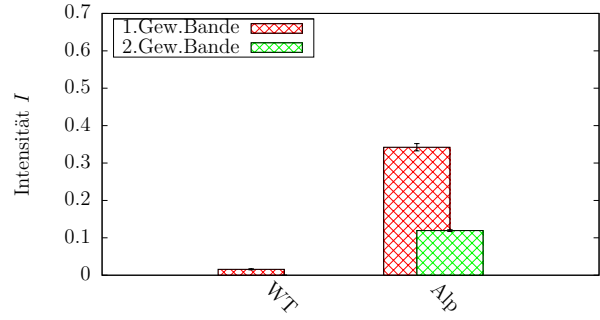

(c) Gewichtete Mittelwerte

Abbildung 3.18: Statistische Auswertung der Bandenintensitäten von Serine protease inhibitor A3K zum Zeitpunkt von 4,5 Wochen.

Serine protease inhibitor A3K ist bei $47 \mathrm{kDa}$ mit bis zu zwei Banden exprimiert. Die Bandenintensitäten bei den COL4A3-Knockout-Mäusen sind im Vergleich zu den Wildtyp-Mäusen deutlich erhöht.

Mäusen deutlich vermehrt in den Urin ausgeschieden. Mit $\mathrm{R}_{1}=0,0462$ ist Serine protease inhibitor $A 3 K$ klinisch relevant hochreguliert. Der gewichtete Mittelwert der 1. Bande ist bei den Alport-Mäusen 21-fach höher als bei den Wildtyp-Mäusen. Eine 2. Bande des Proteins ist bei den Wildtypen nicht feststellbar.
WT 1
WT 2
WT 3
WT 4
Alp 1
Alp 2
Alp 3
Alp 4

$39 \mathrm{kDa}$

(a) Western Blot-Ausschnitt von Haptoglobin

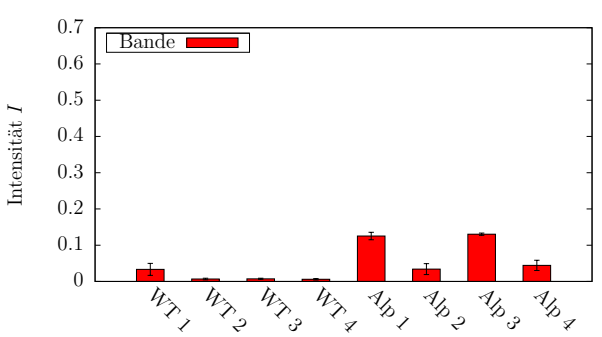

(b) Statistische Auswertung

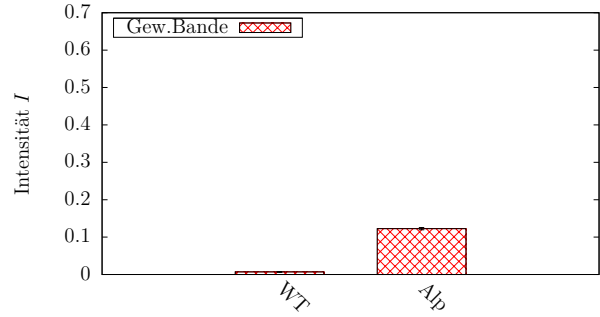

(c) Gewichtete Mittelwerte

Abbildung 3.19: Statistische Auswertung der Bandenintensitäten von Haptoglobin zum Zeitpunkt von 4,5 Wochen.

Haptoglobin ist bei $39 \mathrm{kDa}$ mit einer Bande exprimiert und zeigt eine erhöhte Intensität bei den COL4A3-Knockout-Mäusen. Die Wildtyp-Mäuse zeigen eine geringe Bandenintensität.

In Abbildung 3.19 wird deutlich, dass Haptoglobin sowohl im Urin von Alport- als auch von Wildtyp-Mäusen vorkommt. Dennoch lässt sich aus Abbildung 3.19c feststellen, dass Haptoglobin bei COL4A3-Knockout-Mäusen mit $\mathrm{R}_{1}=0,0563$ etwa 17fach erhöht ausgeschieden wird als bei Wildtyp-Mäusen. Eine 2. Bande kann bei keiner der beiden Mäusegruppen gefunden werden. 


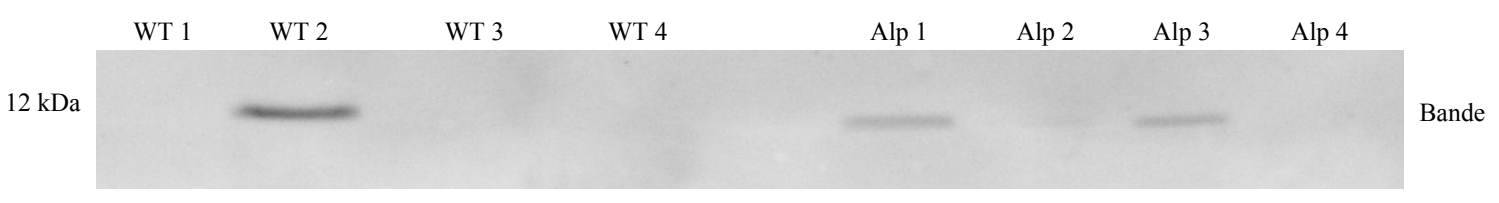

(a) Western Blot-Ausschnitt von Parvalbumin

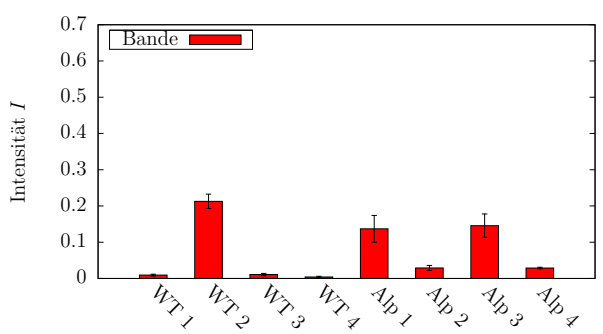

(b) Statistische Auswertung

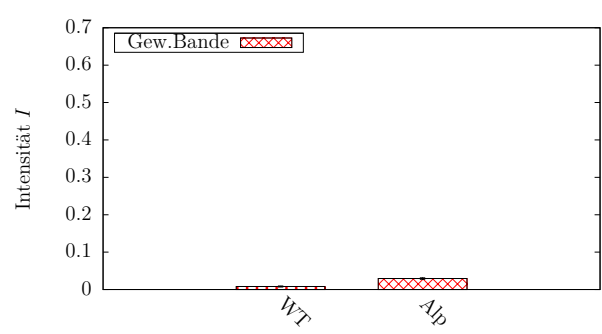

(c) Gewichtete Mittelwerte

Abbildung 3.20: Statistische Auswertung der Bandenintensitäten von Parvalbumin zum Zeitpunkt von 4,5 Wochen.

In (a) wird ein Western Blot-Ausschnitt von Parvalbumin gezeigt. Dieses Protein ist bei $12 \mathrm{kDa}$ mit einer Bande vertreten. Parvalbumin zeigt seine intensivste Bande bei der zweiten Wildtyp-Maus, wie es in (b) statistisch dargestellt ist. In (c) sind die gewichteten Mittelwerte der in Abbildung (b) gezeigten Mittelwerte graphisch aufgetragen.

Abbildung 3.20 zeigt, dass Parvalbumin sowohl von Alport- als auch von WildtypMäusen ohne erkennbarem Trend in den Urin ausgeschieden wird. Als Biomarker im Urin beim Alport-Syndrom scheint Parvalbumin auszuscheiden, obwohl $\mathrm{R}_{1}=0,2712$ nicht klinisch unrelevant ist. Eine 2. Bande ist weder bei den COL4A3-KnockoutMäusen noch bei den Wildtyp-Mäusen vorhanden.

\subsubsection{Auswertung der Bandenintensitäten zum Zeitpunkt von 6 Wochen}

Auch in den Abbildungen 3.21 - 3.26 wird in (a) ein repräsentativer Western BlotAusschnitt des jeweiligen Proteins gezeigt und in (b) die dazu erfolgte statistische Auswertung. In (c) sind die gewichteten Mittelwerte der Intensitäten der 1., 2. und 3. Bande des jeweiligen Proteins graphisch aufgetragen. Die relativen Bandenintensitäten im Urin von Wildtyp- und COL4A3-Knockout-Mäusen werden erneut durch Verhältnis R gestellt. Die Verhältnisse

$$
R_{1}=\frac{\langle\mathrm{WT}\rangle}{\langle\mathrm{Alp}\rangle} \text { und } R_{2}=\frac{\langle\mathrm{WT}\rangle}{\langle\mathrm{Alp}\rangle} \text { und } R_{3}=\frac{\langle\mathrm{WT}\rangle}{\langle\mathrm{Alp}\rangle}
$$

werden im Folgenden thematisiert. Als Kriterium für eine klinisch relevante Proteinregulation gilt für den Quotient der Bandenintensitäten $\mathrm{R}<0,5$. Auch hier werden mögliche Gruppenunterschiede zwischen Wildtyp- und COL4A3-Knockout-Mäusen mittels eines unverbundenen t-Tests untersucht. Die Ergebnisse des t-Tests sind der Tabelle 6.3 auf Seite 89 im Anhang zu entnehmen.

Abbildung 3.21 zeigt, dass Plasminogen deutlich vermehrt in den Urin einzelner 


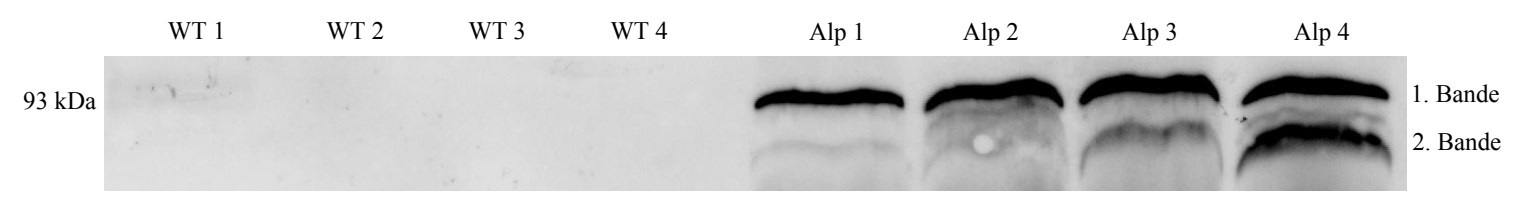

(a) Western Blot-Ausschnitt von Plasminogen

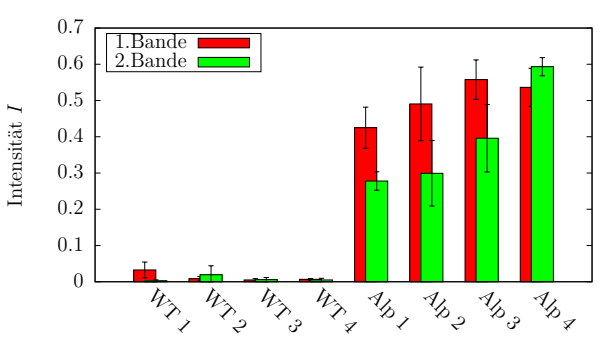

(b) Statistische Auswertung

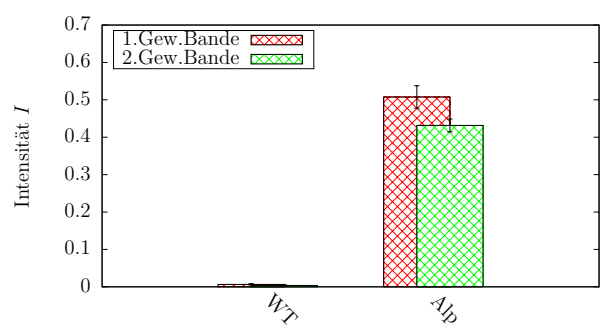

(c) Gewichtete Mittelwerte

Abbildung 3.21: Statistische Auswertung der Bandenintensitäten von Plasminogen zum Zeitpunkt von 6 Wochen.

Die Durchführung des Western Blots erfolgt nach dem gängigen Protokoll (Dihazi et al. 2009). In (a) ist ein Western Blot-Ausschnitt von Plasminogen dargestellt. Der Abbildung ist zu entnehmen, dass Plasminogen bei $93 \mathrm{kDa}$ mit bis zu zwei Banden exprimiert ist. Plasminogen zeigt eine deutlich erhöhte Intensität bei den COL4A3-Knockout-Mäusen, wie es in (b) statistisch belegt ist. Die Wildtyp-Mäuse zeigen kaum Bandenintensität. In (c) sind die gewichteten Mittelwerte der in Abbildung (b) gezeigten Mittelwerte graphisch dargestellt.

COL4A3-Knockout-Mäuse ausgeschieden wird. Mit $\mathrm{R}_{1}=0,0130$ ist dieses Protein klinisch relevant erhöht. Das bedeutet, dass Plasminogen im Urin von WildtypMäusen gerade mal 0,1\% der relativen Intensität im COL4A3-Knockout-Urin beträgt. Der gewichtete Mittelwert der 1. Bande ist dabei etwa 76-fach höher als bei den Wildtyp-Mäusen. Auch die 2. Bande erfährt mit $R_{2}=0,0083$ eine klinisch relevante Hochregulierung. Sie ist damit etwa 119mal höher im Urin an Alport erkrankter Mäuse vertreten.

Serum amyloid P-component wird gemäß Abbildung 3.22 vermehrt in den Urin einzelner COL4A3-Knockout-Mäuse ausgeschieden, sodass $\mathrm{R}_{1}=0,0272$ beträgt, was für eine klinisch relevante Hochregulierung spricht. Der gewichtete Mittelwert der 1. Bande ist bei den Alport-Mäusen 36-fach höher als bei den Wildtyp-Mäusen. Lediglich eine mäßige Bande ist bei einem der Wildtypen zu sehen. Mit $R_{2}=0,0047$ ist dies ebenfalls klinisch relevant. Serum amyloid P-component beträgt daher im WildtypUrin 0,4\% der relativen Bandenintensität im COL4A3-Knockout-Urin. Abbildung $3.22 \mathrm{c}$ veranschaulicht eine 211-fach höhere Exprimierung bei COL4A3-KnockoutMäusen.

In Abbildung 3.23 ist zu sehen, dass Antithrombin III deutlich vermehrt in den Urin einzelner COL4A3-Knockout-Mäuse ausgeschieden wird, sodass $\mathrm{R}_{1}=0,0125$ beträgt, was für eine klinisch relevante Proteinregulation spricht. Antithrombin III beträgt im Wildtyp-Urin 0,1\% der relativen Bandenintensität im COL4A3-Knockout-Urin. Der gewichtete Mittelwert der Bande ist bei den Alport-Mäusen 80-fach höher als bei den Wildtyp-Mäusen. 


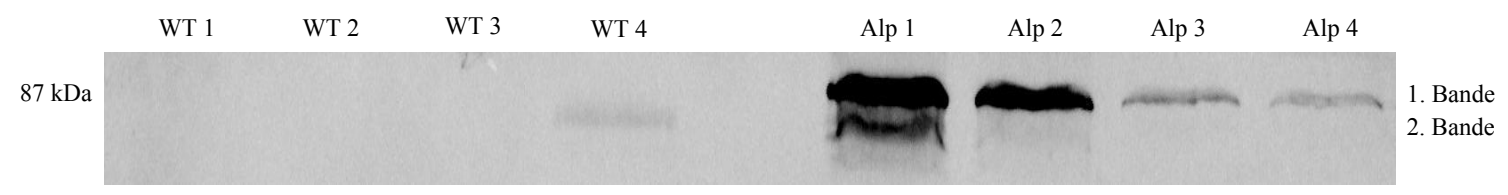

(a) Western Blot-Ausschnitt von Serum amyloid P-component

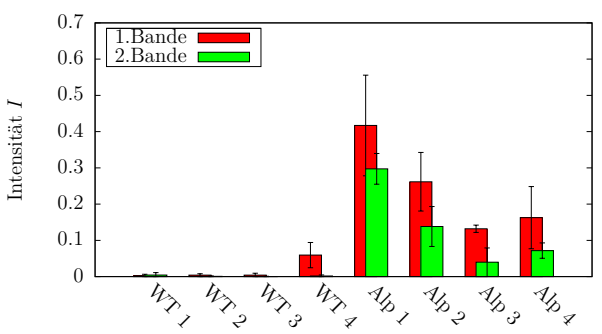

(b) Statistische Auswertung

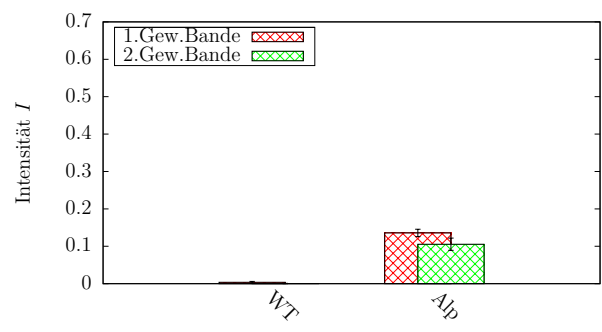

(c) Gewichtete Mittelwerte

Abbildung 3.22: Statistische Auswertung der Bandenintensitäten von Serum amyloid P-component zum Zeitpunkt von 6 Wochen.

In (a) ist ein Western Blot-Ausschnitt von Serum amyloid P-component dargestellt. Die Abbildung zeigt, dass Serum amyloid P-component bei $87 \mathrm{kDa}$ mit zum Teil zwei Banden exprimiert ist. Das Protein hat eine deutlich gesteigerte Intensität bei den COL4A3-KnockoutMäusen, wie es in (b) statistisch belegt ist. In (c) sind die gewichteten Mittelwerte der in Abbildung (b) gezeigten Mittelwerte graphisch aufgetragen.

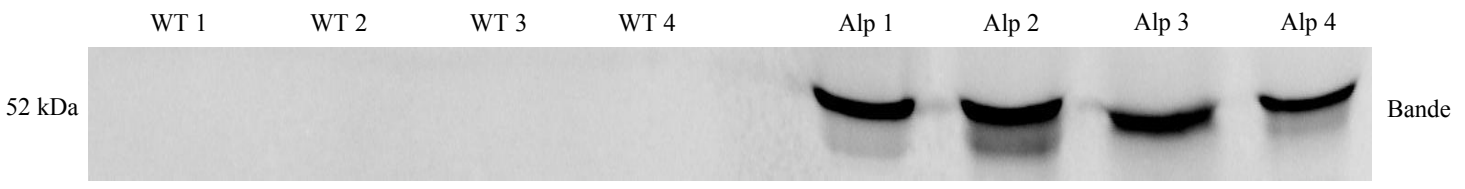

(a) Western Blot-Ausschnitt von Antithrombin III

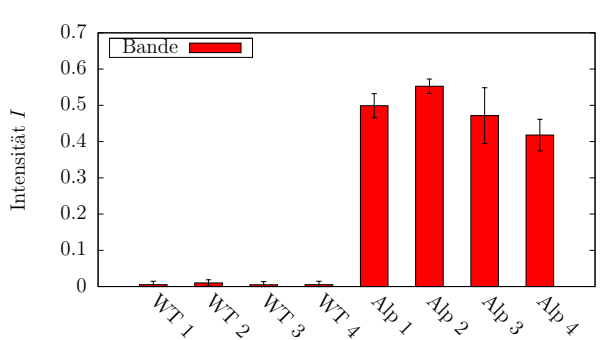

(b) Statistische Auswertung

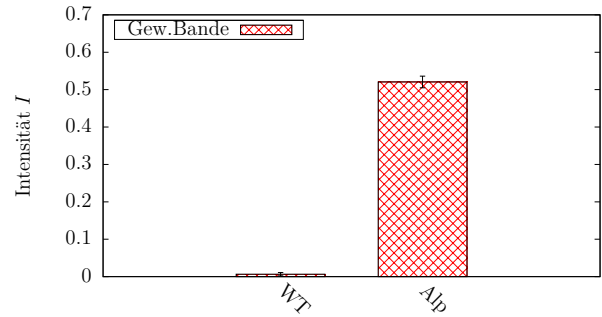

(c) Gewichtete Mittelwerte

Abbildung 3.23: Statistische Auswertung der Bandenintensitäten von Antithrombin III zum Zeitpunkt von 6 Wochen.

In (a) wird ein Western Blot-Ausschnitt von Antithrombin III gezeigt. Antithrombin III ist bei $52 \mathrm{kDa}$ mit einer Bande exprimiert. Die Bandenintensitäten bei den COL4A3-KnockoutMäusen sind auffällig hoch, wie es in (b) statistisch veranschaulicht ist. In (c) sind die gewichteten Mittelwerte der in Abbildung (b) dargestellten Mittelwerte graphisch aufgezeigt. Antithrombin III hat eine klinisch relevante Hochregulierung bei den COL4A3-KnockoutMäusen.

Serine protease inhibitor A3K wird gemäß Abbildung 3.24 von COL4A3-KnockoutMäusen deutlich vermehrt in den Urin ausgeschieden. Mit $\mathrm{R}_{1}=0,0021$ ist Serine protease inhibitor $A 3 K$ klinisch relevant hochreguliert. Der gewichtete Mittelwert der 1. Bande ist bei den Alport-Mäusen 485-fach höher als bei den Wildtyp-Mäusen. Weder die 2. noch die 3. Bande sind beim Wildtyp exprimiert. Im Vergleich mit den anderen im Western Blot untersuchten Proteinen erscheint Serine protease inhibitor 


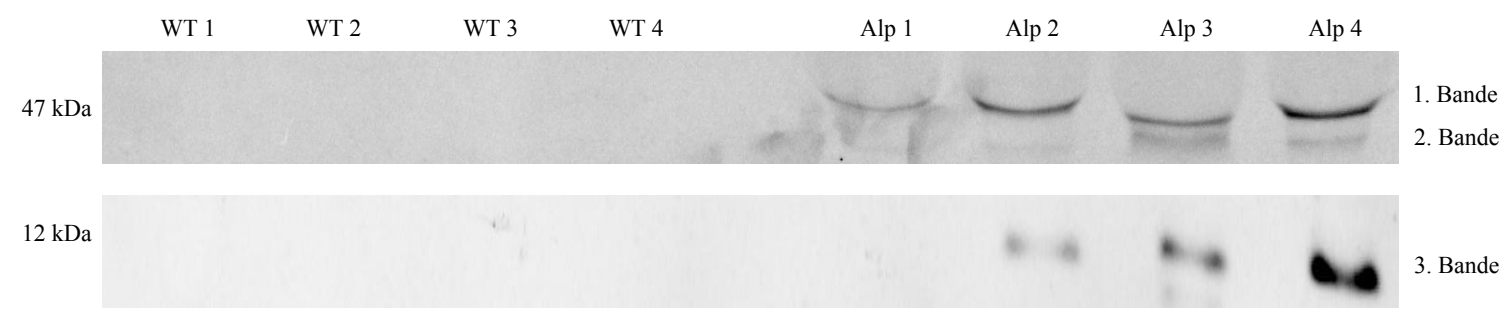

(a) Western Blot-Ausschnitt von Serine protease inhibitor A3K

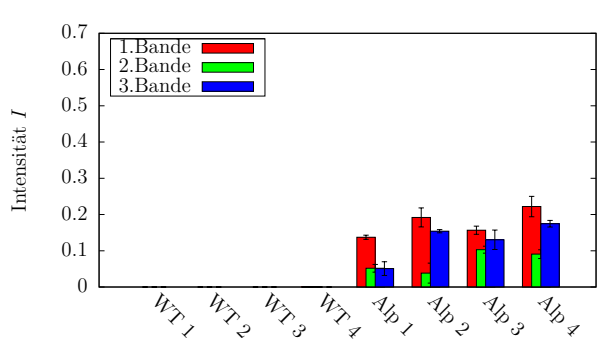

(b) Statistische Auswertung

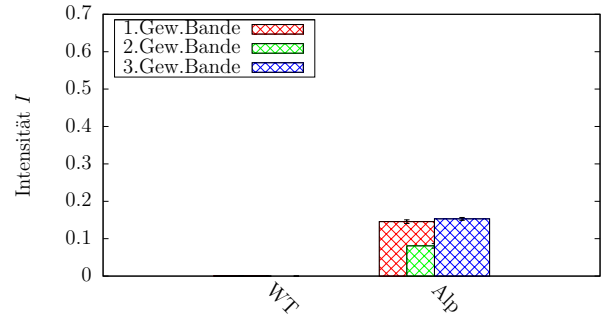

(c) Gewichtete Mittelwerte

Abbildung 3.24: Statistische Auswertung der Bandenintensitäten von Serine protease inhibitor A3K zum Zeitpunkt von 6 Wochen.

In (a) ist ein Western Blot-Ausschnitt von Serine protease inhibitor A3K dargestellt. Dieses Protein ist bei $47 \mathrm{kDa}$ mit bis zu zwei Banden exprimiert. Zusätzlich gibt es eine 3. Bande auf Höhe von $12 \mathrm{kDa}$. Die Bandenintensitäten bei den COL4A3-Knockout-Mäusen sind im Vergleich zu den Wildtyp-Mäusen deutlich erhöht, wie es in (b) graphisch aufgetragen ist. In (c) sind die gewichteten Mittelwerte der in Abbildung (b) gezeigten Mittelwerte graphisch dargestellt. Es besteht eine klinisch relevante Proteinregulation.

A3K als zusätzliche 3 . Bande auf Höhe von $12 \mathrm{kDa}$. Dies stellt eine Besonderheit dar.

$39 \mathrm{kDa}$

(a) Western Blot-Ausschnitt von Haptoglobin

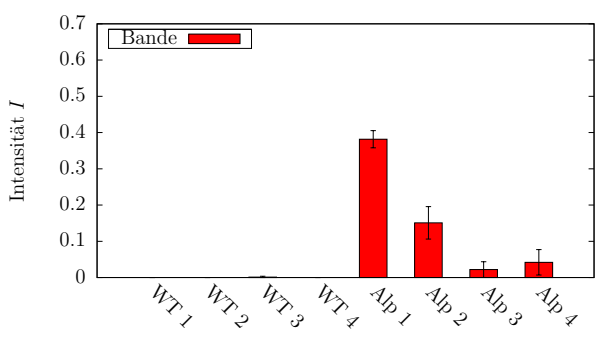

(b) Statistische Auswertung

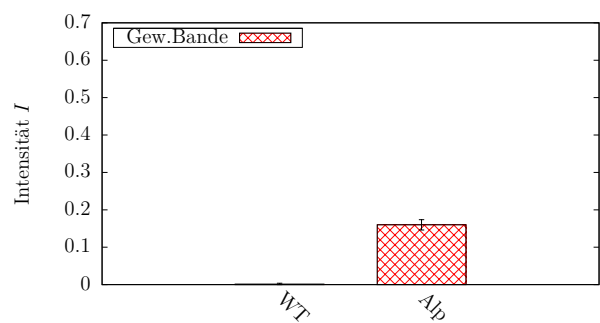

(c) Gewichtete Mittelwerte

Abbildung 3.25: Statistische Auswertung der Bandenintensitäten von Haptoglobin zum Zeitpunkt von 6 Wochen.

In (a) ist ein Western Blot-Ausschnitt von Haptoglobin abgebildet. Haptoglobin ist bei $39 \mathrm{kDa}$ mit einer Bande vorhanden. Es zeigt eine erhöhte Intensität bei den COL4A3-KnockoutMäusen, wie es in (b) statistisch belegt ist. In (c) sind die gewichteten Mittelwerte der in Abbildung (b) gezeigten Mittelwerte graphisch aufgetragen.

Abbildung 3.25 macht deutlich, dass Haptoglobin vorrangig im Urin von AlportMäusen vorkommt. Dieses Protein wird mit einem Verhältnis $R_{1}=0,0081$ etwa 
123mal mehr von COL4A3-Knockout-Mäusen in den Urin ausgeschieden. Eine 2. Bande ist bei keiner der beiden Mäusegruppen gegeben.

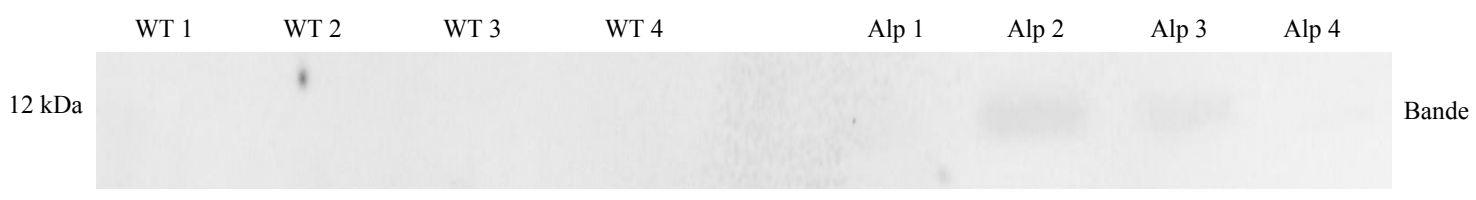

(a) Western Blot-Ausschnitt von Parvalbumin

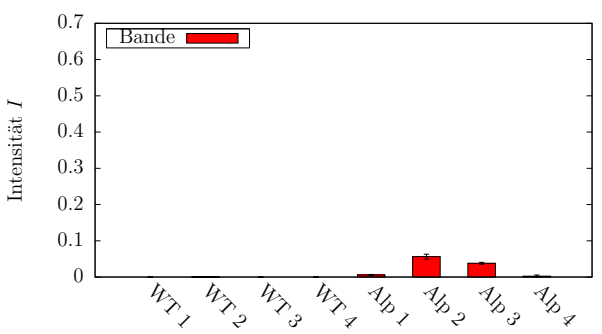

(b) Statistische Auswertung

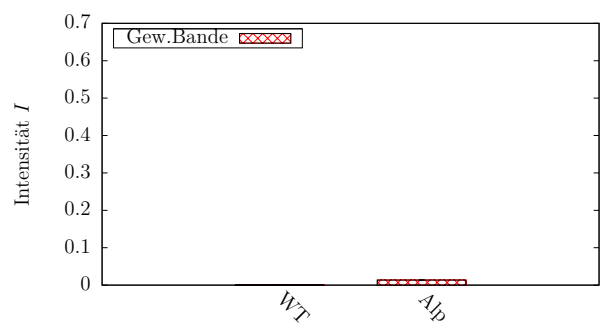

(c) Gewichtete Mittelwerte

Abbildung 3.26: Statistische Auswertung der Bandenintensitäten von Parvalbumin zum Zeitpunkt von 6 Wochen.

In (a) wird ein Western Blot-Ausschnitt von Parvalbumin gezeigt. Dieses Protein ist bei $12 \mathrm{kDa}$ mit einer Bande vertreten. Parvalbumin wird von beiden Mäusegruppen nur ganz wenig in den Urin ausgeschieden. Die Banden bei den COL4A3-Knockout-Mäusen sind ganz schwach zu erkennen. In (c) sind die gewichteten Mittelwerte der in Abbildung (b) gezeigten Mittelwerte graphisch aufgeführt.

Abbildung 3.26 zeigt zwar, dass Parvalbumin mit $\mathrm{R}_{1}=0,0222$ klinisch relevant hochreguliert ist, dennoch wird es nur in sehr geringen Mengen in den Urin der COL4A3Knockout-Mäuse ausgeschieden. Eine 2. Bande ist bei keiner der beiden Mäusegruppen vorhanden.

\subsubsection{Zusammenfassung der Ergebnisse im 1D-Western Blot}

Die Proteine Plasminogen, Serum amyloid P-component und Antithrombin III zeigen jeweils bei den Alport-Mäusen eine Zunahme der Bandenexpression beim Vergleich von 4,5 und 6 Wochen. Diese in den 2D-DIGE-Gelen klinisch relevant hochregulierten Proteine können durch Experimente mit 1D-Western Blot verifiziert werden.

Die Intensitäten der 1. und 2. Bande von Serine protease inhibitor A3K (Abb. 3.24) nehmen teilweise bei den COL4A3-Knockout-Mäusen leicht ab oder sind konstant. Dafür kommt im Stadium von 6 Wochen eine 3. Bande hinzu. Insgesamt lässt sich also sagen, dass auch Serine protease inhibitor A3K bei den Alport-Mäusen klinisch relevant hochreguliert ist und somit verifiziert werden kann.

Haptoglobin und Parvalbumin können trotz guter Verhältnisangaben nicht als ausreichend klinisch relevant erklärt werden. Die gewichtete Bandenintensität von Haptoglobin ist im Vergleich von 4,5 und 6 Wochen zwar etwa konstant, allerdings ist die Intensität der Banden zum Zeitpunkt von 6 Wochen nur bei der Hälfte der 
Alport-Mäuse relevant erhöht. Es ist daher kein Trend der Banden bei den COL4A3Knockout-Mäusen erkennbar, womit Haptoglobin als potentieller Marker entfällt. Bei Parvalbumin ist ebenfalls kein Trend sichtbar, was insbesondere in Abbildung 3.20 deutlich wird. Hier ist die Bande mit der höchsten Intensität bei den WildtypMäusen exprimiert. Im Stadium von 6 Wochen ist die Bandenintensität nur bei der Hälfte der Alport-Mäuse mäßig erhöht. Dies lässt keine Verifizierung des Parvalbumins zu.

Im nächsten Kapitel werden die klinisch relevant hochregulierten und mittels Western Blot verifizierten Proteine Plasminogen, Serum amyloid P-component, Antithrombin III und Serine protease inhibitor A3K biochemisch diskutiert, indem versucht wird einen Zusammenhang zur Pathogenese des Alport-Syndroms herzustellen. 


\section{Diskussion}

Mithilfe von proteomischen Verfahren in Kombination mit der Massenspektrometrie konnten sechs Proteine identifiziert werden, die im Urin von COL4A3-KnockoutMäusen im Stadium von 4,5 und 6 Wochen hochreguliert sind. Mittels Western Blot wurden die Proteine Plasminogen, Serum amyloid P-component, Antithrombin III und Serine protease inhibitor A3K als potentielle Biomarker verifiziert. Diese Proteine gilt es in Bezug auf ihre Relevanz für das Alport-Syndrom zu diskutieren.

\subsection{Biomarkersuche bei der diabetischen Nephropathie}

Das Alport-Syndrom ist eine Nierenerkrankung, dessen Früherkennung essentiell für einen bestmöglichen Therapieeffekt ist. Für die frühe Diagnostik dieser Erkrankung sind Biomarker erforderlich, die einfach und nicht-invasiv vom Patienten zu gewinnen sind.

Die Detektion von Biomarkern in leicht zugänglichen Medien wie Urin stellt einen aussichtsreichen Ansatz dar (Aebersold und Mann 2003). In den letzten Jahren konnten sich die leistungsfähigen massenspektrometrischen Verfahren zur Proteinanalyse immer stärker durchsetzen. Durch ihre rasante Entwicklung ist die Biomarkerdetektion eine der Hauptaufgaben in der Proteomforschung geworden (Schrattenholz 2001). So wurde auch beim Krankheitsbild der diabetischen Nephropathie die Biomarkerdetektion im Urin mittels Proteomics versucht. Durch Vergleich von Proteomprofilen konnten drei mögliche Marker gefunden werden, die im Urin von Patientengruppen mit diabetischer Nephropathie vorhanden sind: Ubiquitin, UbA52 und $\beta 2$-Mikroglobulin (Dihazi et al. 2007).

Beim Alport-Syndrom sind bislang keine Biomarker bekannt. Biomarker in wenig invasiven und leicht gewinnbaren Proben wie Urin wären beim Alport-Syndrom wünschenswert und sollen im Rahmen dieses Projekts konkretisiert werden.

\subsection{Der Podozyt im Fokus der Erkrankung}

Bei der Pathogenese des Alport-Syndroms kommt es zur Mutation der $\alpha 3$-/ $\alpha 4$ - oder $\alpha 5(\mathrm{IV})$-Ketten. Diese werden ausschließlich von den Podozyten synthetisiert, was 
sie in den Fokus der Erkrankung rückt. Zur Übersicht wurde die Abbildung 4.1 auf Seite 75 angefertigt, die der vereinfachten Darstellung der im Zusammenhang mit der Pathogenese des Alport-Syndroms stehenden potentiellen Biomarker dienen soll. Durch die Mutationen kommt es zum Kollagenumbau, indem die embryonalen $\left.\alpha 1_{(2)}\right)^{-}$und $\alpha 2$-Ketten eingebaut werden. Im Vergleich zu den embryonalen Ketten enthalten die $\alpha 3-/ \alpha 4-/ \alpha 5$ (IV)-Ketten jedoch viele Disulfidbrücken, welche für den täglichen Filtrationsprozess notwenig sind Abrahamson et al. 2009, Gross et al. 2010).

Die ortsständigen Zellen wie Podozyten, Mesangiumzellen und Epithelzellen nehmen mit ihren Rezeptoren den Kollagendefekt wahr. Kommt es durch Strukturänderung der GBM zu einem Verlust der direkten Interaktion zwischen $\alpha 1 \beta 1$-Integrin und seinem Liganden Kollagen IV, lösen die Mesangiumzellen pleotrope Effekte in Bezug auf MMPs und TIMPs aus (Kashtan 1999). Veränderungen im Synthese- und Degradationsgleichgewicht hat eine Glomerulosklerose zur Folge, indem die Basalmembran anfängt sich zu verdicken und aufzusplittern. Zum anderen erfolgt eine Hochregulierung vom profibrotischen Faktor TGF- $\beta$ (Cosgrove et al. 2008). EZM wie u.a. Fibronektin und Laminin akkumuliert, was zur Verdickung und Aufsplitterung der GBM beiträgt (Cosgrove et al. 1996; Sayers et al. 1999). Die durch mutiertes Typ-IVKollagen veränderte Signalwahrnehmung des $\alpha 5 \beta 1$-Rezeptors auf Mesenchymzellen führt zur Hochregulierung sowohl von TGF- $\beta$ als auch PAI-1. PAI-1 hemmt PA, der seinerseits dazu in der Lage ist, Plasminogen in Plasmin umzuwandeln. Plasmin ist am Kollagenumbau beteiligt. Dadurch dass die Aktivierung des Plasmins durch PAI-1 verhindert wird, kann es seine Funktion nicht ausüben (Baricos et al. 1999. Matsumoto et al. 2003).

Des Weiteren nimmt die Endothelzelle über das $\alpha 2 \beta 1$-Integrin die Veränderung des Typ-IV-Kollagens wahr. Durch Hochregulierung von TGF- $\beta$ und CTGF wird die Produktion von EZM in Podozyten stimuliert. Dies resuliert in einer weiteren Verdickung der GBM und fördert schließlich das Fortschreiten der Erkrankung Girgert et al. 2010).

Die Podozyten erfassen die Strukturveränderungen durch veränderte Signale ihrer Rezeptoren DDR1, $\alpha 2 \beta 1$ - und $\alpha 3 \beta 1$-Integrine. Der Podozyt reagiert mit einer Hochregulierung von TGF- $\beta$ und erhöhter Produktion der EZM. Ebenfalls führt die Signalveränderung des DDR1 auf dem Podozyten zu pleotropen Effekten von MMPs und TIMPs (Hou et al. 2002; Girgert et al. 2010). Weiterhin hat das veränderte Rezeptorsignal einen partiellen Verlust der Podozyten-Schlitzdiaphragmen zur Folge. Dies lässt sich daraus erklären, dass ein intaktes Signal zur Aufrechterhaltung der Transkription von Nephrin unabdingbar ist (Gross et al. 2004b). Zudem kann TGF- $\beta$ über weitere Signalkaskaden die Apoptose von Podozyten induzieren, was letztlich zu einem kompletten Funktionsverlust der Podozyten führt (Schiffer et al. 
2002). An diesem Punkt soll noch einmal verdeutlich werden, dass den Podozyten eine zentrale Rolle beim Alport-Syndrom zukommt. Einerseits bilden sie die für die GBM wichtigen und reifen $\alpha 3-/ \alpha 4-/ \alpha 5(\mathrm{IV})$-Ketten, die beim Alport-Syndrom mutiert sind. Andererseits reagieren sie bei Strukturveränderungen der GBM mit Hochregulierung von profibrotischen Faktoren sowie pleotropen Effekten auf MMPs und TIMPs und werden beim Reparaturversuch selbst zerstört (Gross et al. 2010). Die GBM verliert ihre Funktion als Filtrationsbarriere für Makromoleküle, die sonst aufgrund ihrer Molekülgröße und Ladung zurückgehalten werden. Sowohl die GBM als auch die Schlitzmembran der Podozyten gehen zugrunde. Die Permeabilität für Proteine, die sogar größer als Albumin sind, steigt. Durch Veränderungen der Ladungseigenschaft der eigentlich stark negativ geladenen GBM können nun auch Proteine die Filtrationsbarriere überwinden, die physiologisch aufgrund ihrer eigenen negativen Ladung diese nicht passieren können. Ist die GBM nicht mehr intakt, gelangen Proteine durch den molekularen Filter in den Bowman-Raum und können in dem sich anschließenden Tubulussystem aufgrund ihrer Molekülgröße nicht mehr rückresorbiert werden, womit sie in den Urin gelangen (Gross et al. 2004b). Ebenfalls ist auf noch ungeklärte Weise das Komplementsystem an der Proteinurie beteiligt (Pavenstädt et al. 2003). Dies wird u.a. durch Serum amyloid P-component aktiviert (Hutchcraft et al. 1981; Zahedi 1996), welches im Rahmen dieser Arbeit als hochreguliertes Protein im Urin von COL4A3-Knockout-Mäusen identifiziert worden ist.

Neben der Proteinurie manifestiert sich beim Alport-Syndrom auch eine Hämaturie, da Erythrozyten die aufgesplitterte GBM als Akanthozyten passieren können (Alport 1927). In diesem Kontext und durch noch weitere nicht geklärte Signale wird die Gerinnungskaskade ausgelöst (Deguchi et al. 1989; Ono et al. 1991). Im weiteren Verlauf bildet sich wie auch bei anderen glomerulären Nierenerkrankungen ein glomerulärer Halbmond mit Fibrinablagerungen, Makrophagen und EZM (Tsunoda et al. 2001). Dies ist teilweise im Nierenpräparat einer COL4A3-Knockout-Maus im Stadium von 6 Wochen in Abbildung 3.2d auf Seite 43 zu ersehen. Zudem lassen sich in diesem Präparat interstitielle Fibrinablagerungen erkennen. Im Urinproteomprofil von COL4A3-Knockout-Mäusen ist Fibrinogen beta chain hochreguliert. Dieses Protein wird zu Fibrin gespalten und ist damit an den Fibrinablagerungen beteiligt. Es sollte im Rahmen dieses Projekts mittels Western Blot geprüft werden. Leider hat der Primärantikörper gegen Fibrinogen beta chain nicht funktioniert, wodurch keine Überprüfung erfolgen konnte. Die Überprüfung wäre ein interessanter Anknüpfungspunkt für zukünftige Studien.

Die Gerinnungskaskade beinhaltet unter anderem die Serinproteasen Thrombin und Kallikrein (Stryer 1991). Thrombin wird durch den glomerulären Schaden generiert und als Progressor der Glomerulosklerose beschrieben (Tsunoda et al. 2001). Sowohl bei Podozyten als auch Mesangiumzellen bewirkt Thrombin eine beschleunigte 
Hochregulierung von TGF- $\beta$. In einem Experiment konnte die Aktivität von Thrombin durch den Serineprotease-Inhibitor Diisopropylfluorophosphat (DFP) blockiert werden (Kaizuka et al. 1999). Es wäre denkbar, dass auch die in dieser Arbeit hochregulierten Proteine Serine protease inhibitor A3K und Antithombin III denselben Effekt versuchen könnten. Sie gehören beide zur Serpin-Familie, der Familie der Serinprotease-Inhibitoren (Gettins 2003, Liu et al. 2011). In der Tat hemmt Antithombin III die Serinprotease Thrombin (Gettins 2003). Der Serine protease inhibitor $A 3 K$ ist auch als Kallikrein-bindendes Protein (KBP) bekannt und ist in der Lage, die Serinprotease Kallikrein zu inhibieren (Chao et al. 1986, Chao et al. 1990, Chai et al. 1991). Daher kann davon ausgegangen werden, dass diese beiden Serinprotease-Inhibitoren versuchen dem Fortschreiten des Alport-Syndroms entgegenzuwirken, indem sie einzelne Serinproteasen der Gerinnungskaskade hemmen. Die Hypothese der Arbeit wird dadurch bekräftigt, dass bei der Pathogenese des Alport-Syndroms Reparaturversuche auch seitens der Podozyten, Mesangiumzellen und Endothelzellen angestrebt werden, diese aber durch die vorkommenden Mutationen daran gehindert werden. Serine protease inhibitor A3K und Antithombin III treten vermehrt in den Urin von COL4A3-Knockout-Mäusen, weil die geschädigte glomeruläre Basalmembran keine Barriere mehr für sie darstellt.

Thrombin führt zusätzlich zur erhöhten Sekretion von PAI-1 und t-PA bzw. u-PA aus Podozyten und Mesangiumzellen (Villamediana et al. 1990; Iwamoto et al. 1990). PAI-1 steht im Zusammenhang mit der Progression der Nierenfibrose, indem es dem Fibrinabbau und somit der Wundheilung entgegenwirkt (Chatziantoniou und Dussaule 2005). PAI-1 ist in der Lage den PA zu hemmen. Dieser hat seinerseits die Aufgabe, die Vorstufe Plasminogen in Plasmin umzuwandeln. Plasmin beteiligt sich zum einen aktiv an der Fibrinolyse, zum anderen wirkt es am Umbau des Kollagens mit, indem es die Prokollagenase in die aktive Kollagenase umwandelt (Saksela 1985. Villamediana et al. 1990). Die indirekte Beteiligung von Plasminogen an der Fibrinolyse ist bewiesen. Es scheint, dass Plasminogen, wie auch Serine protease inhibitor A3K und Antithrombin III, die Intention verfolgt, beim Alport-Syndrom einer überschießenden Gerinnung und damit Progression der Nierenfibrose entgegenzuwirken. Zudem könnte Plasminogen einen physiologischen Umbau anstrengen wollen, indem es selbst durch den PA in Plasmin umgewandelt wird. Dennoch ist Plasminogen im Urin von an Alport erkrankten Mäusen hochreguliert, da es den defekten molekularen Filter trotz seiner hohen molekularen Masse von $93 \mathrm{kDa}$ passieren kann. Bei einer erfolgreichen Therapie mit dem ACE-Hemmer Ramipril könnte Plasminogen folglich weniger im Urin verhanden sein. Dies würde dafür sprechen, dass die Niere histologisch weniger stark geschädigt ist, weniger Glomerulosklerose mit Fibrinablagerungen vorhanden ist und demnach auch weniger Plasminogen für die Fibrinolyse notwendig ist. 
Einen weiteren ganz aktuellen Aspekt stellt TNF- $\alpha$ im Zusammenhang mit der Pathogenese des Alport-Syndroms dar. Studien haben gezeigt, dass die Aktivierung von Podozyten und infiltrierenden Leukozyten zur Progression der renalen Dysfunktion führt. Dennoch war zu diesem Zeitpunkt wenig darüber bekannt, wie diese Zellen aktiviert werden und wie sie am Gewebeabbau beteiligt sind (LeBleu et al. 2008, Jedlicka et al. 2010, Ryu et al. 2012). Es wurde berichtet, dass durch umgebungsbedingte Faktoren, wie der Kontakt mit Bakterien, aktivierte intrarenale Makrophagen mit inflammatorischem Phänotyp mittels TNF- $\alpha$-Sekretion die Apoptose des Podozyten begünstigen können. Daher wird spekuliert, ob das proapoptotische und proinflammatorische Zytokin TNF- $\alpha$ zum natürlichen pathophysiologischen Verlauf des Alport-Syndroms beiträgt (Ryu et al. 2010). TNF- $\alpha$-Rezeptoren sind auf renalen Zellen exprimiert. Eine funktionelle pathologische Rolle intrarenaler TNF- $\alpha$-Sekretion ist in einer Reihe von Tiermodellen mit schwerwiegenden glomerulären Entzündungen beschrieben (Vielhauer und Mayadas 2007; Ryu et al. 2012). Im Zusammenhang mit der Progression des Alport-Syndroms war sie dennoch rein spekulativ. Hier wurde angesetzt und festgestellt, dass TNF- $\alpha$ kontinuierlich bei der Progression des Alport-Syndroms in glomerulären Zellen wie Podozyten exprimiert ist. Es konnte zudem gezeigt werden, dass die Progression im Zusammenhang mit dem Nephrin-Verlust von Podozyten steht, indem TNF- $\alpha$ die Nephrin-Expression supprimiert (Ryu et al. 2012). Die Interaktion zwischen Podozyten und Schlitzdiaphragmen ist nicht mehr möglich, was zur Apoptose des Podozyten führt. Das Zugrundegehen der finalen Filtrationsbarriere trägt wiederum zur Progression der Glomerulosklerose bei (Doublier et al. 2001, Saito et al. 2010; Ryu et al. 2012).

Neben seinem proapoptotischen Effekt verfolgt TNF- $\alpha$ eine prokoagulative Aktivität, indem es die PA- und PAI-1-Sekretion aus Podozyten stimuliert. Die pathophysiologische Rolle des Plasminogen-Aktivators ist noch unklar. Vermutlich überwiegt die Stimulation des PAI-1 (Le und Vilcek 1987; Iwamoto et al. 1990).

Wird die Arbeitshypothese weiterverfolgt, dass Serine protease inhibitor A3K der Progression des Alport-Syndroms entgegenzuwirken versucht, dann kann dies mit seinem inhibitorischen Einfluss auf TNF- $\alpha$ bekräftigt werden. Serine protease inhibitor $A 3 K$ wird in der Literatur als antiinflammatorisches und antifibrotisches Protein beschrieben (Zhang B et al. 2010; Liu et al. 2011). Durch Hemmung des Zytokins TNF- $\alpha$ könnte Serine protease inhibitor A3K einerseits der prokoagulativen Aktivität und andererseits der Apoptose der Podozyten und der damit einhergehenden Glomerulosklerose entgegensteuern.

Die Pathogenese des Alport-Syndroms ist sehr komplex. Einzelne pathophysiologische Aspekte stehen untereinander im Zusammenhang und verstärken sich gegenseitig. Die Proteine Plasminogen, Antithrombin III, Serine protease inhibitor A3K und Serum amyloid P-component sind in diesem Komplex zwischengeschaltet und 
verfolgen antiinflammatorische, antikoagulative und antifibrotische Funktionen. Ihre Intentionen als auch die Reparaturversuche seitens der Podozyten, Mesangiumzellen und Endothelzellen enden frustran, da die Mutationen eine Heilung verhindern.

Sowohl die GBM als auch die Schlitzmembran der Podozyten verlieren ihre Funktion als Filtrationsbarriere für Makromoleküle und gehen zugrunde. Proteine, die aufgrund ihrer Molekülgröße und negativen Ladung von einer intakten GBM zurückgehalten werden, können nun die Filterbarriere überwinden und gelangen in den Bowman-Raum. Sie können in dem sich anschließenden Tubulussystem aufgrund ihrer Molekülgröße nicht mehr rückresorbiert werden (Gross et al. 2004b). Schließlich werden Plasminogen, Antithrombin III, Serine protease inhibitor A3K und Serum amyloid P-component mit dem Urin ausgeschieden. 


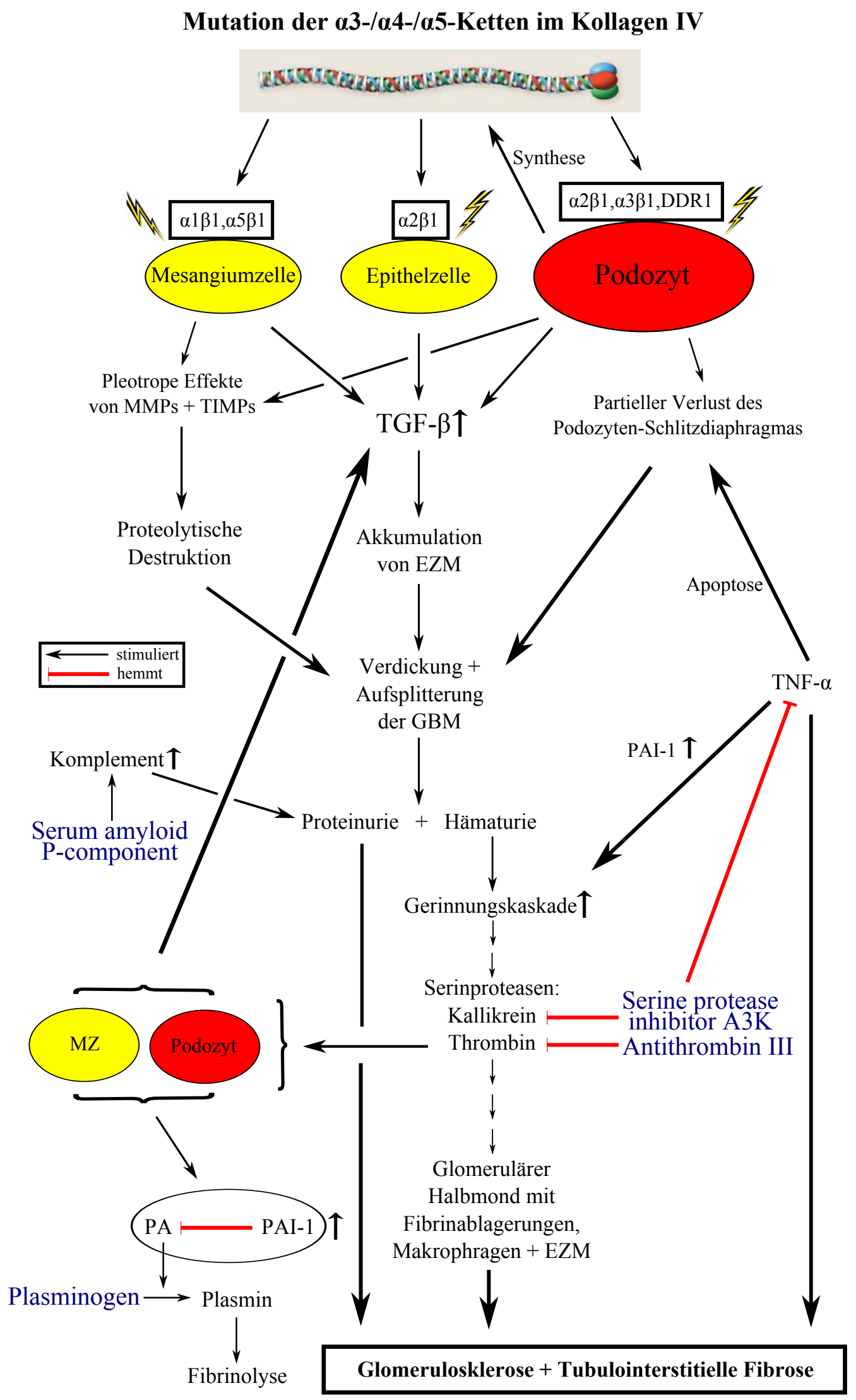

Abbildung 4.1: Schematische Darstellung der Pathogenese beim Alport-Syndrom.

Die in dieser Arbeit im Urin von COL4A3-Knockout-Mäusen hochregulierten Proteine Plasminogen, Serine protease inhibitor A3K, Antithrombin III und Serum amyloid P-component sind blau hervorgehoben. Ihre Relevanz beim Alport-Syndrom wird ausführlich thematisiert. 


\subsection{Die potentiellen Biomarker}

\subsubsection{Plasminogen}

Plasminogen ist ein Protein mit einer molekularen Masse von etwa $93 \mathrm{kDa}$. Mittels Western Blot konnte Plasminogen als potentieller Biomarker verifiziert werden. Bei der Beschreibung dieses Proteins wird sich auf das humane Plasminogen bezogen, da dieses in der Literatur am meisten vertreten ist.

Plasminogen ist auf dem Chromosom 6q26-6q27 lokalisiert und ist 52 Kilobasen lang. Der Genabschnitt besteht aus 19 Exons und 18 Introns (Murray et al. 1987). Plasminogen wird primär in der Leber synthetisiert und in den Blutkreislauf sezerniert (Raum et al. 1980). Zudem sind weitere

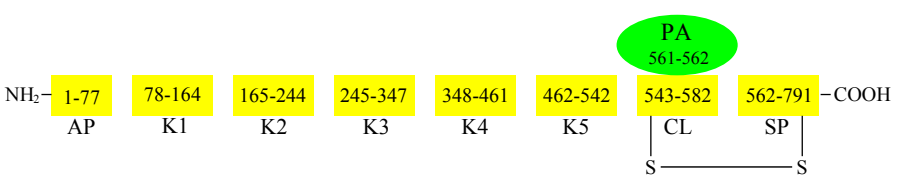
Gewebe wie Nebenniere, Niere, Gehirn, Hoden, Herz, Lunge,

Abbildung 4.2: Schematische Darstellung der PlasminogenStruktur.

Durch Bindung des Plasminogen-Aktivators (PA) an seine Bindungsstelle kann Plasminogen in Plasmin überführt werden. Die Abbildung wurde modifiziert (Castellino und Ploplis 2005, S. 648).

Uterus, Milz, Thymus und Darm identifiziert worden, die Plasminogen beinhalten (Zhang L et al. 2002). Die Plasminogenstruktur ist auf Abbildung 4.2 veranschaulicht. Die N-terminale schwere Kette besteht aus 561 Aminosäuren, die mit ihr über eine Disulfidbrücke verbundene C-terminale leichte Kette beinhaltet 230 Aminosäuren (Forsgren et al. 1987). Das ganze Protein umfasst somit 791 Aminosäuren. Beginnend am N-terminalen Ende besteht Plasminogen aus einem Aktivierungspeptid (AP), fünf Kringel-Domänen (K1-5), die ihrerseits jeweils etwa 80 Aminosäuren beinhalten und es dem Protein ermöglichen an andere Substrate zu binden, einer katalytischen Aktivierungsschleife (CL) und einer funktionellen Serinprotease-Domäne (SP) (Suenson und Thorsen 1981; Castellino und Ploplis 2005).

Es existieren unterschiedliche Plasminogen-Derivate, die sich strukturell und auch in ihren Wechselwirkungen mit anderen Molekülen unterscheiden. Gemeinsam haben sie, dass alle in Plasmin umgewandelt werden können. Glu¹-Plasminogen ist die native Form des Plasminogen, welche im Plasma zirkuliert und N-terminal eine Glutaminsäure trägt. Lys ${ }^{78}$-Plasminogen ist ein proteolytisches Fragment. Es entsteht durch Spaltung im N-terminalen Bereich des Glu¹-Plasminogen-Moleküls (Plow und Miles 1990). Zudem existiert Plasminogen in zwei KohlenhydratFormen. Plasminogen I besitzt sowohl O- als auch N-glykosidische Kohlenhydratreste. Plasminogen II besitzt lediglich einen O-glykosidischen Kohlenhydratrest. In der Literatur sind verschiedene posttranslationale Modifikationen des Plasminogens beschrieben. Es gibt Serin ${ }^{248}$, Asparagin ${ }^{289}{ }_{-}$, Threonin ${ }^{339}$ - und Threonin ${ }^{346}$ gebundene Glykosylierungen und O-gebundene Phosphorylierungen (Hayes und 
Castellino 1979a; Hayes und Castellino 1979b; Hortin 1990; Pirie-Shepherd et al. 1997). Des Weiteren gibt es unterschiedliche Konformationen von Glu'1-Plasminogen und Lys ${ }^{78}$-Plasminogen. Dabei existiert Glu${ }^{1}$-Plasminogen in einer angespannten T-Konformation ( $\mathrm{T}$ für tense, engl.=straff, angespannt) und Lys ${ }^{78}$-Plasminogen in einer offeneren R-Konformation ( $\mathrm{R}$ für relaxed, engl.=entspannt). Die $\mathrm{R}$ Konformation lässt sich durch Plasminogen-Aktivatoren schneller aktivieren (Castellino und Ploplis 2005).

An dieser Stelle sei darauf hingewiesen, dass die Western Blot-Ausschnitte in den Abbildungen 3.15 a auf Seite 60 und 3.21a auf Seite 64 bis zu zwei Banden des Plasminogens zeigen. Es kann nicht sicher gesagt werden, ob es sich hierbei lediglich um Variationen der Bandenexpression der einzelnen Mäuse handelt oder ein Auftreten von zwei unterschiedlichen Banden einen Krankheitswert im Rahmen des AlportSyndroms darstellt.

Plasminogen wird mittels Plasminogen-Aktivatoren durch Verlust des Aktivierungspeptids und Spaltung der Peptidverbindung zwischen den Aminosäuren Arginin ${ }^{561}$ und Valin ${ }^{562}$ in Plasmin überführt (Violand und Castellino 1976). An diesem Punkt soll kurz die Gerinnungskaskade vereinfacht erläutert werden. Sie setzt sich aus einem intrinsischen und extrinsischen Weg zusammen, die in einem gemeinsamen Weg münden. Im Verlauf der enzymatischen Kaskade katalysiert die jeweils aktivierte Form eines Faktors die Aktivierung des nächsten. Durch geschädigte Gefäßinnenflächen wird das intrinsische System aktiv. Kallikrein und Kininogen setzen die Gerinnungskette in Gang, indem sie Faktor XII in den aktiven Faktor XIIa umwandeln. Dieser aktiviert Faktor XI, der wiederum Faktor IX in seine aktive Form umwandelt. Schließlich aktiviert dieser Faktor den Faktor VIII und bildet mit ihm zusammen die sogenannte intrinsische Xase bestehend aus den Faktoren IXa und VIIIa. Die intrinsische als auch die extrinsische Xase aktivieren Faktor X. Der extrinsische Komplex ist für die Auslösung einer Blutgerinnung, die intrinsische Xase für die Signalverstärkung zur Blutgerinnung verantwortlich. Dabei setzt sich die extrinsische Xase aus Faktor VIIa und dem Gewebefaktor Thromboplastin zusammen. Faktor VII wurde zuvor durch Gefäßverletzung aktiviert. Faktor Xa assoziiert mit dem Gerinnungsfaktor Va, welche zusammen den sogenannten Prothrombin-Komplex bilden. Dieser Komplex aktiviert Prothrombin (Faktor II) zu Thrombin (Faktor IIa), der schließlich Fibrinogen (Faktor I) in Fibrin (Faktor Ia) umwandelt. Ein fertiges Fibringerinnsel entsteht (Stryer 1991; Rassow et al. 2008).

Plasminogen wird eine protektive Funktion zugeschrieben, da es eine aktute inflammatorische Verletzungsreaktion des Glomerulums zu unterdrücken versucht Castellino und Ploplis 2005). Durch Plasminogenaktivator t-PA bzw. u-PA wird Plasminogen in Plasmin umgewandelt. Plasmin ist im Sinne der Fibrinolyse tätig und degradiert Fibrin zu Fibrinspaltprodukten (Fay et al. 2007). Progressive Fibrinab- 
lagerungen führen zum Nierenversagen (Castellino und Ploplis 2005). Diesem wirkt Plasminogen indirekt durch Umwandlung zu Plasmin entgegen. Zudem ist Plasmin am Kollagenumbau beteiligt, indem es die Prokollagenase in die aktive Kollagenase umwandelt (Villamediana et al. 1990). Daraus lässt sich sagen, dass Plasminogen auch indirekt am Kollagenumbau beteiligt ist. Plasminogen versucht im Rahmen des Alport-Syndroms einerseits einer überschießenden Gerinnung entgegenzuwirken, andererseits fördert es den Kollagenumbau. Plasminogen kann seiner Aufgabe nicht vollständig nachgehen, da es trotz seiner hohen molekularen Masse von $93 \mathrm{kDa}$ die defekte Filtrationsbarriere passiert und schließlich mit dem Urin ausgeschieden wird.

\subsubsection{Antithrombin III}

Antithrombin III ist ein Plasmaprotein mit einer molekularen Masse im Bereich von $50 \mathrm{kDa}$ und gehört zur Serpin-Familie, der Familie der Serinprotease-Inhibitoren (Gettins 2003: Liu et al. 2011). Zu dieser Familie gehören weitere SerinproteaseInhibitoren wie $\alpha_{1}$-Antitrypsin, Ovalbumin, Angiotensinogen, $\alpha_{1}$-Antichymotrypsin und Serine protease inhibitor A3K (Prochownik et al. 1985). An diesem Punkt wird kurz auf die Serpin-Familie eingegangen. Die Protein-Gennamen werden als SERPINAXy benannt, wobei X für den Serpinstamm und y für die Nummer innerhalb dieses Stammes steht (Law et al. 2006). So trägt Antithrombin III den Gennamen Serpinc1. Es wurden sowohl extrazelluläre als auch intrazelluläre Serpin-Proteine identifiziert (Gettins 2000). Die meisten von ihnen sind Glykoproteine mit einer Masse von 40-60 kDa und bestehen aus einem Polypeptidstrang mit unterschiedlich vielen Oligosaccharid-Resten. Die für Serpin-Proteine charakteristische Struktur enthält drei $\beta$-Faltblätter und acht oder neun $\alpha$-Helices. Zwischen dem $\beta$-Faltblatt A und $\mathrm{C}$ befindet sich das reaktive Zentrum (RCL). Diese reaktive Schleife ist 30 - 40 Aminosäuren vom C-terminalen Ende gelegen (Potempa et al. 1994). Serpinen widerfährt bei Hemmung ihrer Target-Proteasen ein Konformationswandel (Law et al. 2006). Als besonderes Beispiel wird Antithrombin III aufgeführt. Es ist ein Protein, das ohne Kofaktor die Serinprotease Thrombin nur schwach inhibieren kann. In Abbildung 4.3 ist ein aus drei Teilen bestehender Komplex mit Antithrombin III, Thrombin und Heparin gezeigt (Law et al. 2006).

Der Kofaktor Heparin bindet an Antithrombin III, was eine Konformationsänderung seinerseits verursacht. Durch den Konformationswandel wird die RCL-Domäne so positioniert, dass die Serinprotease Thrombin leichter gebunden werden kann. Dies führt erneut zu einem Wandel der Protein-Konformation. In diesem Fall bindet Heparin sowohl an Antithrombin III als auch an Thrombin und ermöglicht eine noch größere Beschleunigung der hemmenden Wirkung von Antithrombin III (Baglin et al. 2002; Law et al. 2006).

Antithrombin III ist auf dem Chromoson 1q23-1q25 lokalisiert (Bock et al. 1985). 


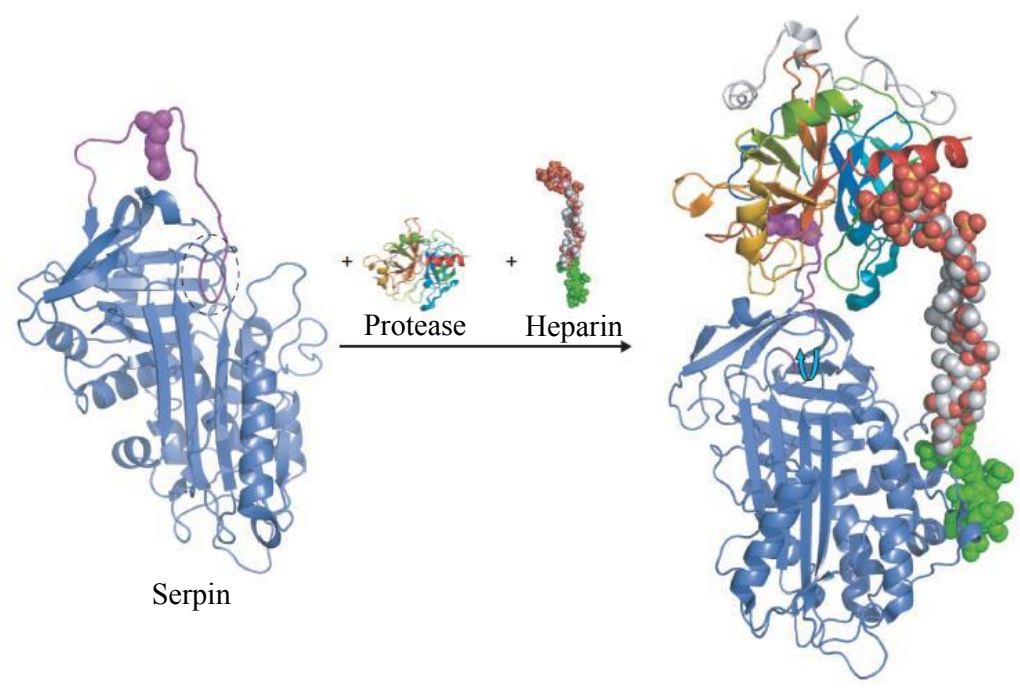

Abbildung 4.3: Modulierung der Serpin-Konformation.

Das Serpin Antithrombin III verändert durch die Interaktion mit seinem Kofaktor Heparin und Bindung an die Serinprotease Thrombin seine Konformation. Die RCL-Domäne ist violett dargestellt (Law et al. 2006, S. 216.5).

Der Genabschnitt besteht aus sechs Exons und fünf Introns und ist 19 Kilobasen lang (Prochownik et al. 1985). Es wird in der Leber synthetisiert und anschließend ins Blut sezerniert (Chandra et al. 1983). Antithrombin III besteht aus einer einzigen Polypeptidkette mit 432 Aminosäuren. Die Polypeptidkette enthält drei Disulfid-Brücken $\left(\mathrm{Cys}^{8}-\mathrm{Cys}^{128}, \mathrm{Cys}^{21}{ }_{-} \mathrm{Cys}^{95}\right.$ und $\mathrm{Cys}^{239}{ }_{-\mathrm{Cys}}{ }^{422}$ ), eine Kohlenhydratreiche Domäne $(\mathrm{CHO})$, N-terminal eine Heparin-Bindungsdomäne und C-terminal eine Serinprotease-Bindungsdomäne (Villanueva 1984). Aufgrund des Kohlenhydratreichen Bereichs gehört Antithrombin III zu den Glykoproteinen. Der Kohlenhydratanteil macht $10 \%$ des gesamten Proteins aus. Dabei sind vier Polysaccharidketten N-glykosidisch mit Asparagin an den Positionen 96, 135, 155 und 192 verbunden (Nordenman et al. 1977). Die Polypeptidkette ist zu $10 \%$ aus einer $\alpha$-Helix, welche die Heparin-Bindungsstelle trägt, und zu 30-40\% als $\beta$-Faltblatt aufgebaut. Der Rest der Aminosäurekette ist willkürlich gewunden (Nordenman et al. 1977; Villanueva 1984).

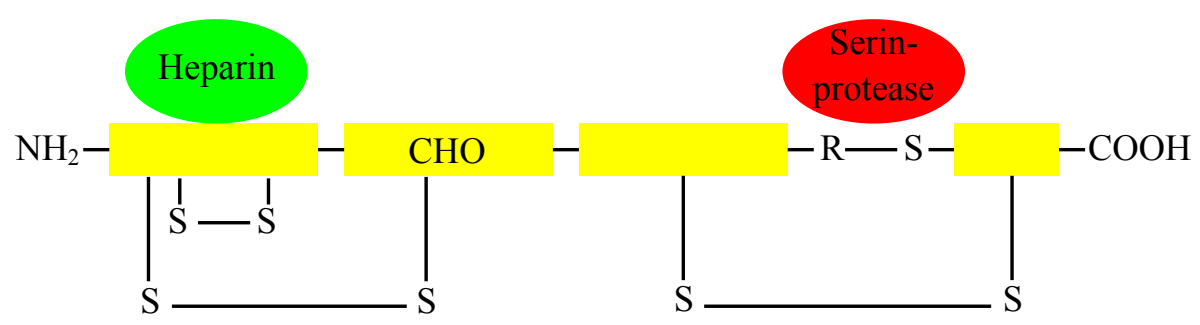

Abbildung 4.4: Schematische Darstellung der Antithrombin-III-Struktur.

Die aus 432 Aminosäuren bestehende Polypeptidkette fasst drei Disulfidbrücken. HeparinBindungsstelle und Serinprotease-Bindungsstelle für beispielsweise Thrombin sind bildlich eingezeichnet. Die Abbildung wurde modifiziert (Huntington 2011, S. 27).

Als natürliches Antikoagulans hemmt Antithrombin III diverse Gerinnungsfaktoren, 
die ihrerseits Serinproteasen sind: XIIa, XIa, Xa, IXa und Thrombin (IIa) Stryer 1991, Gettins 2003). Thrombin ist dabei als primäres Target zu verzeichen. Antithrombin III kann Thrombin hemmen, indem es mit seiner Serinprotease-Domäne an Thrombin bindet. Dabei formt sich ein Komplex dieser zwei Proteine durch Bindung eines Serin-Rests des Thrombins mit einem Arginin-Rest des Inhibitors. Mit Heparin als Kofaktor wird die Bindung und damit Hemmung des Thrombins um das etwa 100-fache beschleunigt. Heparin bindet an seine Bindungsdomäne an positiv geladene Aminosäuren wie Lysin, Arginin oder Histidin am Antithrombin III und verändert dessen Konformation. Es ermöglicht dadurch eine leichtere Komplexbildung mit Thrombin (Rosenberg und Damus 1973; Villanueva 1984).

Thrombin wird durch den glomerulären Schaden generiert und in der Literatur als Progressor der Glomerulosklerose beschrieben (Tsunoda et al. 2001). Thrombin beeinflusst Podozyten und Mesangiumzellen auf verschiedenen Ebenen. Es kann davon ausgegangen werden, dass es durch Hemmung der Serinprotease Thrombin durch Antithrombin III zu einer weniger beschleunigten Hochregulierung von TGF- $\beta$ bei Mesangiumzellen und bei den Podozyten käme, wenn Antithrombin III nicht durch die defekte Basalmembran verloren gehen würde. Eine TGF- $\beta$-Hochregulierung trägt zur vermehrten Akkumulation von EZM bei, was eine weitere Verdickung der GBM zur Folge hat (Yamabe et al. 1997; Kaizuka et al. 1999). Dies könnte durch Antithrombin III gemindert werden. Es wird daher postuliert, dass Antithrombin III als Serinprotease-Inhibitor dem Fortschreiten des Alport-Syndroms versucht entgegenzuwirken, indem es einzelne Serinproteasen der Gerinnungskaskade und dabei insbesondere Thrombin hemmt. Wie der Podozyt als zentraler Verursacher der Erkrankung versucht die Basalmembran zu reparieren, versucht auch Antithrombin III den Progress der Erkrankung aufzuhalten. Dies scheitert jedoch frustran, da die Mutation das Wiederherstellen einer intakten Basalmembran verhindert. Antithrombin III, das normalerweise Thrombin hemmt, kann seiner Aufgabe nicht komplett nachgehen, da es teilweise durch die geschädigte glomeruläre Basalmembran filtriert und in den Urin von COL4A3-Knockout-Mäusen abgegeben wird.

Des Weiteren führt Thrombin zur erhöhten Sekretion von PAI-1 und t-PA bzw. uPA aus Podozyten und Mesangiumzellen (Villamediana et al. 1990; Iwamoto et al. 1990). PAI-1 treibt die Nierenfibrose voran, indem es dem Fibrinabbau und somit der Wundheilung entgegenwirkt (Chatziantoniou und Dussaule 2005). Da Antithrombin III in den Urin ausgeschwemmt wird, kann dieser die indirekte Hemmung der Fibrinolyse nicht genug unterdrücken. Zudem ist es dem Protein kaum mehr möglich, sich indirekt am Umbau des Kollagens über Plasmin zu beteiligen (Saksela 1985. Villamediana et al. 1990). Antithrombin III wäre in der Lage, in verschiedenen Ebenen der Pathogenese des Alport-Syndroms einzugreifen, würde es nicht die defekte Filtrationsbarriere passieren können. Dies macht Antithrombin III zu einem inter- 
essanten Biomarker.

\subsubsection{Serine protease inhibitor A3K}

Serine protease inhibitor A3K ist ein Plasmaprotein mit einer molekularen Masse von $47 \mathrm{kDa}$ und gehört ebenfalls zur Serpin-Familie (Gettins 2003 ; Liu et al. 2011). Dieses Protein wird auch als Contrapsin oder SPI-2 bezeichnet (Suzuki et al. 1990. Ohkubo et al. 1991). Serine protease inhibitor A3K ist auf Chromosom 12 lokalisiert und hat eine Länge von 10 Kilobasen. Der Genabschnitt besteht aus 5 Exons und 4 Introns (Chai et al. 1991; Horvath et al. 2004; Pelissier et al. 2008). Serine protease inhibitor $A 3 K$ wird primär in der Leber exprimiert, zudem in den Nieren, im Pankreas und in der Retina (Horvath et al. 2004). Abbildung 4.5 stellt die Struktur von Serine protease inhibitor A3K schematisch dar. Das Protein besteht aus einer Polypeptidkette mit 418 Aminosäuren.

Die ersten 21 Aminosäuren umfassen das Signalpeptid (SP). Das reaktive Zentrum (RCL) ist relativ weit $\mathrm{C}$ terminal lokalisiert und beinhaltet 26 Aminosäuren. Serine protease inhibitor $A 3 K$ ist ein Glykoprotein und kann

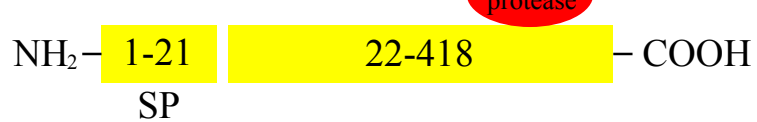

Abbildung 4.5: Schematische Darstellung der Struktur von Serine protease inhibitor A3K posttranslational über seine vier Asparagin-Reste N-glykosidische Bindungen eingehen. Eine unterschiedliche Anzahl an Glykosylierungen kann in variable molekulare Massen resultieren (Ohkubo et al. 1991).

Der Serine protease inhibitor A3K ist als Kallikrein-bindendes Protein (KBP) bekannt und ist in der Lage, die Serinprotease Kallikrein zu hemmen. RCL bindet an Kallikrein, was eine Konformationsänderung zur Folge hat Chao et al. 1986; Chao et al. 1990: Chai et al. 1991). In der Literatur wird angenommen, dass KBP zunächst einen reversiblen und danach einen irreversiblen Komplex mit Kallikrein formt. Dies basiert darauf, dass unterschiedliche Komplexe sich in Nicht-SDS und SDS gebildet haben, was zwei verschiedene Bindungsarten zwischen Kallikrein und seinem Bindeprotein nahelegt. Der reversible und SDS-dissoziierbare KBP-Kallikrein-Komplex kann eine Rolle bei der Aufrechterhaltung der Bioverfügbarkeit des Enzyms spielen. Unter gewissen physiologischen Bedingungen verwandelt sich der Komplex von dem tetraedrischen Überganzszustand in ein Aryl-Enzym-Zwischenprodukt. Hierbei wird ein kleines C-terminales Peptid freigesetzt (Chao et al. 1990). Dies würde die dritte Bande von Serine protease inhibitor A3K im Western Blot in Abbildung 3.24a auf Seite 66 im Krankheitsstadium von 6 Wochen erklären. Nach Freisetzung des C-Peptids schließt sich der Wandel in einen SDS- und Hitze-resistenten Komplex an (Chao et al. 1990). An dieser Stelle bleibt unbeantwortet, ob eine unterschiedlich ausgeprägte Bandenexpression innerhalb der beiden Krankheitsstadien (4,5 und 6 
Wochen) eine Krankheitsrelevanz hat. In weiteren Experimenten kann dieser Punkt noch verhärtet werden.

Wie bereits in Abschnitt 4.3 .2 erläutert ist Kallikrein einer der Initiatoren der Gerinnungskaskade und gehört zum intrinsischen System. Es wäre möglich, dass Serine protease inhibitor A3K versucht, dem Fortschreiten des Alport-Syndroms entgegenzusteuern, indem es dieses Mitglied der Gerinnungskaskade hemmt. Wie die ortsständigen Zellen Reparaturversuche anstreben, so versucht auch der Serine protease inhibitor A3K den Erkrankungsprozess aufzuhalten. Da die Alport-Mutation dies jedoch verhindert und die Filtrationsbarriere immer mehr ihre Funktion verliert, passiert es die GBM und tritt vermehrt in den Urin.

Des Weiteren wird der Serine protease inhibitor A3K als antiinflammatorisches und antifibrotisches Protein beschrieben (Zhang B et al. 2010; Liu et al. 2011). Es ist in der Lage, der Progression der Erkrankung entgegenzusteuern, indem es das Nephrin supprimierende Zytokin TNF- $\alpha$ inhibiert (Doublier et al. 2001; Saito et al. 2010, Ryu et al. 2012). Dadurch wird die Apoptose des Podozyten verringert und das Zugrundegehen der finalen Filtrationsbarriere hinausgezögert.

Zudem wird durch Hemmung von TNF- $\alpha$ dessen prokoagulative Aktivität unterdrückt (Le und Vilcek 1987; Iwamoto et al. 1990). Die PAI-1-Sekretion aus Podozyten wird supprimiert, sodass eine Fibrinolyse möglich ist. Serine protease inhibitor $A 3 K$ greift an verschiedenen Stellen in die Pathogenese des Alport-Syndroms ein, was es zu einem interessanten Biomarker macht. Unter ACE-Hemmer-Therapie

widerfährt den COL4A3-Knockout-Mäusen eine reduzierte Proteinurie (Gross et al. 2004a). Somit wäre unter ACE-Hemmer-Therapie ein Rückgang dieses Proteins im Urin zu erwarten. Serine protease inhibitor $A 3 K$ würde weniger im Urin von COL4A3-Knockout-Mäusen auftreten und damit seinen antinflammatorischen und antifibrotischen Aufgaben nachgehen können.

\subsubsection{Serum amyloid P-component}

Serum amyloid P-component ist ein Glykoprotein und gehört zur Familie der Pentraxine. Diese Familie umfasst Proteine der Immunabwehr oder zu diesen homologe Proteine, zu welchen auch das C-reaktive Peptid (CRP) zählt (Steel und Whitehead 1994). Serum amyloid P-component ist auf Chromosom 1 lokalisiert und besteht aus zwei Exons und einem Intron (Whitehead et al. 1988, Nishiguchi et al. 1988). Es wird in der Leber synthetisiert und anschließend ins Blut sezerniert (Steel und Whitehead 1994). Das Protein besitzt fünf identische nicht-kovalent verbundene Untereinheiten, die sich als Pentamer angeordnet haben. Jede Untereinheit besteht aus 204 Aminosäuren. Das Signalpeptid umfasst zusätzlich 20 Aminosäuren. Die physiologisch aktiven Konformationen sind als Pentamere (125kDa) oder Dekamere (250 kDa) aufgebaut. Unter reduzierenden Bedingungen sind Monomere mit einer molekularen 


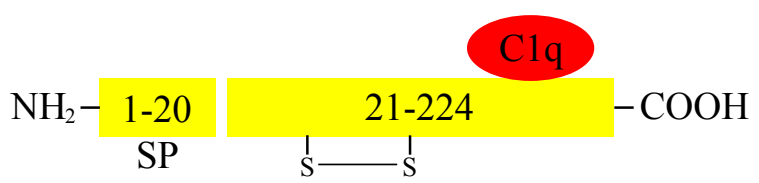

Abbildung 4.6: Schematische Darstellung einer Untereinheit von Serum amyloid P-component. Die Abbildung wurde modifiziert (Whitehead und Rits 1989, S. 28).

Masse von $25 \mathrm{kDa}$ vorhanden (Mole et al. 1988; Mencarelli et al. 2012). Charakteristisch für Serum amyloid P-component als Mitglied der Pentraxin-Familie ist seine Kalzium-abhängige Bindung an Liganden. Es ist ein stark zur Selbstaggregation neigendes Protein, was ebenfalls durch Kalzium beeinflusst wird (Hamazaki 1987). Serum Amyloid P-component erfährt diverse posttranslationale Modifizierungen wie N-Glykosylierungen an den Aminosäure-Positionen 32 -34. Des Weiteren wird das Protein durch N-Methylierungen und Phosphorylierungen modifiziert (Nishiguchi et al. 1988). Es konnte bei der Ergebnisdarstellung der Western Blots in den Abbildungen 3.16a auf Seite 61 und 3.22a auf Seite 65 das Vorhandensein mehrerer Serum-Amyloid-P-component-Banden nachgewiesen werden. Es lässt sich schlussfolgern, dass diese Banden modifizierte Formen des Proteins darstellen. Dennoch ist unsicher, ob es sich hierbei lediglich um Variationen der Bandenexpression der einzelnen Mäuse handelt oder ein Auftreten von zwei unterschiedlichen Banden einen Krankheitswert im Rahmen des Alport-Syndroms haben könnte. Weiterhin stellt sich die Frage, ob auch beim Menschen im Rahmen des Alport-Syndroms mehrere Serum-Amyloid-P-component-Banden vorzufinden sind. Diese Aspekte sollten in weiteren Experimenten beim Menschen untersucht werden.

Serum amyloid P-component wurde als erstes im Zusammenhang mit AmyloidErkrankungen identifiziert. Im Rahmen der Alzheimer-Krankheit bindet es beispielsweise an $\beta$-Amyloid-Ablagerungen im Gehirn. Es versucht diese vor proteolytischem Verdau durch Trypsin oder Chymotrypsin zu schützen (Tennent et al. 1995).

Zudem ist Serum amyloid P-component bei der Aktivierung des Komplementsystems beteiligt. Es ist in der Lage, an den Komplementfaktor C1q zu binden und damit die Aktivierung des klassischen Komplementsystems zu initiieren. Man nimmt an, dass es im Bereich seines Aminosäurenabschnittes 108-120 an die Kollagen-ähnliche Domäne des C1q-Moleküls bindet (Zahedi 1996). Zudem ist in der Literatur beschrieben, dass Serum Amyloid P-component ebenfalls den Komplementfaktor C3b aktiviert (Hutchcraft et al. 1981). Die vermehrt vorhandene Komplementkomponente C3b fördert wie bereits im Abschnitt 1.2.3 auf Seite 16 erwähnt auf noch unbekannte Weise die Proteinurie und damit den Progress der Erkrankung (Pavenstädt et al. 2003).

Das Serum Amyloid P-component thematisiert einen weiteren Aspekt, der im Zusammenhang mit dem Alport-Syndrom von Bedeutung ist. Es ist ein wesentlicher Bestandteil verschiedener Basalmembranen wie insbesondere der glomerulären Ba- 
salmembran. Die Verteilung von Serum Amyloid P-component stimmt mit der begrenzten Lokalisation der $\alpha 3$-/ $\alpha 4$ - $/ \alpha 5$-Heterotrimere des Typ-IV-Kollagens überein (Dyck et al. 1980; Mencarelli et al. 2012). Das Protein interagiert mit Komponenten der EZM wie Proteoglykane, Fibronektin, Laminin und Kollagen IV. Beispielsweise beschleunigt es die Polymerisation des Laminins (DeBeer et al. 1981; Zahedi 1996. Zahedi 1997). Dennoch ist seine Funktion in der GBM nicht eindeutig (Zahedi 1996). Seine Bindung und Interaktion mit der GBM und dabei insbesondere der $\alpha 3-/ \alpha 4$ und $\alpha 5(\mathrm{IV})$-Ketten lässt aber vermuten, dass Serum Amyloid P-component an der korrekten Funktionsausübung und Struktur der GBM beteiligt ist. Es ist beschrieben, dass das Protein möglicherweise an der Aufrechterhaltung der negativen Ladungsverteilung und damit korrekten Filtrationsbarriere mitwirkt. Weiterhin wird vermutet, dass Serum Amyloid P-component die GBM vor Matrixmetalloproteinasen schützt, so wie es auch versucht die $\beta$-Amyloid-Ablagerungen vor proteolytischem Verdau zu schützen. Die Annahmen werden damit begründet, dass beim AlportSyndrom aufgrund der Mutation der $\alpha 3-/ \alpha 4-/ \alpha 5(\mathrm{IV})$-Ketten die Assoziation und Verteilung von Serum Amyloid P-component innerhalb der GBM verändert oder komplett abgebrochen ist (Melvin et al. 1986; Zahedi 1997). Durch die beim AlportSyndrom zugrunde gehende Filterbarriere kann es diese ungehindert passieren und mit dem Urin ausgeschieden werden. Dieser Aspekt verdeutlicht, dass das Serum Amyloid P-component im Rahmen des Alport-Syndroms als möglicher interessanter Marker fungieren könnte.

\subsection{Frühzeitige Biomarker im Urin}

Die in Abschnitt 3.1 gezeigten histologischen und elektronenmikroskopischen Schnitte von COL4A3-Knockout-Nieren zum Zeitpunkt von 4,5 Wochen unterscheiden sich kaum von denen gesunder Mäuse. In Abbildung 4.7 sind histologische Nierenschnitte von 4,5 Wochen alten Wildtyp- und COL4A3-Knockout-Mäusen gezeigt. Es soll verdeutlich werden, dass in diesem frühen Krankheitsstadium kaum histopathologische Veränderungen zu verzeichnen sind. So sind noch keine interstitiellen Fibrinablagerungen und nur wenige vakuoläre Strukturen im Tubuluslumen der proximalen oder distalen Tubuli erkennbar. Zum Krankheitszeitpunkt von 6 Wochen macht sich gemäß Abbildung 3.2d auf Seite 43 ein dezenter struktureller Wandel des Nierenparenchyms mit beginnender pathologischer Matrixvermehrung, erhöhter mesangialer Zellzahl und beginnenden tubulären Schäden bemerkbar. Dennoch zeigen sich nicht immer pathologische Veränderungen. Auch elektronenmikroskopische Nierenschnitte der COL4A3-Knockout-Mäuse in Abbildung 3.4 auf Seite 45 können keine sicheren Hinweise einer Nierenschädigung im Rahmen des Alport-Syndroms geben. 


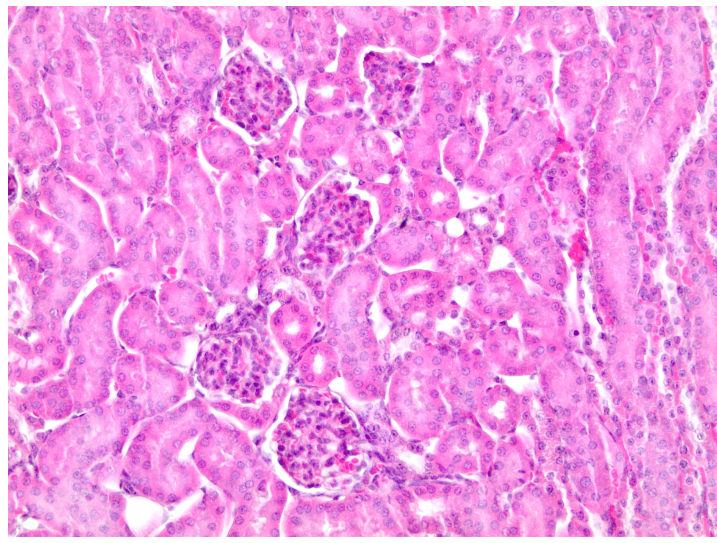

(a) Wildtyp bei 20-facher Vergrößerung

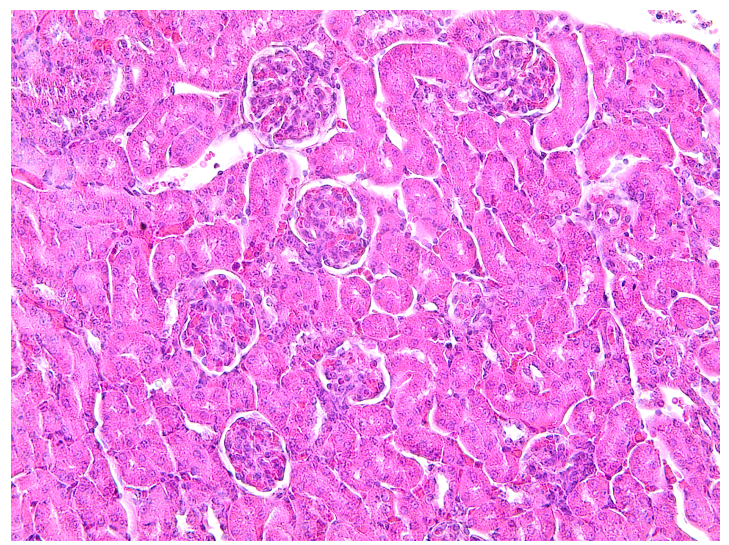

(b) COL4A3 -/- bei 20-facher Vergrößerung

Abbildung 4.7: Histologische Nierenschnitte von Wildtyp- und COL4A3-Knockout-Mäusen zum Zeitpunkt von 4,5 Wochen.

Die abgebildete COL4A3-Knockout-Niere unterscheidet sich kaum von dem dargestellten gesunden Nierenschnitt.

In dieser Arbeit konnte gezeigt werden, dass die Proteine Plasminogen, Antithrombin III, Serine protease inhibitor A3K und Serum amyloid P-component sogar zeitlich früher in den Urin von Alport-Mäusen treten als die Vernarbung der Nieren einsetzt. Daher könnte bei der Diagnostik des Alport-Syndroms die Bestimmung von Frühmarkern in Körperflüssigkeiten wie Urin einer Nierenpunktion vorgezogen werden. 


\section{Zusammenfassung}

Das Alport-Syndrom ist eine erbliche, progredient verlaufende Nierenerkrankung, die durch Mutation der $\alpha 3-/ \alpha 4$ - oder $\alpha 5$-Ketten des Typ-IV-Kollagens entsteht. Infolge von charakteristischen Veränderungen der glomerulären Basalmembran manifestiert sich eine Proteinurie und Hämaturie. Die Erkrankung kann außerdem mit Innenohrschwerhörigkeit und typischen Augenveränderungen einhergehen. Im Verlauf der Erkrankung kommt es sowohl zur Glomerulosklerose als auch zur tubulointerstitiellen Fibrose, was schließlich zum terminalen Nierenversagen führt.

Die Therapie der ersten Wahl stellt derzeit der ACE-Hemmer Ramipril dar. Zwar kann Ramipril den strukturellen Schaden der glomerulären Basalmembran nicht beheben, dafür aber bei frühzeitigem Therapieeinsatz die Proteinurie vermindern sowie nephroprotektiv und antifibrotisch wirken.

Demzufolge ist es wichtig, das Alport-Syndrom so früh wie möglich zu diagnostizieren. Bislang sind keine diagnostischen Marker für das Alport-Syndrom bekannt. Im Rahmen dieser Arbeit wurde unter Verwendung der COL4A3-Knockout-Maus als Tiermodell des Alport-Syndroms nach Proteinen gesucht, die für ein frühes Stadium des Alport-Syndroms charakteristisch sind.

Zunächst wurden histologische und elektronenmikroskopische Nierenschnitte von 4,5 und 6 Wochen alten Wildtyp- und COL4A3-Knockout-Mäusen angefertigt, um die Arbeitshypothese zu bekräftigen, dass zum frühen Krankheitszeitpunkt des AlportSyndroms kaum histologische oder elektronenmikroskopische Veränderungen zu verzeichnen sind.

Des Weiteren wurde der Urin von Wildtyp- und COL4A3-Knockout-Mäusen in den beiden genannten Stadien analysiert. Dazu wurden mittels 2D-SDS-PAGE und 2DDIGE Urinproteine von Wildtyp- und COL4A3-Knockout-Mäusen nach Ladung und Masse getrennt, um ihre Proteomprofile darstellen zu können. Im Anschluss erfolgten die massenspektrometrische Analyse und die quantitative Auswertung der Regulationsunterschiede der identifizierten Proteine. Insgesamt konnten 207 Proteinspots identifiziert werden, von denen die sechs Proteine Plasminogen, Antithrombin III, Serine protease inhibitor A3K, Serum amyloid P-component, Haptoglobin und Parvalbumin klinisch relevant hochreguliert waren.

Diese Proteine wurden mittels 1D-Western Blot geprüft, wobei Plasminogen, Antithrombin III, Serine protease inhibitor A3K und Serum amyloid P-component als 
mögliche Biomarker verifiziert werden konnten. Schließlich wurden diese vier Proteine im Rahmen dieser Arbeit biochemisch diskutiert und dabei in den Zusammenhang der Pathogenese des Alport-Syndroms gebracht.

Auszüge meiner Ergebnisse wurden bzw. werden in diesem Jahr auf dem Jahreskongress der deutschen Gesellschaft für Innere Medizin in Wiesbaden, auf dem Jahreskongress der europäischen Renal Association in Paris, auf dem Jahreskongress der deutschen Gesellschaft für Nephrologie in Hamburg und auf dem Jahreskongress der American Society of Nephrology in San Diego präsentiert. Abschließend durfte ich die Ergebnisse meiner Arbeit als Vortrag auf der Fachtagung Junge Niere in Graz in diesem Jahr vorstellen.

Für die Zukunft erhoffe ich mir, dass die Erkenntnisse dieser Arbeit dazu beitragen, das Alport-Syndrom auch beim Menschen frühzeitig zu diagnostizieren. Eine mögliche Anwendung dieser oder weiterer Biomarker könnte in Form von standardisierten Teststreifen in den frühkindlichen Untersuchungen ihren Platz finden. 


\section{Anhang: Messwerttabellen 6.1-6.3}

Tabelle 6.1: Messwerte der 2D-DIGE-Auswertung

\begin{tabular}{|c|c|c|c|c|}
\hline Spot & MW WT 4,5 & MW WT 6 & MW Alp 4,5 & MW Alp 6 \\
\hline 1 & 0,0188 & 0,0153 & 0,3954 & 0,1839 \\
\hline 2 & 0,1220 & 0,1811 & 0,0683 & 0,0083 \\
\hline 3 & 0,0059 & 0,0004 & 0,2035 & 0,1279 \\
\hline 4 & 0,0122 & 0,0577 & 0,0505 & 0,0650 \\
\hline 6 & 0,0948 & 0,3320 & 2,4800 & 1,7074 \\
\hline 7 & 0,0392 & 0,1012 & 0,2029 & 0,1833 \\
\hline 9 & 0,0666 & 0,1355 & 0,0661 & 0,0311 \\
\hline 13 & 0,0176 & 0,0456 & 0,2428 & 0,1363 \\
\hline 16 & 0,0293 & 0,1321 & 1,0163 & 0,7475 \\
\hline 17 & 0,0725 & 0,1337 & 0,8520 & 0,1308 \\
\hline 19 & 0,3467 & 0,3571 & 0,3385 & 0,4432 \\
\hline 21 & 0,0139 & 0,0013 & 0,3229 & 0,0303 \\
\hline 22 & 0,0079 & 0,0060 & 0,6493 & 0,0640 \\
\hline 23 & 0,1060 & 0,0919 & 2,6429 & 0,1448 \\
\hline 26 & 0,0020 & 0,0071 & 0,0167 & 0,0260 \\
\hline 27 & 0,0407 & 0,2112 & 0,1949 & 0,0851 \\
\hline 29 & 0,0056 & 0,0139 & 0,0520 & 0,0779 \\
\hline 31 & 0,0097 & 0,0529 & 0,4898 & 0,2828 \\
\hline 32 & 0,0868 & 0,0773 & 0,0328 & 0,0340 \\
\hline 33 & 0,1377 & 0,1599 & 0,0354 & 0,0378 \\
\hline 34 & 0,0651 & 0,0547 & 0,0489 & 0,0129 \\
\hline 42 & 0,0116 & 0,0111 & 0,0049 & 0,0011 \\
\hline 44 & 5,3352 & 3,6091 & 0,3039 & 0,1161 \\
\hline 50 & 0,0026 & 0,0152 & 0,0940 & 0,0521 \\
\hline 52 & 0,0200 & 0,0594 & 0,0809 & 0,5009 \\
\hline 53 & 0,0049 & 0,0225 & 0,2977 & 0,1855 \\
\hline 55 & 0,0073 & 0,0104 & 0,2239 & 0,0579 \\
\hline 56 & 0,0166 & 0,0393 & 0,0130 & 0,0059 \\
\hline 57 & 0,0052 & 0,0193 & 0,2117 & 0,0541 \\
\hline 58 & 0,0544 & 0,0197 & 0,0858 & 0,1640 \\
\hline 59 & 0,0139 & 0,0170 & 0,1676 & 0,1151 \\
\hline 61 & 0,0839 & 0,0439 & 0,2115 & 0,0952 \\
\hline 62 & 0,0501 & 0,0339 & 0,1258 & 0,1234 \\
\hline 67 & 0,0199 & 0,0205 & 0,3616 & 0,0736 \\
\hline 70 & 0,0154 & 0,0135 & 0,2323 & 0,0480 \\
\hline 73 & 0,0155 & 0,0254 & 0,1573 & 0,0820 \\
\hline 75 & 0,0219 & 0,0715 & 0,0461 & 0,0484 \\
\hline 86 & 0,0106 & 0,0251 & 0,3756 & 0,2464 \\
\hline 90 & 0,0008 & 0,0047 & 0,0483 & 0,1068 \\
\hline 91 & 0,0037 & 0,0402 & 0,3018 & 0,1490 \\
\hline 92 & 0,0627 & 0,1269 & 0,1799 & 0,0432 \\
\hline 93 & 0,0003 & 0,0027 & 0,0575 & 0,0994 \\
\hline 94 & 0,0346 & 0,0354 & 0,5343 & 0,3623 \\
\hline 96 & 0,0316 & 0,1603 & 0,0563 & 0,1068 \\
\hline 99 & 0,1446 & 0,2624 & 0,0861 & 0,0410 \\
\hline 102 & 0,0650 & 0,0889 & 0,3731 & 0,3611 \\
\hline 104 & 0,1008 & 0,1549 & 0,9034 & 0,4225 \\
\hline 106 & 0,0187 & 0,0464 & 0,4379 & 0,3948 \\
\hline 107 & 0,0223 & 0,1297 & 0,0641 & 0,0160 \\
\hline 108 & 0,0045 & 0,0631 & 0,0575 & 0,1271 \\
\hline 112 & 0,0643 & 0,1225 & 0,5268 & 1,0474 \\
\hline 114 & 0,0095 & 0,0276 & 0,0695 & 0,1361 \\
\hline 115 & 28,2256 & 20,7636 & 3,6989 & 1,1199 \\
\hline 118 & 0,0719 & 0,0808 & 0,0157 & 0,0039 \\
\hline 119 & 0,0525 & 0,0608 & 0,0106 & 0,0052 \\
\hline 120 & 0,0275 & 0,0357 & 0,0086 & 0,0038 \\
\hline 123 & 0,4745 & 0,4233 & 0,1951 & 0,3014 \\
\hline 124 & 0,0062 & 0,0017 & 0,3254 & 0,0488 \\
\hline 125 & 0,3404 & 1,2328 & 0,1992 & 0,1245 \\
\hline 126 & 0,3437 & 0,6067 & 1,1289 & 1,3958 \\
\hline
\end{tabular}




\begin{tabular}{|c|c|c|c|c|}
\hline 127 & 0,3165 & 0,4144 & 0,4035 & 0,1852 \\
\hline 128 & 0,4081 & 0,5722 & 0,3456 & 0,1499 \\
\hline 134 & 0,3028 & 0,0949 & 0,0478 & 0,0380 \\
\hline 135 & 0,7518 & 0,3953 & 0,0634 & 0,0437 \\
\hline 136 & 0,4119 & 0,2867 & 0,0531 & 0,0173 \\
\hline 143 & 0,2933 & 0,2617 & 0,0865 & 0,1792 \\
\hline 144 & 1,5579 & 2,1599 & 0,0888 & 0,1346 \\
\hline 145 & 0,0449 & 0,1394 & 0,0782 & 0,0450 \\
\hline 147 & 0,0206 & 0,0353 & 0,1790 & 0,1264 \\
\hline 155 & 0,4674 & 0,3516 & 0,0641 & 0,0259 \\
\hline 157 & 0,2449 & 0,6580 & 0,0094 & 0,0250 \\
\hline 159 & 0,0001 & 0,0105 & 0,0647 & 0,0170 \\
\hline 160 & 0,0106 & 0,0180 & 0,0899 & 0,0966 \\
\hline 167 & 0,0323 & 0,0539 & 0,1330 & 0,6113 \\
\hline 171 & 0,0445 & 0,0908 & 0,0670 & 0,1993 \\
\hline 175 & 0,2885 & 0,3824 & 0,0843 & 0,1108 \\
\hline 176 & 0,1409 & 0,1203 & 0,0297 & 0,0554 \\
\hline 179 & 0,0031 & 0,0027 & 0,1256 & 0,1038 \\
\hline 180 & 0,1393 & 0,2414 & 0,2731 & 0,3329 \\
\hline 181 & 0,0389 & 0,0952 & 0,1770 & 0,2080 \\
\hline 183 & 0,1188 & 0,1599 & 0,4169 & 0,4153 \\
\hline 184 & 0,3205 & 0,2787 & 1,5448 & 0,4241 \\
\hline 195 & 0,0007 & 0,0060 & 0,1074 & 0,1842 \\
\hline 198 & 0,0261 & 0,0476 & 0,4840 & 0,3743 \\
\hline 202 & 0,3958 & 0,2910 & 0,2775 & 0,2229 \\
\hline 204 & 0,0808 & 0,0436 & 1,2773 & 0,1104 \\
\hline 207 & 0,0478 & 0,1369 & 0,2240 & 0,3596 \\
\hline 208 & 0,1063 & 0,1958 & 3,3468 & 0,5684 \\
\hline 209 & 0,0059 & 0,0103 & 0,0679 & 0,0758 \\
\hline 220 & 0,0063 & 0,0085 & 0,2112 & 0,1112 \\
\hline 224 & 0,0046 & 0,0203 & 0,2303 & 0,1690 \\
\hline 227 & 0,6541 & 0,6000 & 0,4264 & 0,2133 \\
\hline 228 & 0,0353 & 0,0282 & 0,1121 & 0,1350 \\
\hline 229 & 0,0156 & 0,0451 & 0,1442 & 0,2289 \\
\hline 230 & 0,0058 & 0,0105 & 0,0077 & 0,0471 \\
\hline 231 & 0,1411 & 0,0418 & 0,0034 & 0,0531 \\
\hline 233 & 0,0253 & 0,1627 & 0,0074 & 0,0065 \\
\hline 234 & 0,0802 & 0,0266 & 0,0140 & 0,0070 \\
\hline 248 & 0,0883 & 0,0491 & 0,0585 & 0,0151 \\
\hline
\end{tabular}

Tabelle 6.2: Ergebnisse des unverbundenen t-Tests bei WT- und COL4A3Knockout-Mäusen zum Zeitpunkt von 4,5 Wochen

\begin{tabular}{|l|l|l|l|l|l|l|}
\hline Protein & MW WT & MW Alp & SD WT & SD Alp & p-2-sided & p-Wert \\
\hline PLG & 0,0105 & 0,1895 & 0,0210 & 0,1326 & 0,0721 & 0,0129 \\
\hline Serpina & 0,0118 & 0,2558 & 0,0118 & 0,0354 & 0,0003 & 0,1038 \\
\hline APCS & 0,0015 & 0,1399 & 0,0018 & 0,0836 & 0,0454 & 0,0001 \\
\hline Serpinc & 0,0299 & 0,3809 & 0,0465 & 0,1316 & 0,0088 & 0,1213 \\
\hline Hp & 0,0133 & 0,0835 & 0,0133 & 0,0514 & 0,0679 & 0,0528 \\
\hline Pvalb & 0,0592 & 0,0851 & 0,1024 & 0,0650 & 0,6866 & 0,4759 \\
\hline
\end{tabular}

Tabelle 6.3: Ergebnisse des unverbundenen t-Tests bei WT- und COL4A3Knockout-Mäusen zum Zeitpunkt von 6 Wochen

\begin{tabular}{|l|l|l|l|l|l|l|}
\hline Protein & MW WT & MW Alp & SD WT & SD Alp & p-2-sided & p-Wert \\
\hline PLG & 0,0107 & 0,4470 & 0,0061 & 0,0942 & 0,0026 & 0,0001 \\
\hline Serpina & 0,0001 & 0,1251 & 0,0001 & 0,0340 & 0,0052 & 0,0003 \\
\hline APCS & 0,0693 & 0,2115 & 0,1134 & 0,0877 & 0,0973 & 0,0943 \\
\hline Serpinc & 0,0064 & 0,4853 & 0,0024 & 0,0561 & 0,0004 & 0,0001 \\
\hline Hp & 0,0003 & 0,1492 & 0,0007 & 0,1650 & 0,1691 & 0,1214 \\
\hline Pvalb & 0,0001 & 0,0256 & 0,0002 & 0,0261 & 0,1452 & 0,0981 \\
\hline
\end{tabular}




\section{Literaturverzeichnis}

Abdulhussein R, Koo D und Vogel W (2008): Identification of disulfide-linked dimers of the receptor tyrosine kinase DDR1. J Biol Chem 283, 12026-12033

Abrahamson D, Hudson B, Stroganova L, Borza D und John P (2009): Cellular origins of type IV collagen networks in developing glomeruli. J Am Soc Nephrol 20, 1471-1479

Aebersold R und Mann M (2003): Mass spectrometry-based proteomics. Nature 422, 198-207

Alport A (1927): Hereditary familial congenital haemorrhagic nephritis. Br Med J $\underline{1927,1}, 504-506$

Andrews K, Betsuyaku T, Rogers S, Shipley J, Senior R und Miner J (2000): Gelatinase B (MMP-9) is not essential in the normal kidney and does not influence progression of renal disease in a mouse model of Alport syndrome. Am J Pathol $157,303-311$

Aumüller G, Aust G, Doll A, Engele J, Kirsch J, Mense S, Reissig D, Salvetter J, Schmidt W und Schmitz F: Duale Reihe Anatomie; Thieme, Stuttgart 2007

Baglin T, Carrell R, Church F, Esmon C und Huntington J (2002): Crystal structures of native and thrombin-complexed heparin cofactor II reveal a multistep allosteric mechanism. Proc Natl Acad Sci 99, 11079-11084

Baricos W, Cortez S, Deboisblanc M und Xin S (1999): Transforming growth factor$\beta$ is a potent inhibitor of extracellular matrix degradation by cultured human mesangial cells. J Am Soc Nephrol 10, 790-795

Baum A, Pohl M, Kreusch S, Cumme G, Ditze G, Misselwitz J, Kiehntopf M, Udby L, Meier-Hellmann A und Rhode H (2008): Searching biomarker candidates in serum using multidimensional native chromatography. II Method evaluation with Alport syndrome and severe inflammation. J Chromatogr B Analyt Technol Biomed Life Sci 876, 31-40

Bock S, Harris J, Balazs I und Trent J (1985): Assignment of the human antithrombin III structural gene to chromosome 1q23-25. Cytogenet Cell Genet 39, 67-69

Border W und Ruoslahti E (1992): Transforming growth factor-beta in disease: the dark side of tissue repair. J Clin Invest 90, 1-7 
Bradford M (1976): A rapid and sensitive method for the quantitation of microgram quantities of protein utilizing the principle of protein-dye binding. Anal Biochem $\underline{72}, 248-254$

Castellino F und Ploplis V (2005): Structure and function of the plasminogen/plasmin system. Thromb Haemost 93, 647-654

Chai K, Ma J, Murray S, Chao J und Chao L (1991): Molecular cloning and analysis of the rat kallikrein-binding protein gene. J Biol Chem 266, 16029

Chandra T, Stackhouse R, Kidd V und Woo S (1983): Isolation and sequence characterization of a cDNA clone of human antithrombin III. Proc Natl Acad Sci 80, $1845-1848$

Chao J, Tillman D, Wang M, Margolius H und Chao L (1986): Identification of a new tissue-kallikrein-binding protein. Biochem J 239, 325-331

Chao J, Chai K, Chen L, Xiong W, Chao S, Woodley-Miller C, Wang L, Lu H und Chao L (1990): Tissue kallikrein-binding protein is a serpin. I. Purification, characterization, and distribution in normotensive and spontaneously hypertensive rats. J Biol Chem 265, 16394-16401

Chatziantoniou C und Dussaule J (2005): Insights into the mechanisms of renal fibrosis: is it possible to achieve regression? Am J Physiol Renal Physiol 289, F227-F234

Cosgrove D (2012): Glomerular pathology in Alport syndrome: a molecular perspective. Pediatr Nephrol 27, 885-890

Cosgrove D, Meehan D, Grunkemeyer J, Kornak J, Sayers R, Hunter W und Samuelson G (1996): Collagen COL4A3 knockout: a mouse model for autosomal Alport syndrome. Genes Dev 10, 2981-2992

Cosgrove D, Rodgers K, Meehan D, Miller C, Bovard K, Gilroy A, Gardner H, Kotelianski V, Gotwals P und Amatucci A (2000): Integrin $\alpha 1 \beta 1$ and transforming growth factor- $\beta 1$ play distinct roles in Alport glomerular pathogenesis and serve as dual targets for metabolic therapy. Am J Pathol 157, 1649-1659

Cosgrove D, Meehan D, Delimont D, Pozzi A, Chen X, Rodgers K, Tempero R, Zallocchi M und Rao V (2008): Integrin $\alpha 1 \beta 1$ regulates matrix metalloproteinases via P38 mitogen-activated protein kinase in mesangial cells: implications for Alport syndrome. Am J Pathol 172, 761-773

DeBeer F, Baltz M, Holford S, Feinstein A und Pepys M (1981): Fibronectin and C4-binding protein are selectively bound by aggregated amyloid P component. J Exp Med 154, 1134-1149 
Deguchi F, Tomura S, Yoshiyama N und Takeuchi J (1989): Intraglomerular deposition of coagulation-fibrinolysis factors and a platelet membrane antigen in various glomerular diseases. Nephron 51, 377-383

Dihazi H, Asif A, Agarwal N, Doncheva Y und Müller G (2005): Proteomic analysis of cellular response to osmotic stress in thick ascending limb of Henle's loop (TALH) cells. Mol Cell Proteomics 4, 1445-1458

Dihazi H, Müller G, Lindner S, Meyer M, Asif A, Oellerich M und Strutz F (2007): Characterization of diabetic nephropathy by urinary proteomic analysis: identification of a processed ubiquitin form as a differentially excreted protein in diabetic nephropathy patients. Clin Chem 53, 1636-1645

Dihazi H, Dihazi G, Nolte J, Meyer S, Jahn O, Müller G und Engel W (2009): Multipotent adult germline stem cells and embryonic stem cells: comparative proteomic approach. J Proteome Res $\underline{8}$, 5497-5510

Doublier S, Ruotsalainen V, Salvidio G, Lupia E, Biancone L, Conaldi P, Reponen P, Tryggvason K und Camussi G (2001): Nephrin redistribution on podocytes is a potential mechanism for proteinuria in patients with primary acquired nephrotic syndrome. Am J Pathol 158, 1723-1731

Dyck R, Lockwood C, Kershaw M, McHugh N, Duance V, Baltz M und Pepys M (1980): Amyloid P-component is a constituent of normal human glomerular basement membrane. J Exp Med 152, 1162-1174

Fay W, Garg N und Sunkar M (2007): Vascular functions of the plasminogen activation system. Arterioscler Thromb Vasc Biol 27, 1231-1237

Flinter F, Chantler C, Stewart Cameron J, Houston I und Bobrow M (1988): Genetics of classic Alport's syndrome. Lancet 332, 1005-1007

Fogo A (1999): Mesangial matrix modulation and glomerulosclerosis. Exp Nephrol 7, $147-159$

Forsgren M, Råden B, Israelsson M, Larsson K und Hedén L (1987): Molecular cloning and characterization of a full-length cDNA clone for human plasminogen. FEBS Lett 213, 254-260

Gettins P (2000): Keeping the serpin machine running smoothly. Genome Res 10, 1833-1835

Gettins P (2003): Serpin structure, mechanism, and function. Chem Rev 34, 47514804

Girgert R, Martin M, Kruegel J, Miosge N, Temme J, Eckes B, Müller G und Gross O (2010): Integrin 2-deficient mice provide insights into specific functions of collagen receptors in the kidney. Fibrogenesis Tissue Repair $\underline{3}, 19$ 
Gross O und Weber M (2005): From the molecular genetics of Alport's syndrome to principles of organo-protection in chronic renal diseases. Med Klin 100, 826-831

Gross O und Kashtan C (2009): Treatment of Alport syndrome: beyond animal models. Kidney Int $\underline{76}, 599-603$

Gross O, Netzer K, Lambrecht R, Seibold S und Weber M (2002): Meta-analysis of genotype-phenotype correlation in X-linked Alport syndrome: impact on clinical counselling. Nephrol Dial Transplant 17, 1218-1227

Gross O, Beirowski B, Koepke M, Kuck J, Reiner M, Addicks K, Smyth N, SchulzeLohoff E und Weber M (2003): Preemptive ramipril therapy delays renal failure and reduces renal fibrosis in COL4A3-knockout mice with Alport syndrome. Kidney Int $63,438-446$

Gross O, Schulze-Lohoff E, Koepke M, Beirowski B, Addicks K, Bloch W, Smyth N und Weber M (2004a): Antifibrotic, nephroprotective potential of ACE inhibitor vs AT1 antagonist in a murine model of renal fibrosis. Nephrol Dial Transplant 19, $1716-1723$

Gross O, Beirowski B, Harvey S, McFadden C, Chen D, Tam S, Thorner P, Smyth N, Addicks K und Bloch W (2004b): DDR1-deficient mice show localized subepithelial GBM thickening with focal loss of slit diaphragms and proteinuria. Kidney Int $66,102-111$

Gross O, Girgert R, Beirowski B, Kretzler M, Kang H, Kruegel J, Miosge N, Busse A, Segerer S und Vogel W (2010): Loss of collagen-receptor DDR1 delays renal fibrosis in hereditary type IV collagen disease. Matrix Biol 29, 346-356

Gubler M, Knebelmann B, Beziau A, Broyer M, Pirson Y, Haddoum F, Kleppel M und Antignac C (1995): Autosomal recessive Alport syndrome: immunohistochemical study of type IV collagen chain distribution. Kidney Int $\underline{47}, 1142-1147$

Gunwar S, Ballester F, Noelken M, Sado Y, Ninomiya Y und Hudson B (1998): Glomerular basement membrane. Identification of a novel disulfide-cross-linked network of alpha3, alpha4, and alpha5 chains of type IV collagen and its implications for the pathogenesis of Alport syndrome. J Biol Chem 273, 8767-8775

Hamazaki H (1987): Ca2+-mediated association of human serum amyloid P component with heparan sulfate and dermatan sulfate. J Biol Chem 262, 1456-1460

Hayes M und Castellino J (1979a): Carbohydrate of the human plasminogen variants. I. Carbohydrate composition, glycopeptide isolation, and characterization. J Biol Chem 254, 8768-8771

Hayes M und Castellino F (1979b): Carbohydrate of the human plasminogen variants. II. Structure of the asparagine-linked oligosaccharide unit. J Biol Chem $254,8772-8776$ 
Hellman U, Wernstedt C, Gonez J und Heldin C (1995): Improvement of an InGel digestion procedure for the micropreparation of internal protein fragments for amino acid sequencing. Anal Biochem 224, 451-455

Hortin G (1990): Isolation of glycopeptides containing O-linked oligosaccharides by lectin affinity chromatography on jacalin-agarose. Anal Biochem 191, 262-267

Horvath A, Forsyth S und Coughlin P (2004): Expression patterns of murine antichymotrypsin-like genes reflect evolutionary divergence at the Serpina3 locus. J Mol Evol 59, 488-497

Hou G, Vogel W und Bendeck M (2002): Tyrosine kinase activity of discoidin domain receptor 1 is necessary for smooth muscle cell migration and matrix metalloproteinase expression. Circ Res 90, 1147-1149

Hudson B, Reeders S und Tryggvason K (1993): Type IV collagen: structure, gene organization, and role in human diseases. Molecular basis of Goodpasture and Alport syndromes and diffuse leiomyomatosis. J Biol Chem 268, 26033-26036

Hudson B, Tryggvason K, Sundaramoorthy M und Neilson E (2003): Alport's syndrome, Goodpasture's syndrome, and type IV collagen. N Engl J Med 348, 25432556

Huntington J (2011): Serpin structure, function and dysfunction. J Thromb Haemost $\underline{9}, 26-34$

Hutchcraft C, Gewurz H, Hansen B, Dyck R und Pepys M (1981): Agglutination of complement-coated erythrocytes by serum amyloid P-component. J Immunol $\underline{126}, 1217$

Iwamoto T, Nakashima Y und Sueishi K (1990): Secretion of plasminogen activator and its inhibitor by glomerular epithelial cells. Kidney Int 37, 1466-1476

Jedlicka J, Soleiman A, Draganovici D, Mandelbaum J, Ziegler U, Regele H, Wüthrich R, Gross O, Anders H und Segerer S (2010): Interstitial inflammation in Alport syndrome. Hum Pathol $\underline{41}, 582-593$

Johnsson L und Arenberg I (1981): Cochlear abnormalities in Alport's syndrome. Arch Otolaryngol 107, 340

Kaizuka M, Yamabe H, Osawa H, Okumura K und Fujimoto N (1999): Thrombin stimulates synthesis of type IV collagen and tissue inhibitor of metalloproteinases1 by cultured human mesangial cells. J Am Soc Nephrol 10, 1516-1523

Kalluri R, Shield C, Todd P, Hudson B und Neilson E (1997): Isoform switching of type IV collagen is developmentally arrested in X-linked Alport syndrome leading to increased susceptibility of renal basement membranes to endoproteolysis. J Clin Invest 99, 2470-2478 
Kashtan C (1999): Alport syndrome: an inherited disorder of renal, ocular, and cochlear basement membranes. Medicine 78, 338-360

Kashtan C und Michael A (1996): Alport syndrome. Kidney Int 50, 1445-1463

Kashtan C, Ding J, Gregory M, Gross O, Heidet L, Knebelmann B, Rheault M und Licht C (2012): Clinical practice recommendations for the treatment of Alport syndrome: a statement of the Alport Syndrome Research Collaborative. Pediatr Nephrol, 1-7

Kasper G, Braunwald E, Fauci A, Hauser S, Longo D und Jameson J: Harrisons Innere Medizin; ABW Wissenschaftsverlag, Berlin 2005

Korhonen M, Ylänne J, Laitinen L und Virtanen I (1990): The alpha 1-alpha 6 subunits of integrins are characteristically expressed in distinct segments of developing and adult human nephron. J Cell Biol 111, 1245-1254

Kreidberg J, Donovan M, Goldstein S, Rennke H, Shepherd K, Jones R und Jaenisch R (1996): Alpha 3 beta 1 integrin has a crucial role in kidney and lung organogenesis. Development 122, 3537-3547

Law R, Zhang Q, McGowan S, Buckle A, Silverman G, Wong W, Rosado C, Langendorf C, Pike R und Bird P (2006): An overview of the serpin superfamily. Genome Biol ㅁ, 216-216.11

Le J und Vilcek J (1987): Tumor necrosis factor and interleukin 1: cytokines with multiple overlapping biological activities. Lab Invest $\underline{56}, 234-248$

LeBleu V, Sugimoto H, Miller C, Gattone V und Kalluri R (2008): Lymphocytes are dispensable for glomerulonephritis but required for renal interstitial fibrosis in matrix defect-induced Alport renal disease. Lab Invest 88, 284-292

Liu X, Lin Z, Zhou T, Zong R, He H, Liu Z, Ma J, Liu Z und Zhou Y (2011): Anti-angiogenic and anti-inflammatory effects of SERPINA3K on corneal injury. PLoS One $\underline{6}$, e16712

Löffler G und Petrides PE: Biochemie und Pathobiochemie; Springer, Wien 2003

Lüllmann-Rauch R: Taschenlehrbuch Histologie; Thieme, Stuttgart 2009

Matsumoto N, Ishimura E, Koyama H, Tanaka S, Imanishi Y, Shioi A, Inaba M und Nishizawa Y (2003): Blocking of alpha 5 integrin stimulates production of TGF-beta and PAI-1 by human mesangial cells. Biochem Biophys Res Commun 305, 815-819

Melvin T, Kim Y und Michael A (1986): Amyloid P component is not present in the glomerular basement membrane in Alport-type hereditary nephritis. Am J Pathol 125, 460-464

Mencarelli C, Bode G, Losen M, Kulharia M, Molenaar P, Veerhuis R, Steinbusch H, De Baets M, Nicolaes G und Martinez-Martinez P (2012): The Goodpasture- 
antigen binding protein/ceramide transporter binds to human serum amyloid Pcomponent and is present in brain amyloid plaques. J Biol Chem 287, 1489714991

Miner J und Sanes J (1994): Collagen IV alpha 3, alpha 4, and alpha 5 chains in rodent basal laminae: sequence, distribution, association with laminins, and developmental switches. J Cell Biol 127, 879-891

Mole J, Beaulieu B, Geheran C, Carnazza J und Anderson J (1988): Isolation and analysis of murine serum amyloid $\mathrm{P}$ component cDNA clones. J Immunol $141,3642-3646$

Müller G, Müller C und Dihazi H (2007): Clinical proteomics-on the long way from bench to bedside? Nephrol Dial Transplant 22, 1297-1300

Murphy G und Nagase H (2008): Progress in matrix metalloproteinase research. Mol Aspects Med 29, 290-308

Murphy G, Willenbrock F, Crabbe T, O'Shea M, Ward R, Atkinson S, O'Connell J und Docherty A (1994): Regulation of matrix metalloproteinase activity. Ann NY Acad Sci 732, 31-41

Murray J, Buetow K, Donovan M, Hornung S, Motulsky A, Disteche C, Dyer K, Swisshelm K, Anderson J und Giblett E (1987): Linkage disequilibrium of plasminogen polymorphisms and assignment of the gene to human chromosome 6q26-6q27. Am J Hum Genet 40, 338-350

Nagase H, Visse R und Murphy G (2006): Structure and function of matrix metalloproteinases and TIMPs. Cardiovasc Res 69, 562-573

Nakamura T, Miller D, Ruoslahti E und Border W (1992): Production of extracellular matrix by glomerular epithelial cells is regulated by transforming growth factor-beta. Kidney Int $\underline{41}, 1213-1221$

Nangaku M (1998): Complement regulatory proteins in glomerular diseases. Kidney Int $\underline{54}, 1419-1428$

Nishiguchi S, Maeda S, Araki S und Shimada K (1988): Structure of the mouse serum amyloid P component gene. Biochem Biophys Res Commun 155, 13661373

Noordeen N, Carafoli F, Hohenester E, Horton M und Leitinger B (2006): A transmembrane leucine zipper is required for activation of the dimeric receptor tyrosine kinase DDR1. J Biol Chem 281, 22744-22751

Nordenman B, Nyström C und Björk I (1977): The size and shape of human and bovine antithrombin III. Eur J Biochem 78, 195-203 
Ohkubo K, Ogata S, Misumi Y, Takami N, Sinohara H und Ikehara Y (1991): Cloning, structure and expression of cDNA for mouse contrapsin and a related protein. Biochem J 276, 337-342

Ono T, Kanatsu K, Doi T, Sekita K, Onoe C, Nagai H, Muso E, Yoshida H, Tamura T und Kawai C (1991): Relationship of intraglomerular coagulation and platelet aggregation to glomerular sclerosis. Nephron 58, 429-436

Oohashi T, Naito I, Ueki Y, Yamatsuji T, Permpoon R, Tanaka N, Naomoto Y und Ninomiya Y (2011): Clonal overgrowth of esophageal smooth muscle cells in diffuse leiomyomatosis-Alport syndrome caused by partial deletion in COL4A5 and COL4A6 genes. Matrix Biol 30, 3-8

Pavenstädt H, Kriz W und Kretzler M (2003): Cell biology of the glomerular podocyte. Physiol Rev 83, 253-307

Pelissier P, Delourme D, Germot A, Blanchet X, Becila S, Maftah A, Leveziel H, Ouali A und Bremaud L (2008): An original SERPINA3 gene cluster: Elucidation of genomic organization and gene expression in the Bos taurus 21q24 region. BMC Genomics 9, 151

Pesic I, Stefanovic V, Cukuranovic R, Jahn O, Bojanic V, Koziolek M und Dihazi H (2011): Identification and validation of six proteins as marker for endemic nephropathy. J Proteomics 74, 1994-2007

Pirie-Shepherd S, Stevens R, Andon N, Enghild J und Pizzo S (1997): Evidence for a novel O-linked sialylated trisaccharide on Ser-248 of human plasminogen 2. J Biol Chem 272, 7408-7411

Plow E und Miles L (1990): Plasminogen receptors in the mediation of pericellular proteolysis. Cell Differ Dev 32, 293-298

Potempa J, Korzus E und Travis J (1994): The serpin superfamily of proteinase inhibitors: structure, function, and regulation. J Biol Chem 269, 15957-15960

Prochownik E, Bock S und Orkin S (1985): Intron structure of the human antithrombin III gene differs from that of other members of the serine protease inhibitor superfamily. J Biol Chem 260, 9608-9612

Rao V, Meehan D, Delimont D, Nakajima M, Wada T, Gratton M und Cosgrove D (2006): Role for macrophage metalloelastase in glomerular basement membrane damage associated with Alport syndrome. Am J Pathol 169, 32-46

Rassow J, Hauser K, Netzker R und Deutzmann R: Duale Reihe Biochemie; Thieme, Stuttgart 2008

Raum D, Marcus D, Alper C, Levey R, Taylor P und Starzl T (1980): Synthesis of human plasminogen by the liver. Science 208, 1036-1037 
Roeb E, Behrmann I, Grötzinger J, Breuer B und Matern S (2000): An MMP-9 mutant without gelatinolytic activity as a novel TIMP-1-antagonist. FASEB J $\underline{14}, 1671-1673$

Rosenberg R und Damus P (1973): The purification and mechanism of action of human antithrombin-heparin cofactor. J Biol Chem 248, 6490-6505

Ryu M, Kulkarni O, Radomska E, Miosge N, Gross O und Anders H (2010): Bacterial CpG-DNA accelerates Alport glomerulosclerosis by inducing an M1 macrophage phenotype and tumor necrosis factor- $\alpha$-mediated podocyte loss. Kidney Int 79, 189-198

Ryu M, Mulay S, Miosge N, Gross O und Anders H (2012): Tumour necrosis factor$\alpha$ drives Alport glomerulosclerosis in mice by promoting podocyte apoptosis. $\mathrm{J}$ Pathol 226, 120-131

Saito Y, Okamura M, Nakajima S, Hayakawa K, Huang T, Yao J und Kitamura M (2010): Suppression of nephrin expression by TNF- $\alpha$ via interfering with the cAMP-retinoic acid receptor pathway. Am J Physiol Renal Physiol 298, F1436F1444

Saksela O (1985): Plasminogen activation and regulation of pericellular proteolysis. Biochim Biophys Acta 823, 35-65

Sayers R, Kalluri R, Rodgers K, Shield C, Meehan D und Cosgrove D (1999): Role for transforming growth factor- $\beta 1$ in Alport renal disease progression. Kidney Int 56, 1662-1673

Schiffer M, Schiffer L, Gupta A, Shaw A, Roberts I, Mundel P und Böttinger E (2002): Inhibitory Smads and TGF- $\beta$ signaling in glomerular cells. J Am Soc Nephrol 13, 2657-2666

Schmidt R, Thews G und Lang F: Physiologie des Menschen; Springer, Wien 2005

Schrattenholz A: Methoden der Proteomforschung, Molekulare Analyse der Proteinexpression; Spektrum Akademischer Verlag, Heidelberg 2001

Schünke M, Schulte E, Schumacher U, Voll M und Wesker K: Prometheus LernAtlas der Anatomie, Hals und Innere Organe; Thieme, Stuttgart 2005

Seo J und Lee K (2004): Post-translational modifications and their biological functions: proteomic analysis and systematic approaches. J Biochem Mol Biol 37, 3544

Steel D und Whitehead A (1994): The major acute phase reactants: C-reactive protein, serum amyloid $\mathrm{P}$ component and serum amyloid A protein. Immunol Today $\underline{15}, 81-88$

Stryer L: Biochemie; Spektrum Akademischer Verlag GmbH, Heidelberg 1991 
Suenson E und Thorsen S (1981): Secondary-site binding of Glu-plasmin, Lysplasmin and miniplasmin to fibrin. Biochem J 197, 619-628

Suzuki Y, Yamamoto K und Sinohara H (1990): Molecular cloning and sequence analysis of full-length cDNA coding for mouse contrapsin. J Biochem 108, 344-346

Takemori N, Komori N und Matsumoto H (2006): Highly sensitive multistage mass spectrometry enables small-scale analysis of protein glycosylation from twodimensional polyacrylamide gels. Electrophoresis 27, 1394-1406

Tennent G, Lovat L und Pepys M (1995): Serum amyloid P component prevents proteolysis of the amyloid fibrils of Alzheimer disease and systemic amyloidosis. Proc Natl Acad Sci 92, 4299-4303

Thompson S, Deady J, Willshaw H und White R (1987): Ocular signs in Alport's syndrome. Eye (Lond) 1, 146-153

Tilleman K, Deforce D und Elewaut D (2005): Rheumatology: a close encounter with proteomics. Rheumatology 44, 1217-1226

Tomooka S, Border W, Marshall B und Noble N (1992): Glomerular matrix accumulation is linked to inhibition of the plasmin protease system. Kidney Int $\underline{42}, 1462-1462$

Towbin H, Staehelin T und Gordon J (1979): Electrophoretic transfer of proteins from polyacrylamide gels to nitrocellulose sheets: procedure and some applications. Proc Natl Acad Sci U S A $\underline{76}$, 4350-4354

Tryggvason K, Zhou J, Hostikka S und Shows T (1993): Molecular genetics of Alport syndrome. Kidney Int 43, 38-38

Tsunoda S, Yamabe H, Osawa H, Kaizuka M, Shirato K und Okumura K (2001): Cultured rat glomerular epithelial cells show gene expression and production of transforming growth factor- $\beta$ : expression is enhanced by thrombin. Nephrol Dial Transplant $\underline{16}, 1776-1782$

Van Der Loop F, Monnens L, Schröder C, Lemmink H, Breuning M, Timmer E und Smeets H (1999): Identification of COL4A5 defects in Alport's syndrome by immunohistochemistry of skin. Kidney Int $\underline{55}$, 1217-1224

Van Der Loop F, Heidet L, Timmer E, Van Den Bosch B, Leinonen A, Antignac C, Jefferson J, Maxwell A, Monnens L und Schröder C (2000): Autosomal dominant Alport syndrome caused by a COL4A3 splice site mutation. Kidney Int $\underline{58}$, 18701875

Vielhauer V und Mayadas T (2007): Functions of TNF and its receptors in renal disease: distinct roles in inflammatory tissue injury and immune regulation. Semin Nephrol 27, 286-308 
Villamediana L, Rondeau E, He C, Medcalf R, Peraldi M, Lacave R, Delarue F, Sraer J et al. (1990): Thrombin regulates components of the fibrinolytic system in human mesangial cells. Kidney Int 38, 956-961

Villanueva G (1984): Predictions of the secondary structure of antithrombin III and the location of the heparin-binding site. J Biol Chem 259, 2531-2536

Violand B und Castellino F (1976): Mechanism of the urokinase-catalyzed activation of human plasminogen. J Biol Chem 251, 3906-3912

Vogel W, Brakebusch C, Fässler R, Alves F, Ruggiero F und Pawson T (2000): Discoidin-domain-rezeptor 1 is activated independently of beta1 integrin. J Biol Chem 275, 5779-5784

Vogel W, Abdulhussein R und Ford C (2006): Sensing extracellular matrix: an update on discoidin domain receptor function. Cell Signal 18, 1108-1116

Wei S, Kashiwagi M, Kota S, Xie Z, Nagase H und Brew K (2005): Reactive site mutations in tissue inhibitor of metalloproteinase-3 disrupt inhibition of matrix metalloproteinases but not tumor necrosis factor-alpha-converting enzyme. J Biol Chem 280, 32877-32882

Welsch U: Lehrbuch Histologie; Urban \& Fischer, München 2003

Wessel D und Flügge U (1984): A method for the quantitative recovery of protein in dilute solution in the presence of detergents and lipids. Anal Biochem 138, 141143

Westermeier R und Naven PT: Proteomics in Practice: A Laboratory Manual of Proteome Analysis; Wiley-VCH Verlag, Weinheim 2002

Whitehead A und Rits M (1989): Characterization of the gene encoding mouse serum amyloid $\mathrm{P}$ component. Comparison with genes encoding other pentraxins. Biochem J 263, 25-31

Whitehead A, Rits M und Michaelson J (1988): Molecular genetics of mouse serum amyloid P component (SAP): cloning and gene mapping. Immunogenetics 28 , 388390

Wilkins M, Sanchez J, Gooley A, Appel R, Humphery-Smith I, Hochstrasser D und Williams K (1996): Progress with proteome projects: why all proteins expressed by a genome should be identified and how to do it. Biotech Genet Eng Rev 13, 19 50

Yamabe H, Osawa H, Inuma H, Kaizuka M, Tamura N, Tsunoda S, Baba Y, Shirato K und Onodera K (1997): Thrombin stimulates production of transforming growth factor-beta by cultured human mesangial cells. Nephrol Dial Transplant $\underline{12}, 438-$ 442 
Zahedi K (1996): Characterization of the binding of serum amyloid P to type IV collagen. J Biol Chem 271, 14897-14902

Zahedi K (1997): Characterization of the binding of serum amyloid P to laminin. J Biol Chem 272, 2143-2148

Zeisberg M, Khurana M, Rao V, Cosgrove D, Rougier J, Werner M, Shield C, Werb Z und Kalluri R (2006): Stage-specific action of matrix metalloproteinases influences progressive hereditary kidney disease. PLoS Med $\underline{3}$, e100

Zhang L, Seiffert D, Fowler B, Jenkins G, Thinnes T, Loskutoff D, Parmer R und Miles L (2002): Plasminogen has a broad extrahepatic distribution. Thromb Haemost $\underline{87}$, 493-501

Zhang B, Abreu J, Zhou K, Chen Y, Hu Y, Zhou T, He X und Ma J (2010): Blocking the Wnt pathway, a unifying mechanism for an angiogenic inhibitor in the serine proteinase inhibitor family. Proc Natl Acad Sci 107, 6900-6905 


\section{Danksagung}

Hiermit möchte ich mich bei Prof. Dr. med. G. A. Müller für die Möglichkeit bedanken, in der Abteilung Nephrologie und Rheumatologie promovieren zu dürfen. Besonderer Dank gilt meinem Betreuer Prof. Dr. med. Oliver Gross für die tolle Unterstützung und Bereitstellung des Themas, sowie für das gebrachte Vertrauen und die Möglichkeit, bei der Fachtagung Junge Niere in Graz in diesem Jahr die Ergebnisse meiner Arbeit vorstellen zu dürfen. Zudem möchte ich mich bei Andrea Bernhard für die Erstellung der histologischen Präparate und bei Diana Rubel für das tatkräftige Bereitstellen von Mäuseurin bedanken.

Weiterhin danke ich herzlich dem Team der Proteomics-Laborgruppe von Prof. Dr. Hassan Dihazi für die Bereitstellung des Labors und die tolle Zusammenarbeit. Dabei danke ich vor allem Prof. Dr. Hassan Dihazi, der mir fast täglich mit Rat und Tat zur Seite stand. Zudem möchte ich mich bei Elke Brunst-Knoblich bedanken, die mich in die Laborarbeiten eingeführt hat sowie Asima Bibi, Gry Helene Dihazi und Marwa Eltoweissy für die Unterstützung bei der Durchführung meiner Laborarbeit. Jede dieser vier wurde nicht müde, sich vor allem der alltäglichen kleinen technischen Probleme und Fragen anzunehmen.

Zuletzt danke ich ganz besonders meinem Freund Fabian Knoch für seinen Enthusiasmus und seine Geduld, mir das Programm LaTex beizubringen, und für seine äußerst guten und konstruktiven Ratschläge. 


\section{Lebenslauf}

Am 04.02.1989 wurde ich, Imke Schmidt-Eylers, als zweite Tochter von Thea und Joost Schmidt-Eylers in Bremerhaven geboren. Von 1995-1999 besuchte ich die Grundschule Stotel, von 1999 - 2001 die Orientierungsstufe Loxstedt sowie von 2001 2005 das Gymnasium Loxstedt. In der 10. Klasse habe ich einen vierwöchigen Schüleraustausch nach Südafrika gemacht. Danach erlebte ich ein tolles Highschool-Jahr in den USA. Anschließend verbrachte ich die letzten beiden Schuljahre auf dem Lloyd-Gymnasium, wo ich 2008 das bilinguale Abitur absolvierte. Im Herbst 2008 bin ich nach Göttingen gezogen, um das Medizinstudium aufzunehmen. Im Sommer 2010 bestand ich den Ersten Abschnitt der Ärztlichen Prüfung - das Physikum. Nach dem Physikum habe ich die Doktorarbeit angefangen und seither mit großer Motivation viel Zeit im Labor verbracht. Zudem habe ich mit Freude Histologie-Tutorien gegeben und Französisch am ZESS gelernt, um das neunte Semester als Erasmusstudentin in Frankreich verbringen zu können. Danach werde ich noch ein Semester in Göttingen studieren, bevor ich im Sommer 2013 in das Praktische Jahr gehe. Im Herbst 2014 werde ich zum zweiten Abschnitt der Ärztlichen Prüfung antreten. 